THE INFLUENCE OF HOST GENETICS, VIROME, AND GUT MICROBIOTA TRANSFER METHODS IN MOUSE MODEL REPRODUCIBILITY

A Dissertation
presented to
the Faculty of the Graduate School
at the University of Missouri-Columbia
In Partial Fulfillment
of the Requirements for the Degree
Doctor of Philosophy
Dr. Aaron Ericsson, Dissertation Supervisor
CHUNYE ZHANG
by

MAY 2021 
The undersigned, appointed by the dean of the Graduate School, have examined the dissertation entitled

\title{
THE INFLUENCE OF HOST GENETICS, VIROME, AND GUT MICROBIOTA TRANSFER METHODS IN MOUSE MODEL REPRODUCIBILITY
}

\author{
presented by Chunye Zhang, \\ a candidate for the degree of Doctor of Philosophy, and hereby certify that hat, in their \\ opinion, it is worthy of acceptance.
}

Dr. Aaron Ericsson

Dr. Craig Franklin

Dr. Elizabeth Bryda

Dr. Nicole Nichols

Dr. Lane Clarke 
C Copyright by Chunye Zhang 2021 All Rights Reserved 


\section{DEDICATION}

This dissertation is dedicated to my awesome husband Ming, whose love, care, and accompany during my research study made the entire experience full of fun. To my parents, my sisters, my brother-in-law, my nephew, and my niece, my parent-in-law, sister-in-law,

and brother-in-law, because of your deep love and inspiration, I have the freedom and courage to pursue anything I dreamed for. You are all my superstars in my life. I am so honored to have you all. I love you all. 


\section{ACKNOWLEDGMENTS}

I would like to take this precious opportunity to express my great thanks to my mentors Dr. Aaron Ericsson and Dr. Craig Franklin. I was lucky enough to have both of you as my mentors in my academic, professional development, and personal growth. It is such a great honor and I value the mentorships you provided for me along the road. Your passion for science, your critical thinking, hard work are great inspirations for me. Without the encouragement and guidance from you, I would not accomplish so much. Thanks for being such great mentors.

I would love to express my deep appreciation to my Doctoral committee members: Dr. Elizabeth Bryda, Dr. Nicole Nichols, Dr. Lane Clarke, Dr. Craig Franklin and Dr. Aaron Ericsson. Each of you is a great role model for me. I learned a lot from you all in different ways. I was so moved by your unconditional support, respect, and professional guidance during my entire Ph. D study. Without the help, encouragement, and strong support from you all, I would not achieve what I have today. I offer my greatest respect to each of you. You are all amazing. I admire your high-quality mentorships and I pursue to be a great mentor like you in my academic career.

I also like to express my deep thanks to Dr. James AmosLandgraf for your encouragement and many meaningful questions you asked in each lab meeting, which inspired me to think in different ways.

Thank Dr. Yuksel Agca and Dr. Cansu Agca for your friendship and professional guidance

during my study at MIZZOU. Dr. Daniel Davis and Dr. Jacob E. Moskowitz, thanks for your availability for me anytime I have questions to reach out. You are always there to help me. I appreciate your friendship and any help along the way. 
Shelly Nail, thank you for everything you have done for me. I value your friendship deeply. Thanks, Marie E. Schlup, for her great help for processing paperwork those years.

Thanks, Brian, for your strong technical support for any kind of software and other issues that happened in my research computer, I know you can always fix them promptly. Thanks to all the faculties, all the members of CMP and OAR for the positive and encouraging environment and culture you all created. Your passion and dedication to the training program, the research, and the animal health are very impressive and valuable. I feel so grateful to meet you all during those years. You all are awesome!

Thank MMRRC and MUMC for the financial support.

I value the time I spend together with you all at Disco ridge. I value this amazing experience in my life.

Last but not least, Thanks to the School of Veterinary Medicine, the pathobiology program, the graduate school, and the international center for all kinds of support you provided for the success of a young scientist at MIZZOU. 


\section{TABLE OF CONTENTS}

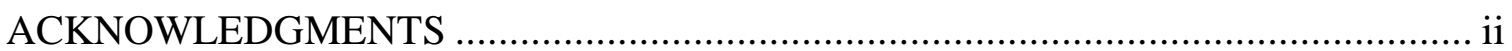

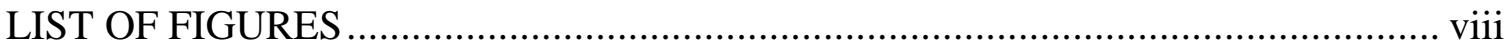

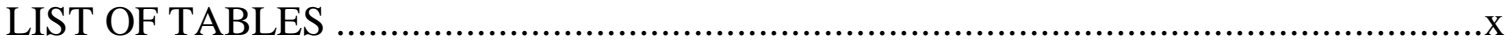

LIST OF ABBREVIATIONS ...................................................................... xi

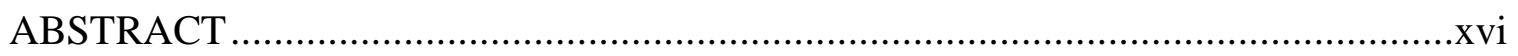

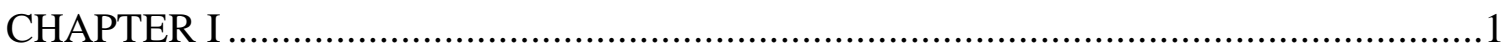

Consideration of gut microbiome in murine models of diseases ..................................1

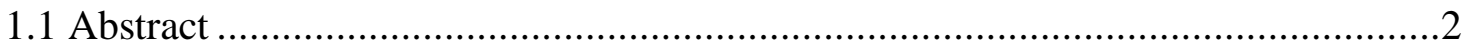

1.2 Role of gut microbiome in disease ........................................................

1.2.1 Gut microbiome in health and disease ............................................

1.2.2 Gut microbiome and colonization resistance ............................................

1.2.3 Gut microbiome and immunity .....................................................

1.2.4 Gut microbiome and metabolites ..........................................................

1.3 Factors contributing to gut microbiome variation .....................................

1.4 Microbiome variation and reproducibility of an animal disease model.................8

1.5 Microbiome and translatability of animal model for human disease ......................

1.6 Genetic drift of substrain and disease in mouse model......................................10

1.7 Methodology to investigate the contribution of genetic and microbiome ..............11

1.8 Why modulate microbiome in animal model and the potential application ..........12 
1.8.1 Improve reproducibility through a better understanding of methods to transfer the GM

1.8.2 Investigation of the disease mechanism and diagnostic biomarker .14

1.8.3 The efficiency of microbiome-mediated therapeutic exploration. .15

1.9 Research gap in the field .17

1.10 Conclusion and perspectives 18

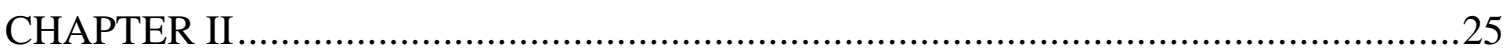

Characterization of the eukaryotic virome of mice from different sources ..... .25

2.1 Abstract .26

2.2 Introduction .28

2.3 Results .29

2.3.1 Comparison of the eukaryotic virome of mice from laboratories and pet stores .29

2.3.2 Comparison of the viruses in specific tissues/tropisms 31

2.3.3 Potential for novel virus identification. .32

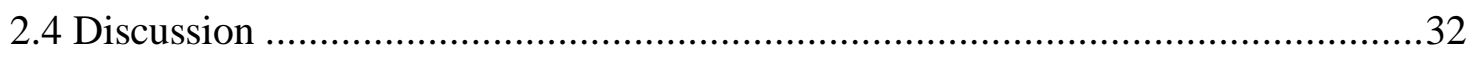

2.5 Methods .35 CHAPTER III. .45

Gut microbiome transfer method influences transfer efficiency and disease phenotype ..45

3.1 Abstract .46 
3.4.2 Mice generated using ET differ in susceptibility to DSS-induced colitis in GMand substrain-dependent manner

3.4.3 Transfer methods (ET, $\mathrm{CF}, \mathrm{CH})$ differ in transfer efficiency when transferring high richness GM4 to recipient $\mathrm{B} 6 \mathrm{~J}$ mice .56

3.4.4 B6J(GM4) mice generated using different transfer methods display differential susceptibility to DSS-induced colitis

3.4.5 Transfer methods differ in transfer efficiency when transferring low richness GM1 to recipient B6NHsd mice

3.4.6 B6NHsd(GM1) mice generated using different transfer methods display differential susceptibility to DSS-induced colitis

3.5 Discussion

4.1 Summary 


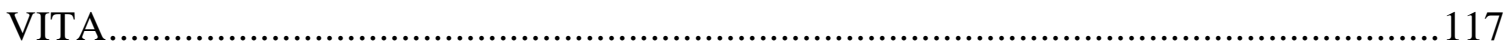




\section{LIST OF FIGURES}

\section{Chapter I}

Figure 1-1. Gut microbiome in disease through different axis and gut microbiome play the

role through colonization resistance, host immune response, and metabolism. .20

Figure 1-2. Organic factors that contribute to the variation of microbiome. .21

Figure 1-3. Inorganic factors influence the variation of gut microbiome.

Figure 1-4. Exploration of the potential application of microbiome transfer in biomedical research

Figure 1-5. Different approaches of gut microbiome transfer. .24

\section{Chapter II}

Figure 2-1. Heat map of vertebrate viruses from individual mice.

Figure 2-2. Heat map of vertebrate viruses from pet store mice.

Figure 2-3. Retroviruses detected in mice obtained from different sources.....................41

Figure 2-4. Phylogenetic tree of murine noroviruses ...................................................42

\section{Chapter III}

Figure 3-1. Experimental design of GM transfer studies and chronic DSS colitis. .66

Figure 3-2. Donor GM (primary) and recipient genetics (secondary) sources of GM variability in embryo transfer derived recipient mice.

Figure 3-3. Both donor GM and recipient substrain influence susceptibility to DSS-induced colitis in mice derived by embryo transfer.

Figure 3-4. Differing transfer efficiency among transfer methods when transferring high richness GM4 to B6J mice. 
Figure 3-5. Recipients with the same B6 substrain genetics received the same GM4 through different transfer methods that display different susceptibility to DSS-induced colitis....73 Figure 3-6. Different transfer method differs in GM transfer efficiency when transfer low richness GM1 to B6NHsd mice through ET, $\mathrm{CF}$, and $\mathrm{CH}$ methods................................75 Figure 3-7. Recipient mice with the same B6NHsd genetics received the same GM1 through different transfer methods that display different susceptibility to DSS-induced

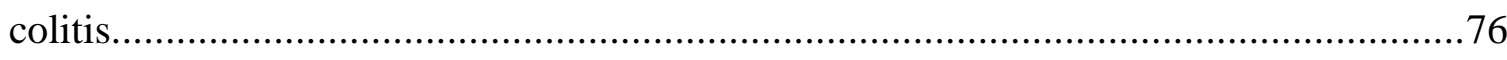




\section{LIST OF TABLES}

Table 2-1. Categorization of viruses identified (retroviruses excluded). .......................43

Table 2-2. Categorization and tissue tropism of viruses identified............................44 


\section{LIST OF ABBREVIATIONS}

ALS

ANOVA

ASF

B6J

B6J(GM1CF)

B6J(GM1CH)

B6J(GM1ET)

B6J(GM4CF)

B6J(GM4CH)

B6J(GM4ET)

B6NHsd(GM1CF)

B6NHsd(GM1CH)
Amyotrophic lateral sclerosis

Analysis of variance

Altered Schaedler Flora

C57BL/6 mice ordered from Jax

B6J mice cross fostered to a CD-1 colony harboring GM1

B6J mice co-housed at weaning with a CD-1 colony harboring GM1

B6J mice derived by CMTR (embryo transfer) using surrogates from MU:CD-1 colony harboring GM1

B6J mice cross fostered to a CD-1 colony harboring GM4

B6J mice co-housed at weaning with a CD-1 colony harboring GM4

B6J mice derived by CMTR (embryo transfer) using surrogates from MU:CD-1 colony harboring GM4 B6NHsd mice cross fostered to a CD-1 colony harboring GM1

B6Hsd mice co-housed at weaning with a CD-1 colony harboring GM1 
B6Hsd mice derived by CMTR (embryo transfer)

using surrogates from MU:CD-1 colony harboring

B6NHsd(GM1ET) $\quad$ GM1

B6NHsd mice cross fostered to a CD-1 colony

B6NHsd(GM4CF) harboring GM4

B6Hsd mice co-housed at weaning with a CD-1

B6NHsd(GM4CH) colony harboring GM4

B6Hsd mice derived by CMTR (embryo transfer)

using surrogates from MU:CD-1 colony harboring

B6NHsd(GM4ET) GM4

B6NNsd C57BL/6NHsd mice ordered from Hsd/Envigo

C57BL/6J C57BL/6 mice ordered from Jax

C57BL/6NHsd C57BL/6NHsd mice ordered from Hsd/Envigo

CCR5 Chemokine receptor 5

CD Crohn's disease

CF Cross foster

$\mathrm{CH} \quad$ Co-house

CMRT Complex microbiome rederivation transfer

CR Colonization resistance

D DNA

DSS Dextran sulfate sodium

ERVs Endogenous retroviruses

ET Embryo transfer 


$\begin{array}{ll}\text { FMT } & \text { Fecal microbiome transplantation } \\ \text { GIT } & \text { gastrointestinal tissue } \\ \text { GM } & \text { Gut microbiome } \\ & \text { GM maintained in our CD-1 colony through embryo } \\ \text { GM1 } & \text { transfer that originated from Jackson Laboratory } \\ & \text { GM maintained in our CD-1 colony through embryo } \\ \text { GM4 } & \text { transfer that originated from Hsd/Envigo Laboratory } \\ \text { GWAS } & \text { Genome-wide association studies } \\ \text { HIV-1 } & \text { Human immunodeficiency virus 1 } \\ \text { HLA } & \text { human leukocyte antigen } \\ \text { HSD } & \text { Harlan Laboratory } \\ \text { IBD } & \text { Inflammatory bowel disease } \\ \text { IBS } & \text { Irritable bowel syndrome } \\ \text { IDO-1 } & \text { Indoleamine 2,3-dioxygenase-1 } \\ \text { IgA } & \text { Metagenomics shotgun sequencing } \\ \text { IL } & \text { Immunoglobulin A } \\ \text { JAX } & \text { Interleukin } \\ \text { LDA } & \text { Jackson Laboratory } \\ \text { LEfSe } & \text { Linear discriminant analysis } \\ \text { MLV } & \text { Murine leukemia virus } \\ \text { MMRC } & \\ \text { MMS } & \end{array}$




\begin{tabular}{|c|c|}
\hline MU & University of Missouri \\
\hline MU:CD-1 & CD-1 colony in University of Missouri MMRRC \\
\hline MU:CD-1(GM1ET) & MU CD-1 colony with Jax derived GM (GM1) \\
\hline & MU CD-1 colony with Hsd/Envigo derived GM \\
\hline MU:CD-1(GM4ET) & (GM4) \\
\hline OMM12 & Oligo-Mouse-Microbiota \\
\hline PAST & PAleontological STatistics \\
\hline PBMC & peripheral blood mononuclear cells \\
\hline PCOA & Principal coordinates analysis \\
\hline PD-1 & Programmed cell death 1 protein \\
\hline PERMANOVA & Permutational multivariate analysis of variance \\
\hline PS & Pet store \\
\hline $\mathrm{R}$ & RNA \\
\hline SCFAs & Short-chain fatty acids \\
\hline S-DVF & Syr-Darya Valley Fever \\
\hline SEM & Standard error of the mean \\
\hline SFB & Segmented filamentous bacteria \\
\hline $\operatorname{sIg} \mathrm{A}$ & Secretory Immunoglobulin A \\
\hline SPF mice & Specific-pathogen-free mice \\
\hline SRA & Sequence Read Archive \\
\hline TAC & Taconic Farms \\
\hline Th17 & T helper 17 \\
\hline Treg cell & Regulatory T cell \\
\hline
\end{tabular}


W

XMRV week

Xenotropic murine leukemia virus-related virus 


\begin{abstract}
Gut microbiome (GM), the complex community that combines all bacteria, viruses, protozoa, and fungi located in the gut of human or animal, plays a significant role in host health and disease. Animal model are widely used to investigate human disease in biomedical research. The GM differs in animal models results from many factors such as vendors, facilitates, husbandry, environment, etc. The variation of GM can contribute to the difference of the disease phenotype in animal models which results in poor reproducibility and repeatability in biomedical research. The differences in the gut virome can also impact the repeatability between animal models and contribute to the poor translatability of animal disease models to human disease due to less pathogen exposure in lab animals. The different methods of GM modulation also can lead to differences between animal models of disease.

In this project, first, we investigated the potential contributors to research repeatability and translatability of animal models by characterizing the gut virome differences between mice from different sources including pet stores and different laboratories. Second, we assessed the role of differing GM transfer methods of efficiency and completeness of transfer of GM and impact of transfer on the DSS model of colitis. Ultimately to explore and provide a better way for the biomedical research community to do the GM transfer with higher transfer efficiency and more practical in any genetically modified animal disease model with desired GM.
\end{abstract}

We applied the gold standard GM transfer method, embryo transfer (ET), to assess the genetic background and GM contributing to the GM transfer efficiency and subsequent disease phenotype in animal model. We transferred well-established richness GM4 and low 
richness GM1 to two different substrain B6J and B6N mice to assess the GM and genetic influence on the recipient mice and the subsequent influence on disease phenotype in DSSinduced chronic colitis mouse model. We found that both GM and substrain genetic background contributing to the GM transfer efficiency and have an influence on the disease phenotype in mouse models.

We then designed experiments using the same GM transfer to the same genetic background recipient mice to compare and investigated the different transfer methods (standard ET, commonly used co-house, and newly explored cross-foster) influence on GM transfer efficiency in animal models and subsequent influence on disease phenotype.

In conclusion, by comparing the gut virome of standard lab mice and presumably more antigen-experienced wild and pet store mice we explored how informative and translational standard lab mice are in contemporary biomedical research and by comparing the gut virome of mice from different vendors the project addressed one of the possible causes of poor reproducibility in biomedical research that uses mice.

We investigated and determined whether differing GM transfer methods and the associated differences in GM transfer efficiency result in differences in animal model phenotypes using the DSS model of colitis. We also established efficient and economically feasible methods of GM transfer that can be applied to any genetically engineered mouse model of disease. Cross-foster could be used as an alternate GM transfer method to transfer the same desired GM to an animal model if the gold standard ET is not available in the lab. The result generated using co-house method as a GM-associated modulation manner should be interpreted with caution. 


\section{CHAPTER I}

Consideration of gut microbiome in murine models of diseases

(Chunye Zhang, Craig L. Franklin, Aaron C. Ericsson) 


\subsection{Abstract}

The gut microbiome (GM), a complex community of bacteria, viruses, protozoa, and fungi located in the gut of humans and animals, plays significant roles in host health and disease. Animal models are widely used to investigate human diseases in biomedical research and the GM within animal models can change due to the impact of many factors such as vendor, husbandry, and environment. Notably, variations in GM can contribute to differences in disease model phenotypes, which can result in poor reproducibility in biomedical research. Variation of the gut microbiome can also impact the translatability of animal models. For example, standard lab mice have different pathogen exposure experiences when compared to wild or pet store mice. Because humans have antigen experiences more similar to the latter, the use of lab mice with more simplified microbiomes may not be yielding optimally translatable data. Last, the literature uses many methods of manipulation and differences between these methods can also result in differing interpretation of outcomes measures.

In this review, we focus on the GM as a potential contributor to poor reproducibility and translatability of mouse models of disease. First, we summarize the important role of GM in host disease and health through different gut-organ axes and the close association between GM and disease susceptibility through colonization resistance, immune response, and metabolic pathways. Then we focus on the variation of the microbiome in mouse models of disease and address how this variation can potentially impact disease phenotypes and subsequently influence research reproducibility and translatability. We also discuss variation between genetic substrains as potential factors that cause poor reproducibility via effects on the microbiome. In addition, we discuss the utility of complex microbiomes in prospective studies and how modulation of GM through differing transfer methods impact 
model phenotypes. Lastly, we highlight current knowledge gaps in the field and emphasize the need to explore novel methods of GM characterization and manipulation.

Keywords: gut microbiome, virome, mouse model of disease, modulation, reproducibility, translatability 


\subsection{Role of gut microbiome in disease}

\subsubsection{Gut microbiome in health and disease}

The term gut microbiome (GM) refers to the community of all microorganisms including bacteria, viruses (virome), protozoa (protozoome), and fungi (mycobiome) that colonize and exist in the gut of all animals [1,2]. In the host, the GM plays a critical role in providing nutrition through metabolism of dietary components [3] and absorption of minerals [4], maintenance of the normal function of the gut barrier $[5,6]$, protection against pathogen infection through colonization resistance [7] and contributing to immune system development [8], drug metabolism [9] and hormone secretion [10], all of which contribute to the health of the host.

Accumulating studies suggest that changes or differences in the GM are associated with numerous diseases such as inflammatory bowel disease (IBD) [11-13], irritable bowel syndrome (IBS) [14-16], colon cancer [17, 18], and Clostridium difficile infection [19, 20]. Differences in GM are also associated with non-intestinal conditions through different axes (Fig. 1). For instance, differing GM can influence the phenotype in neurological diseases such as Alzheimer's disease [21] through the gut-brain axis [22], respiratory diseases via the gut-lung axis [23, 24], liver diseases through the gut-liver axis [25-27], cardiovascular diseases [28, 29], autoimmune disorders [30, 31], and more. In the proceeding paragraphs, we review the current knowledge of the GM of laboratory mice, and its influence on host health and disease susceptibility through colonization resistance, immune responses, and metabolic pathways. 


\subsubsection{Gut microbiome and colonization resistance}

The GM, harboring symbiotes and commensals during health, can also serve as a reservoir and transporter of pathogenic bacteria and viruses $[32,33]$. Pathogenic bacteria such as $E$. coli replicate and proliferate mainly in the gut after infection [34]. The commensal microbiome plays an essential role in protecting the host from foreign pathogenic bacterial and viral infection using different strategies, collectively referred to as colonization resistance (CR). These include out-competing pathogenic bacteria for space and nutrition, and producing bactericidal factors like antimicrobial peptides [35]. Notably, conventional mice harboring a specific pathogen free (SPF) microbiome are less susceptible to bacterial infection compared to germ-free mice [36]. Similarly, germ-free mice inoculated with Oligo-Mouse-Microbiota $\left(\mathrm{OMM}^{12}\right)$, a commensal bacterial community containing 12 bacterial species originally isolated from mice, are less susceptible to infection compared to Altered Schaedler Flora (ASF) colonized mice due to the increased colonization resistance in $\mathrm{OMM}^{12}$ mice [37]. Both examples demonstrate the protective function of colonization resistance conferred by the commensal microbiome.

\subsubsection{Gut microbiome and immunity}

Commensal bacteria protect the host not only by directly competing with pathogenic bacteria for available space and energy sources, but also indirectly through their role in immune system development. Many studies [38, 39] have demonstrated the complex interaction between the gut microbiome and host immunity, including both local and systemic immune responses, in a variety of diseases.

Certain commensal bacterial species such as segmented filamentous bacteria (SFB) [4042] have been identified as potent inducers of secretory $\operatorname{IgA}(\operatorname{Ig} \mathrm{A}), \operatorname{IL} 17$, and defensins. 
The presence of these immune mediators can enhance host resilience to bacterial pathogens. For example, immunoglobulin A produced at the mucosal surface plays a critical role in intestinal immunity. When infection occurs, high-affinity pathogen-specific secretory IgA (sIgA) is secreted into the intestinal lumen to serve a protective function via mechanisms such as viral or bacterial toxin neutralization[43-45].

The presence of SFB in the gut microbiome play a protective role against Citrobacter rodentium [46] and decrease the host susceptibility to Salmonella colonization in rats [47] and E. coli $\mathrm{O} 103$ infection in rabbits [48]. sIgA plays an important role in pathogen clearance through effector functions such as limiting pathogen growth in the gut lumen, preventing the interaction between pathogen and host intestinal mucosa, and decreasing bacteria-induced inflammatory responses in the case of Salmonella typhimurium diarrhea [49] and Shigella flexneri infection [50].

SFB also induces increased production of IL-17, IL-22, and the antimicrobial peptide RegIII $\gamma$ [51-53]. This protective $\mathrm{T}$ helper 17 (Th17) response has been shown to be important in defense against Citrobacter rodentium infection [54]. Similarly, IL-17 and IL22 play protective roles in Salmonella infection $[55,56]$, and IL-22 can enhance the secretion of antimicrobial peptides in intestinal epithelial cells.

Another example of association between the gut microbiome and immunity can be seen with members of the bacterial genus Helicobacter. Helicobacters serve as provocateurs to include a potent $\mathrm{T}$ helper type 1 (Th1) immune response to normally commensal bacteria. In turn, helicobacters, such as H. hepaticus and H. bilis are used as disease triggers in many mouse models of gastrointestinal disease, including models of inflammatory bowel disease (IBD) and colitis-associated colorectal cancer (CAC) [57, 58]. 


\subsubsection{Gut microbiome and metabolites}

Microbiome metabolites such as bile acids and short-chain fatty acids (SCFAs) can maintain host health by providing nutrition and energy and modulating host immunity. These metabolites include small compounds produced directly by commensal bacteria and end products of dietary substrates metabolized by commensal bacteria with both playing an important role in maintaining host health [59]. Primary bile acids such as chenodeoxycholic acids [60] have been demonstrated to have bactericidal activity against pathogenic bacteria, associated with increased production of host antimicrobial peptides. GM-derived secondary bile acids and symbiotic products such as propionate also hinder colonization of bacterial pathobionts, such as Clostridium difficile [61, 62]. GM-derived SCFAs have also been shown to influence diseases such as obesity, Parkinson's disease, and those that disrupt intestinal epithelial integrity [63-66]. SCFAs also have beneficial effects on maintaining the intestinal homeostasis through immune modulation [67]. Kang et al. [68] reported the reduced abundance of butyrate-producing bacterial species within the family Ruminococcaceae in Crohn's disease (CD) patients compared to healthy individuals. These studies support the notion that the GM exerts a portion of its influence on disease susceptibility through metabolites present in the lumen of the gut. Collectively, through various direct and indirect mechanisms, such as colonization resistance, immune modulation, and modulation of host metabolism, the gut microbiome plays an essential role in host health and disease.

\subsection{Factors contributing to gut microbiome variation}

Considering the important role that the GM plays in host health and disease, differences in the GM between mice could result in a different disease phenotype in a given model, 
causing poor research reproducibility [69]. Mouse models are useful and valuable tools to investigate many disease mechanisms of and therapeutics for human disease. However, there are many factors that can influence the gut microbiome of mouse models including the interaction between different organic components within the gut microbiome (Fig. 2) and environmental factors (Fig. 3). Organic factors that contribute to the variation of gut microbiome include the interaction between the virome and commensal bacteria. For example, bacteriophages can transfer antibiotic resistance genes to commensal bacteria or pathogenic bacteria in the gut through transduction. Similarly environmental factors ranging from supplier or even housing facility can alter the GM [70]. For example, mice obtained from Envigo (Harlan Sprague Dawley) usually harbor a higher richness GM when compared to those provided by Jackson Laboratory. In addition, many environmental factors such as diet, bedding, caging, housing size, the mode of birth delivery can contribute to the variance of the microbiome composition between mice [71].

Host genetics have also been shown to "shape" the GM. For example, in the IL $10^{-/-}$mouse model, the different genetic backgrounds ( $\mathrm{C} 3 \mathrm{H}$ and $\mathrm{B} 6$ ) showed variation in $\mathrm{GM}$ colonization [72]. In summary, the existence of variations in GM in contemporary mouse colonies and the multitude of factors that can modulate the GM highlight the need to consider GM as a potential cause when differences in in disease phenotypes arise resulting in poor reproducibility.

\subsection{Microbiome variation and reproducibility of an animal disease model}

In addition to the aforementioned role of SFB in mucosal immune system development and subsequent influence on Citrobacter rodentium colitis, there are many examples of how certain commensal bacteria can modulate host physiology and disease. For example, 
members of the phylum Firmicutes produce butyrate, which down-regulates the expression of epithelial indoleamine 2,3-dioxygenase-1 (IDO-1), an important molecule that modulates intestinal immune responses [73].

Interactions between commensal bacteria and host immune responses also have potential to alter disease phenotypes. For example, germfree mice colonized by commensal bacterial consortia highly coated with IgA were more susceptible to colitis when compared to mice colonized by a commensal consortium with lower levels of IgA coating [74].

Thus, the variation of GM, their products and complex interactions with the host have great potential to modulate disease phenotypes of animal models. Therefore, when lack of model reproducibility is found, consideration should be given the role of the GM.

\subsection{Microbiome and translatability of animal model for human disease}

Mouse models are widely used to investigate the genetic basis of human disease due to the feasibility of genetic modification in mice [75-77]. In addition, the GM of mice and humans are similar in that both are made up of roughly 90\% Firmicutes and Bacteroidetes [78]. Recently, attention has been focused on mice from non-laboratory sources (e.g., pet stores, feral populations and wild mice) due to the significant difference in antigen experience compared to traditional lab mice. For example, more antigen-exposed pet store mice develop a human adult-like immune system, while the less antigen-experienced lab mice develop an infant-like immune system [79]. In a separate study, lab mice colonized with the GM of wild mice show increased resistance to influenza virus infection, and reduced incidence of AOM/DSS-induced colorectal cancer compared to the cohorts harboring the GM profile of standard lab mice [80]. These studies highlight that differences in antigen 
experience have a profound impact on the immune profile and associated susceptibility to a broad range of diseases.

\subsection{Genetic drift of substrain and disease in mouse model}

The susceptibility to many diseases, both infectious and immune-mediated, often has an underlying genetic basis [81-85]. For example, early discovery of the mutation of Chemokine receptor 5 (CCR5)- $\Delta 32$ (32bp deletion) revealed a link to susceptibility to human immunodeficiency virus 1 (HIV-1) infection [86, 87]. Similarly, susceptibility to chronic hepatitis B virus infection is strongly associated with human leukocyte antigen (HLA) loci $[88,89]$. Genome-wide association studies (GWAS) also revealed genetic loci associated with susceptibility to Mycobacterium leprae infection [90]. The different genetic background of BALB/c and C57BL/6 mice results in differences in the ability to produce IgA, which results in a higher diversity of microbiota in BALB/c mice compared to $\mathrm{C} 57 \mathrm{BL} / 6$ mice, and BALB/c mice are susceptible to Salmonella infection compared to C57BL/6 mice [91]. Additionally, genetic drift describes variation between different mouse substrains within the same genetic background. The genetic variation between substrains potentially impacts the diversity of the GM and disease susceptibility of mouse model. Genetic factors play an important role in shaping the human gut microbiome as well, and consequently, influencing metabolism and disease susceptibility [84]. When studies were conducted using two different substrains of C57BL/6 mice (B6N and B6J), the results of select neurological function tests were significantly different between substrains [92]. Some metabolism-related diseases differ between the different substrains of C57BL/6 mice due to the mutation of nicotinamide nucleotide transhydrogenase (Nnt) gene [93-96].These examples demonstrate that differences between mouse substrains can 
impact disease phenotypes. Unfortunately, many of these studies were performed prior to the recognition that GM can also influence model phenotype and almost invariably, they were performed without consideration of differing GM, for example the profound differences seen in B6 substrains from the Jackson Laboratory and Envigo. Moving forward, when designing or troubleshooting experiments using animal models, it will be critical to consider host genetic and microbial factors as well as complex interactions between the two.

\subsection{Methodology to investigate the contribution of genetic and microbiome}

As described above, both GM and host genetics can play critical roles in host disease susceptibility and the interaction between these two factors is often complex. To address this challenge, we have applied complex microbiota targeted rederivation (CMTR) [97] to generate genetically engineered mouse models harboring distinct microbiome profiles. Simply, embryos from mice of the chosen genetically engineered model are transferred into surrogate MU:CD-1 dams that harbor different complex microbiome profiles. Pups thus obtain their GM during the natural process of delivery and maternal care. In this way, the complex microbiome can be faithfully transferred to any genetically engineered mouse model for further research purposes. Using this strategy, isogenic (genetically identical) mice harboring different GM are created and can be used to investigate the role of GM variation in model phenotype. This approach can also be used to transfer the same GM into mice with different genetic backgrounds, to investigate the genetic factors that may shape the microbiome. Using the described methods, we [72] successfully identified the GM as a contributing determinant in IL10 ${ }^{-/-}$IBD disease model, demonstrating that the variation of GM among commercial vendors could affect the disease severity. Recent studies [98, 
99] using a similar approach showed that the microbiome and genetics both play a critical role in the susceptibility of development of colon cancer in a $\mathrm{Apc}^{\mathrm{Min}}$ mouse model. This approach can also be applied to investigate different areas such as identifying the contributing commensal bacteria to disease, signal pathways, drug metabolism, and treatment efficacy.

\subsection{Why modulate microbiome in animal model and the potential application}

Manipulation and modulation of the gut microbiome are performed for different purposes, such as creating a well-controlled GM environment for further investigation of the underlining mechanism [98], identifying the contributing component(s) of the GM [100], exploring the interaction between different commensal bacteria of the GM [101], therapeutic approaches $[102,103]$ investigating drug metabolism for development of precision medicine [104-106], and improving the reproducibility [107] of biomedical research by decreasing the variability induced by differing GM. A controlled GM transferred to a mouse can provide a controlled GM environment in any genetically modified disease model as illustrated in the figure (Fig. 4).

\subsubsection{Improve reproducibility through a better understanding of methods to transfer}

\section{the GM}

A better tool or platform is needed for modulating the GM between mouse models. Currently, there are several different ways to transfer the gut microbiome in mouse models of disease (Fig. 5). Embryo transfer (ET) is considered the gold standard method. For facilities where ET is not possible, researchers often use alternative methods such as fecal microbiome transfer (FMT), co-house (CH), and cross-foster (CF). These methods each carry certain limitations and the method of GM transfer can itself affect model outcomes. 
Researchers should therefore be aware of these method-based influences, control for them accordingly, and interpret resulting data in the context of the transfer methods used. The pro and cons for each method should be considered.

The fecal microbiome transfer (FMT) method is a commonly used method. Fecal or cecal contents (either frozen or freshly prepared slurries) from donors are transferred to recipient mice through gastric gavage. The advantage of FMT in animal models is its flexibility of using stored fecal or ceca contents, as well as ease of use. Most mouse FMT studies use germfree mice. However, for some studies that do not use germfree mice, prior to transfer, the administration of antibiotics was required to deplete the microbiome in recipient mice. For those studies that used post-antibiotic treatment, the drawback of using FMT is, that the transfer efficacy is highly dependent on the GM richness of donor and recipient [108]. The embryo transfer (ET) method is considered the gold standard for GM transfer. In this approach, embryos of the intended GM recipient mice are collected and surgically transferred to a pseudopregnant GM donor dam. The transferred embryos go through the fetal development stage in the donor GM environment. The recipient pups can obtain the vaginal microbiome from the donor dam through natural delivery. After birth, the pups acquire the donor GM through maternal care. In this way, the complete donor GM can be transferred to the GM recipient mice and pups harboring the transferred GM can be used for study. ET results in very high efficiency transfer of the donor GM due to exposure to the donor GM environment during the delivery process, and with maternal care. However, this method requires considerable expertise and well-trained personnel, and is relatively expensive, making it inaccessible for many labs. 
Co-housing is another commonly used method in the literature. Co-housing the recipient mice with the donor mice after weaning results in the transfer of the donor GM, through coprophagy and grooming. The advantage of co-housing is the ease of use and low cost. However, co-housing results in transfer of GM after a critical pre-weaning period during which immune system development occurs and the microbiome is changing rapidly, which results in an incomplete transfer and does not capture any GM-mediated influences on phenotypes dependent on some developmental process.

Additionally, the transfer efficiency of using the co-housing method is low due to the fact that recipient mice already have an established GM, resulting in a hybridized GM.

Using cross fostering as a method of GM transfer represents a third option. The recipient pups are put with the GM donor dam within 24 hours after birth, allowing the recipients to pick up most of the GM from an early stage during the maternal care process from the GM donor dam. Theoretically, cross-fostering will transfer the GM with higher transfer efficiency compared to the co-housing method. Cross fostering has the advantages of ease of use and low cost compared to the ET method. However, there are some drawbacks of using the $\mathrm{CF}$ method such as requirement of timed mating, incomplete transfer due to the lack of vaginal GM transfer and potential hybridized GM.

\subsubsection{Investigation of the disease mechanism and diagnostic biomarker}

The composition of the gut microbiome has been proposed as a potential diagnostic biomarker for many diseases. The exploration of microbiome-based biomarkers has included associating bacterial phyla ratios with disease, such as identifying a higher ratio of Firmicutes/Bacteroidetes as a biomarker for obesity [109]. Microbiome-based biomarkers have also been used to predict disease progression, For example, 
Lactobacillales and Verrucomicrobiales are enriched in early-stage liver fibrosis, while Enterobacteriales are enriched at later stages [110]. Other examples include Fusobacterium nucleatum as a potential biomarker for colorectal cancer [111] and increases of Bacillus as a biomarker of lung cancer [112]. However, the variation of GM impacts the accuracy of diagnosis as a disease biomarker and thus much work is needed to fully appreciate the use of microbes as biomakers.

\subsubsection{The efficiency of microbiome-mediated therapeutic exploration}

The exploration of gut microbiome-mediated treatment for various diseases has drawn extensive attention in the field. Beneficial microbiome components alone, as well as in combination, have been administered through diet intervention, probiotic supplementation, and fecal microbiome transplantation (FMT), to enhance the stability of the gut ecosystem and modulate the immune response to ameliorate the disease. An example is FMT as an effective microbiome-based therapeutic option [113-116] for Clostridium difficile colitis. This involves the transfer of fecal material from a healthy donor to a patient with C. difficile bacterial infection. Many other studies [117-119] have investigated the use of microbiomebased treatment for inflammatory bowel disease, including FMT to transfer beneficial commensal bacteria such as Bifidobacterium sp. One recent study [120] demonstrated the modulatory function of microbiota in regulatory $\mathrm{T}$ (Treg) cell MyD88/ROR $\gamma \mathrm{t}$ signaling in the treatment of food allergy. Other therapeutic applications include treatment of chronic kidney disease [121, 122], autism [102, 123], diabetes [124, 125], obesity [126, 127] and cancer [128-132].

Therefore, the exploration of microbiome-based therapeutic approaches is dependent on the GM environment in which they are studied. Animal models are critical to develop new 
microbiome-based therapies and have the advantage of being done in a controlled GMs which cannot be done in human studies. The variation of GM could result in different outcomes that not only influence the reproducibility or translatability of animal disease models, but have a fundamental impact on the efficacy of the tested therapies. A welldefined and well-controlled GM environment coupled with a well-validated microbiome modulation method are needed for the investigation of treatment approaches, and conceivably the efficacy of the therapy.

The gut microbiome is associated with the immunotherapy response to cancer treatment for hepatocellular carcinoma [133], gastrointestinal cancer [134], lung cancer [135], and others [136]. The abundance of certain commensal bacteria or combinations such as Bifidobacterium longum [137, 138], and Akkermansia muciniphila [135] showed a significant association with the treatment efficacy. Manipulation of microbiome such as oral supplementation with the commensal bacteria, Akkermansia muciniphila, enhanced the response to immune checkpoint inhibitor treatment in a mouse model of melanoma [139]. In addition to the studies of disease development, in an immunotherapy study [140] significantly higher levels of Ruminococcaceae family were found in cancer patients that showed a response to the immunotherapy compared with that in the patients who did not respond to the anti-programmed cell death 1 protein (PD-1) immunotherapy for melanoma treatment.

The gut microbiome is critical for drug metabolism through both direct and indirect processes $[9,106,141,142]$. Commensal bacteria transform xenobiotics (i.e., drugs) in the lumen (via enzymes to steal carbon as an energy source), and the possible effects on the 
parent compound (such as activate the inactivated prodrug to conduct the therapeutic function, make toxic, change the half-life of medicine, etc.) [143, 144].

Thus, the development and characterization of a novel drug and the metabolism pathway in the model host will benefit from a well-controlled microbiome environment due to the important contribution of microbiome on drug metabolism.

\subsection{Research gap in the field}

Until now, it is unclear whether the mice with different genetic substrain background due to the genetic drift have an influence on GM transfer efficiency, as well as whether the mice generated using different transfer methods display different disease susceptibility in the context of transfer with an identical complex GM. The assessment and evaluation of how the GM and genetic substrain impact the GM transfer outcome and the disease phenotype of mouse models are needed.

To date, there are limited data available regarding GM transfer efficiency using different transfer methods in a controlled manner. The associated GM transfer efficiency influence on disease phenotype is unclear. Thus, there is a desire to assess the efficiency of the microbiome transfer between mice using different transfer methods and evaluate the subsequent influence on the susceptibility to disease in the generated mouse model.

Considering both the advantages and disadvantages of each transfer method to transfer the GM (FMT, ET, CH, CF), it is important to better understand the specific limitations in transfer efficacy using each method, and the implications in disease models. Cross-foster is an efficient and economically feasible method to do GM transfer especially for the studies that investigate the GM-associated early-state development such as before the weaning age. 
In addition, investigation of the co-housing method is necessary regarding its influence on the susceptibility to disease phenotype in an animal model. The appropriate time to expose to the foreign GM components, oral tolerance, the stage of the immune system development, the GM richness of the recipient mice and the donor mice, the genetic background of both, all the above-mentioned factors need to be taken into consideration when conducting the experiment that involves the co-housing method.

Assessment of GM transfer methods and evaluation of associated differences in disease phenotype will improve our understanding of the method-specific effects on host physiology and reproducibility and repeatability in biomedical research using mouse models. Our current study (Chapter3) revealed that the co-housing method had a significant influence on DSS-induced colitis phenotype compared with the ET and CF methods. Mice generated using $\mathrm{CH}$ method and the data generated using $\mathrm{CH}$ method should be interpreted with caution. Cross-foster method can be used as an alternative approach to transfer the GM between mice.

\subsection{Conclusion and perspectives}

Despite their limitations, mouse models are still a valuable, practical, and irreplaceable tool for studying human disease. There is no one type of animal model that is $100 \%$ percent ideal for human disease. However, a better understanding of each model system can provide an improved study design and overcome the limitations associated with animal models.

Most importantly, it is necessary to consider experimental methods and platforms as factors affecting experimental reproducibility and explore novel tools to identify and investigate the different factors that influence animal disease-associated factors. Application of the 
well-controlled GM and appropriate transfer method to transfer the GM between genetically generated mouse models can provide an advantage of putting both the genetics and GM under a well-controlled condition, such as our CMTR platform. With the rigorous experimental design, such as the optimal GM transfer method and necessary experimental control, the reproducibility of using animal disease model in a more efficacy way can be improved. A better platform combined with a well-designed study can provide a more informative and translational animal model in different areas such as drug development, diagnostic biomarker, to meet the requirement of maximizing and optimizing the use of animal models.

\section{Funding}

This project was funded in part by the NIH U42 OD010918 (the University of Missouri Mutant Mouse Resource and Research Center).

\section{Authors' contributions}

$\mathrm{CZ}$ prepared the manuscript. $\mathrm{CF}$ and $\mathrm{AE}$ provided revisions. All the authors have read and approved the final product.

\section{Competing interests}

The authors declare that there is no conflict of interest. 


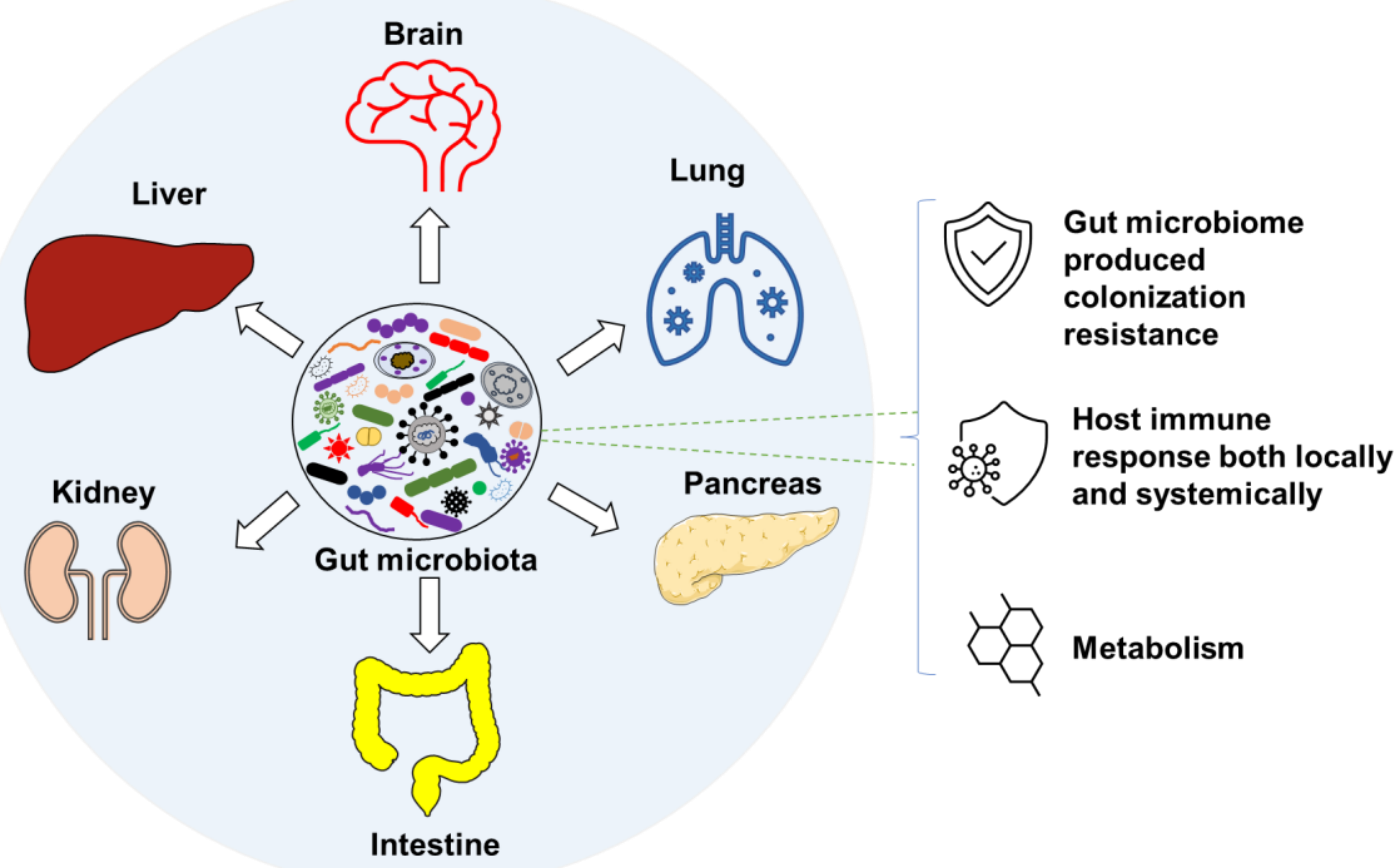

Figure 1-1. Gut microbiome in disease through different axis and gut microbiome play the role through colonization resistance, host immune response, and metabolism. 

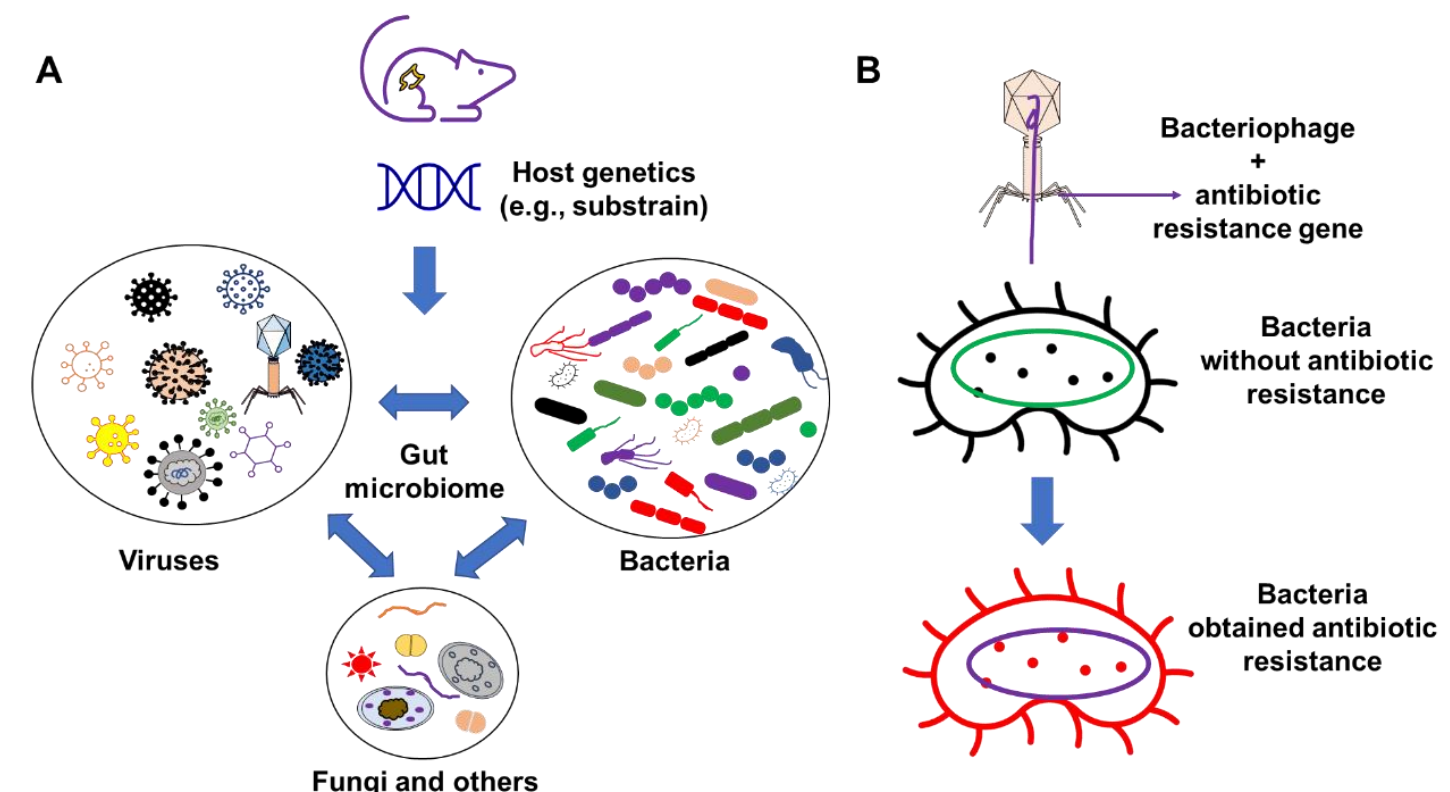

Figure 1-2. Organic factors that contribute to the variation of microbiome.

(A) The interaction of the gut microbiome between bacteria, virus, fungi, and other components. (B)

Example of the bacteriophage influence on the commensal bacteria by transferring the antibiotic resistance gene to non-resistant bacteria. 


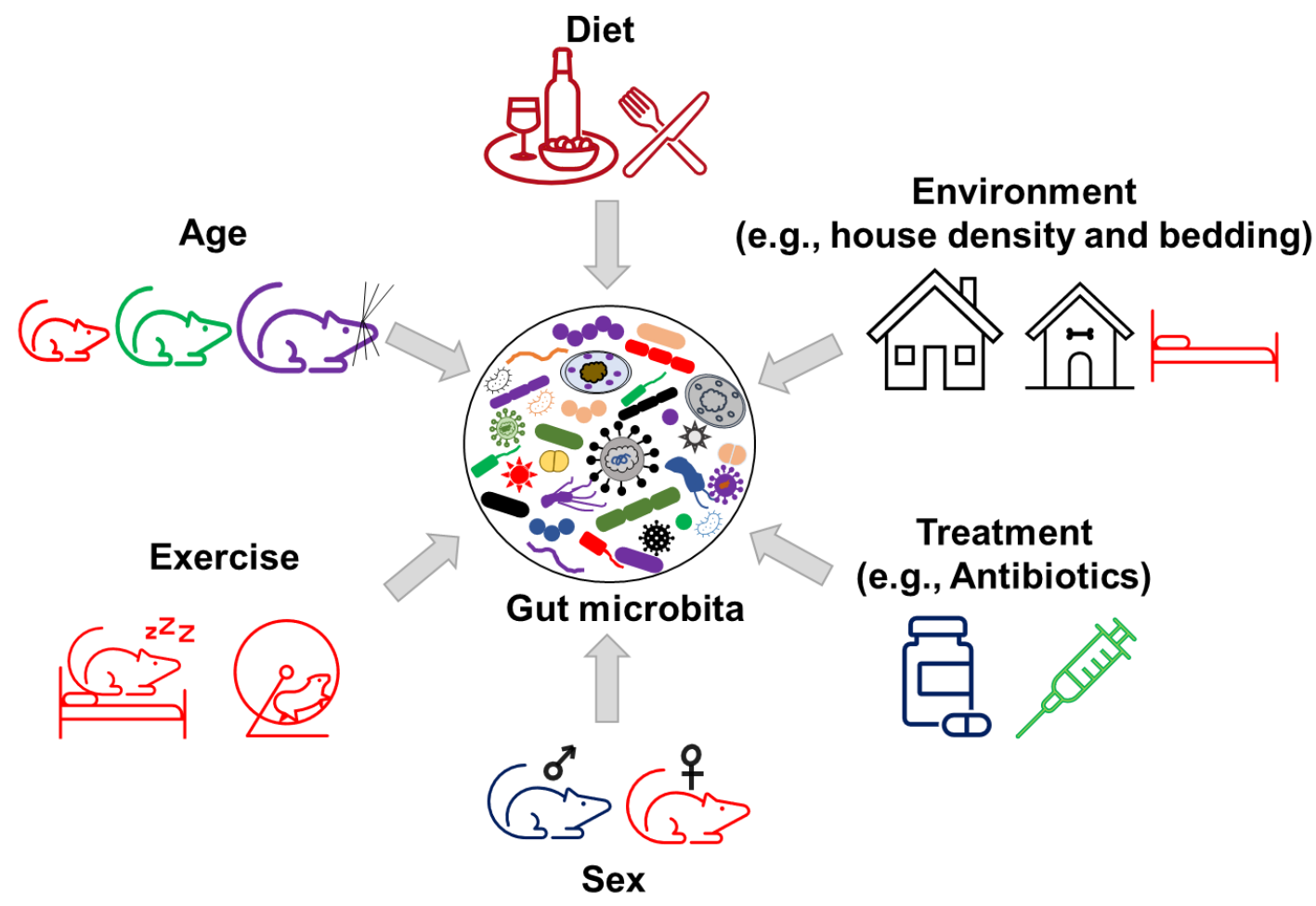

Figure 1-3. Inorganic factors influence the variation of gut microbiome. 


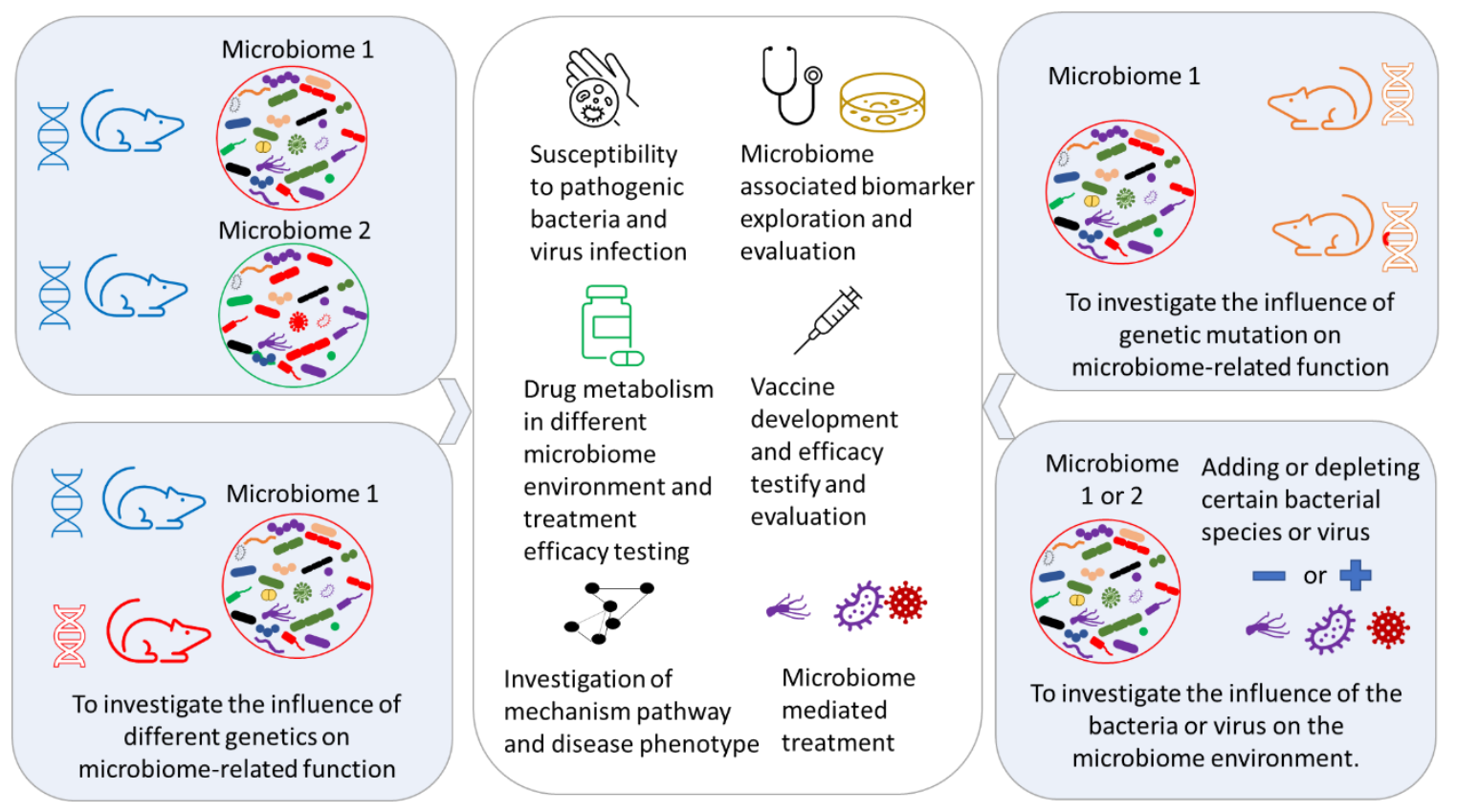

Figure 1-4. Exploration of the potential application of microbiome transfer in biomedical research. 
A Embryo Transfer<smiles></smiles>

Recipient
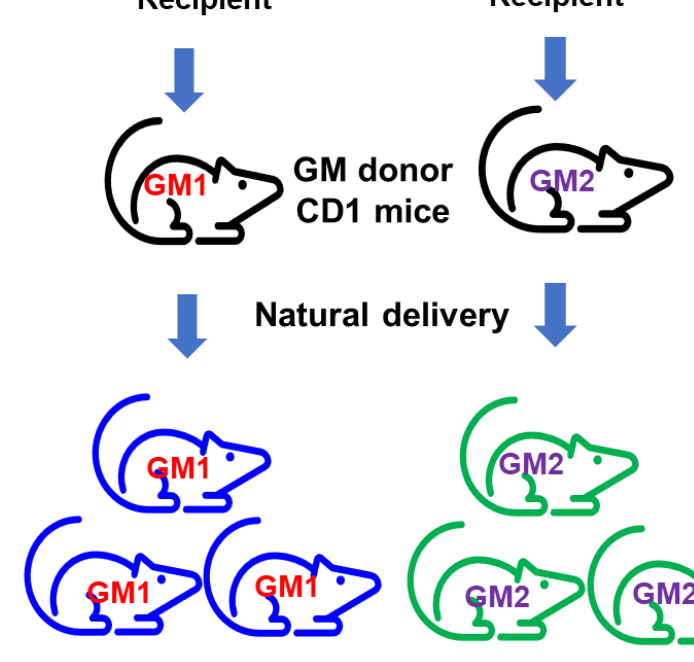

delivery
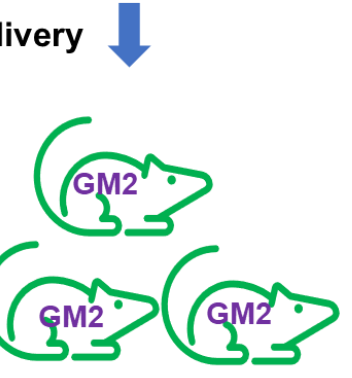

B

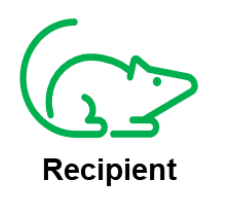

$$
\text { ( }
$$

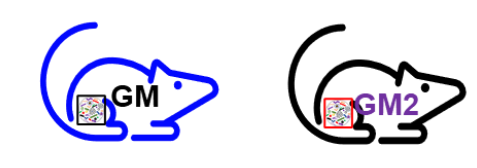

Recipient with GM before weaning)

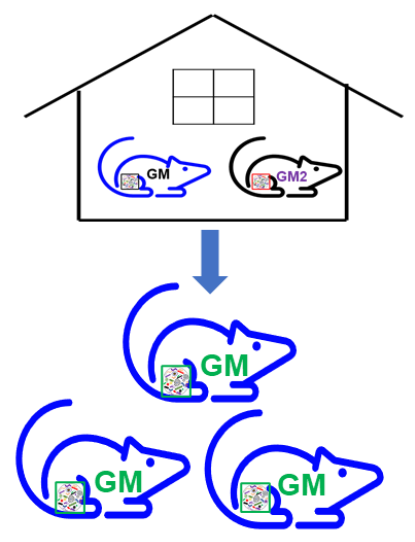

Recipient mouse $\mathrm{GM}=\mathrm{GM}+\mathrm{GM} 2$
C Cross-foster

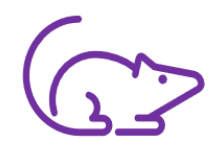

Recipient

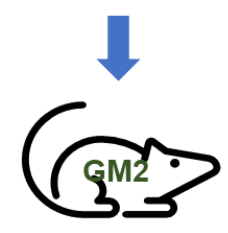

\section{GM donor}

CD1 mice

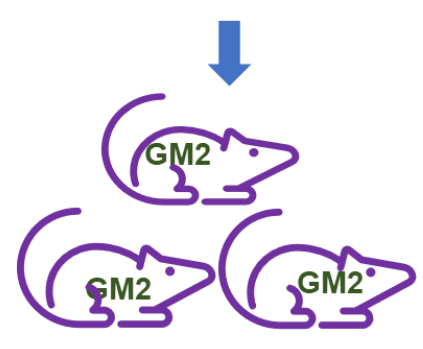

D

\section{FMT}
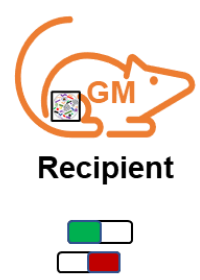

Antibiotics

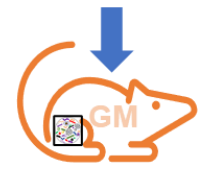

Recipient
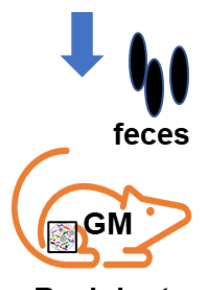

Recipient

Figure 1-5. Different approaches of gut microbiome transfer.

(A) Embryo transfer. (B) Co-house method. (C) Cross-foster method. (D) Fecal microbiota transfer (FMT). 


\section{CHAPTER II}

\section{Characterization of the eukaryotic virome of mice from different}

\section{sources}

(Chunye Zhang, Matt Burch, Kristine Wylie, Brandi Herter, Craig L. Franklin, Aaron

C. Ericsson) 


\subsection{Abstract}

Accumulating studies show that the host microbiome influences the development or progression of many diseases. The eukaryotic virome, as a key component of the microbiome, plays an important role in host health and disease in human and animals, including research animals designed to model human disease. To date, the majority of research on the microbiome has focused on bacterial populations while less attention has been paid to the viral component. Members of the eukaryotic virome interact with the commensal bacterial microbiome through trans-kingdom interactions, and influence host immunity and disease phenotypes as a collective microbial ecosystem. As such, differences in the virome may affect reproducibility of animal models, and supplementation of the virome may enhance the translatability of animal models of human disease. However, there are minimal empirical data regarding differences in the virome of mice from different commercial sources.

Our hypotheses were that the mice obtained from pet store sources and lab mice differ in their eukaryotic virome, and that lab mice from different sources would also have different viromes. To test this hypothesis, the ViroCap platform was used to characterize the eukaryotic virome in multiple tissues of mice from different sources including three sources of laboratory mice and two pet stores. As expected, pet store mice harbored a much greater diversity within the virome compared to lab mice. This included an ostensibly novel norovirus strain identified in one source of these mice. Viruses found in both populations included four strains of endogenous retroviruses and murine astrovirus with the latter being restricted to one source of lab mice. 
Considering the relative high richness virome within different samples from healthy humans, these data suggest that mouse models from alternative sources may be more translational to the human condition. Moreover, these data demonstrate that, by characterizing the eukaryotic murine virome from different sources, novel viruses may be identified and used in the lab as field strains.

Keywords: Gut microbiome, Virome, Laboratory mice, Pet store mice, Translatability, Reproducibility, Novel virus 


\subsection{Introduction}

Animal models, especially mouse models, are used in biomedical research to investigate conditions including chronic diseases such as autoimmune diseases, cancer, HIV, and acute conditions such as many infectious diseases. While the advantages of using mouse models are appreciated, there are limitations to be considered in terms of their reproducibility and accurate recapitulation of the human conditions they are used to study [75, 145-147]. For example, one clinical study using the same drugs that worked very well in experimental treatment in a well-established mouse model of human amyotrophic lateral sclerosis (ALS) disease [148] was unable to reproduce these preclinical results when applied to a human population [146]. This example of therapeutic failure of a promising drug during clinical trials, combined with other study results [149-151] related to the reproducibility or translatability of rodent studies, suggests a need for a more thorough characterization and consideration of mouse models used in biomedical research.

The bacterial microbiome has gained extensive attention among the biomedical research community because of its influence on many physiological parameters, and association with many adverse health outcomes. For instance, the bacterial gut microbiome is important for metabolism [152], mucosal barrier function [153], defense against certain pathogens [154], and regulation of the immune system [155, 156]. Certain compositional features of the microbiome have also been associated with specific diseases such as inflammatory bowel disease [157], colorectal cancer [158] and obesity [159], among others [160]. In contrast to research on the bacterial microbiome, there are relatively few studies focused on the viral portion of the microbiome, i.e., the virome (including prokaryotic and eukaryotic viruses), a fundamental component of the host-associated microbiome [161, 
162]. Investigations of the eukaryotic virome are hindered by the lack of an efficient technique for untargeted detection of all viral nucleic acid present within a sample, with high sensitivity and specificity.

Previous studies comparing the bacterial gut microbiota of mice from different commercial sources showed significant differences in diversity and composition between the suppliers, and dramatically increased viral pathogen loads in mice obtained from not-traditional sources of mice such as pet stores $[70,163]$. Therefore, in the present study, we hypothesized that pet store mice would harbor a more complex eukaryotic virome than mice from traditional sources of research mice, and that lab mice from different sources would also differ in their virome.

To characterize the eukaryotic virome (including both DNA and RNA viruses) present in multiple tissues of mice from different sources, weaning age mice (4 weeks old) were purchased from three commercial suppliers of laboratory mice (Jackson, Taconic, and Envigo) and two local pet stores, and multiple tissues (ileum, perianal skin, and lung) were collected for processing using a robust, virus isolation-independent, probe-based approach, ViroCap. ViroCap contains a targeted sequence capture panel containing specific targets of 337 viral species [164] and enabling the detection of known viruses, as well as novel viruses based on sequence similarity to viral capture sequences.

\subsection{Results}

\subsubsection{Comparison of the eukaryotic virome of mice from laboratories and pet stores}

A subjective review of viruses detected in each group of mice revealed two clear patterns. First, pet store mice harbored a rich virome in multiple tissues while lab mice harbored a limited diversity of eukaryotic viruses. Second, several eukaryotic retroviral sequences 
were detected in all groups. Twenty-one virus strains in total were detected in samples from pet store mice, including both DNA and RNA viruses belonging to ten families. Within those 21 strains, there were 9 DNA and 12 RNA viruses, respectively. As expected, most RNA viruses (i.e., Picornaviridae, Arteriviridae, Astroviridae, Coronaviridae, and Caliciviridae) were detected primarily from sequenced cDNA reverse-transcribed from sample RNA. In contrast, DNA viruses (i.e., Parvoviridae, Herpesviridae, Adenoviridae, and Papillomaviridae) were detected in both DNA and RNA extracted from samples, suggesting active replication by many of these viruses. Also, in contrast to most RNA viruses, sequences matching Retroviridae were detected in both DNA and RNA from all tissues, suggesting that the former may represent proviral DNA within the host genome. In samples from laboratory mice, all viral sequences belonged to either Retroviridae or, in a handful of samples, astrovirus. The four detected retroviruses included xenotropic murine leukemia virus-related virus (XMRV), murine leukemia virus (MLV), Moloney murine sarcoma virus, and Mus musculus mobilized endogenous polytropic provirus. Murine Astrovirus was detected in only one of the three lab mouse suppliers (Envigo) in only two mice, as well as in two of the four pet store mice (Fig. 1). While not absolutely quantitative, the number of sequences detected suggested a trend in viral load among the retroviruses comprising greater amounts of XMRV and MLV relative to Moloney murine sarcoma and the polytropic provirus, in both lab mice and pet store mice. For pet store mice, when analyzed based on the sex, we found that Lactate dehydrogenase elevating virus and adenoassociated virus were only detected in samples from the male mice (Fig. 2). The number or retrovirus sequences detected differed between lab mice and pet store mice. Most curiously, differences were also seen in lab mice from different vendors. Murine leukemia 
viruses detected from JAX showed statistically significant differences compare to PS (JAX vs. PS $p=0.005$ ) and HSD (JAX vs. HSD: $p=0.037$ ) (Fig.3). There is significant difference within males between JAX and PS (JAX vs. PS $p=0.008$ ). Moloney murine sarcoma virus showed significant difference between JAX male and PS male (JAX vs. PS $p=0.045)$.

Aside from the Retroviridae, the remaining viruses detected in pet store mice reflected three different assigned orders, five different unassigned orders, and nine different families of viruses, ranging from Picornaviridae to Caliciviridae (Table 1).

Based on the number of sequences detected, the six most frequently detected viruses (sequence count $>100000)$ included mouse parvovirus $(35,422,544)$, minute virus of mice (13940530), murine adenovirus $2(3,413,654)$, murine coronavirus $(400,590)$, murine hepatitis virus $(330,627)$, and Theiler's encephalomyelitis virus $(117,708)$.

\subsubsection{Comparison of the viruses in specific tissues/tropisms}

In this study, we took samples from the respiratory tissue (lungs; whole pluck), dermal tissue (glabrous perianal skin), and gastrointestinal tissue (ileum). Within the more diverse pet store virome, tissue tropisms were readily apparent. The recently identified Mus musculus papillomavirus, first reported in 2011 [165, 166], is skin-trophic [167-169] and was detected only in skin tissue (Table 2). All three members of the herpesviridae (MHV1, MCMV, and muromegalovirus) were detected in skin and lung, but not the ileum, while murine adenovirus 2 and adeno-associated viruses were detected in the ileal and skin samples, but not lung. Endogenous retroviruses (ERVs) were present in all tissue types. In specific tissues tropisms, according to the percentage of detected viral sequence from different tissue, some ERVs appeared in greater abundance than others across all tissue 
types tested. For example, the detected sequence of endogenous retroviruses XMRV and MLV displayed a higher percentage in all tissues compared to Moloney murine sarcoma virus (Table 2).

\subsubsection{Potential for novel virus identification}

In an effort to identify putative novel viruses, the sequence of the norovirus found in a pet store mouse was compared to known murine noroviruses (Fig. 4). This virus was found to share $92 \%$ sequence identity with the most closely related strain found in GenBank. Given that noroviruses are highly mutable RNA viruses, this finding was not surprising, but reinforces that screening tools such as ViroCap can yield data on novel strains that may be worth further characterization and pursuit.

\subsection{Discussion}

While the majority of microbiota research focuses on the bacterial component, characterization of the eukaryotic virome has lagged due to the lack of efficient methods to comprehensively survey viromes in a non-targeted fashion. Viruses, different from bacteria, lack a universal conserved gene (such as the 16S rRNA gene in bacteria) enabling the identification and classification of different community members based on variable regions within that conserved gene. Virome identification, on the other hand, is complicated by the large diversity of viruses which do not share any universal phylogenetic marker $[170,171]$. While shotgun metagenomic sequencing has been used to identify eukaryotic viral sequences, the development of capture-based methods like ViroCap enrich the sequenced pool of nucleic acid for viral DNA and RNA, and allows investigation of the eukaryotic virome in greater detail [164]. Our results are in agreement with previous reports regarding the differences in virome composition between laboratory, pet store [79, 
$172]$ and wild mice $[80,173]$ and confirm that while most murine viral pathogens have been eradicated from lab mouse production facilities, these agents are abundant in nonlaboratory populations [77].

The virome in mammalian hosts includes prokaryotic viruses (bacteriophages) that infect resident bacteria, eukaryotic viruses which transiently infect the host cells, and viral elements including retroviruses that are integrated into the host genome [174]. There is increasing evidence of a relationship between the eukaryotic virome and susceptibility to immune-mediated diseases such as inflammatory bowel disease (IBD) [175] and rheumatoid arthritis $[176,177]$. Furthermore, studies on the interaction between virus and bacteria suggest direct inter-kingdom communication, and synergistic influences on the development of host immunity and susceptibility to various conditions [178]. The eukaryotic virome as a key component of the virome likely plays a critical role in host health and disease, including unidentified, subclinical viruses which may influence host physiology, immune system development, and disease/model susceptibility. As a consequence, there are potential influences on preclinical research investigating disease mechanisms, and development of novel therapeutics. All of these issues highlight the importance of a deeper understanding of the eukaryotic virome of mouse models [179, 180]. To optimize mouse models of disease, a better understanding of the role of the microbiome, including the virome, in model phenotypes is needed. However, the variability in endogenous retroviruses remain. This finding was not unexpected given recent studies by Lee et al [181] that used a TREome probe from murine leukemia virus-type endogenous retroviruses to survey C57BL/6J mice. They noted marked variability in the MLV-ERV landscape that depended on several factors, including individual mouse, sex, tissue, and 
cell type. What remains to be determined is the impact of such variation on individual mice as well as mouse models of disease in general.

Our study also identified murine astrovirus in both laboratory and pet store mice. Murine astrovirus was first found in nude mice in 1985, followed by the complete genome sequence from a wild mouse in 2011 [182, 183]. The first complete murine astrovirus genome sequence was obtained from immunocompetent lab mice and published in 2012 [184]. Subsequent reports have confirmed the existence of astrovirus in laboratory mice $[184,185]$, but the true prevalence in most research colonies remains unknown as it is not on many health monitoring profiles.

It has been speculated that the high prevalence of murine astrovirus in lab mice coupled with the diversity of virus strain [185] and asymptomatic infection could contribute to phenotypic differences between mice used in research.

This study also identified a murine norovirus in pet store that shared $92 \%$ sequence identity to the next most-closely related strain. Murine noroviruses have been proposed as model agents for the study of human noroviruses $[186,187]$. However, unlike their human counterparts, which are a leading cause of non-bacterial epidemic gastroenteritis, murine noroviruses are asymptomatic unless infections occur in mice lacking anti-viral defense mechanisms [188]. However, their study has revealed novel putative roles for these viruses in intestinal homeostasis. For example, germfree mice infected with MNV have increased numbers of CD4+, CD8+ T cells and IFN- $\gamma$ when compared to norovirus-free mice [189]. To this end, MNV-CR6 infection suppresses the expansion of group 2 innate lymphoid cells, a function similar to that of commensal bacteria [190]. In addition, MNV-CR6 infection of antibiotic-treated mice protected against DSS-induced intestinal injury. These 
findings suggest that noroviruses may play a physiological beneficial role in intestinal homeostasis. The identification of additional noroviruses such as the one identified in this study provide further tools to understand the complex role of this family of viruses in health and disease.

Characterization of the microbiome of lab mice, pet store mice and wild mice stands to greatly aid our understanding of the crucial roles the microbiome play in host physiology and disease. Moreover, investigating at what extend the murine microbiome is representative of that seen in humans can promote the exploration of more informative and translational mouse models of disease. Critical to this characterization and refinement is inclusion of the virome in discussions of the microbiome. Because lab mice are relatively free of viral pathogens, inclusion of studies of pet store or wild mice are needed to better incorporate the role of viruses. Collectively, such studies will also enhance our understanding of inter-kingdom interactions between viral and bacterial communities and the host.

\subsection{Methods}

\section{Ethical approval and informed consent}

All studies were conducted in accordance with the recommendations put forth in the Guide

for the Care and Use of Laboratory Animals and were approved by the University of Missouri Institutional Animal Care and Use Committee.

\section{Animals}

C57BL/6 mice (4 males, 4 female) were purchased from Jackson Laboratory (Sacramento, CA and Bar Harbor, ME), C57BL/6NHsd mice (4 males, 4 female) from Harlan Laboratory (Envigo, Indianapolis, IN) and C57BL/6NTac mice (4 males, 4 female) from 
Taconic Biosciences, Inc. (Cambridge City, IN facilities). Pet store mice were purchased from Petco pet store (PS, Columbia, MO) (2 males and 2 females) and Columbia Pet Center (PS, Columbia, MO) (2 males and 2 females). All mice were around 4 weeks old and were post-weaning.

\section{Tissue collection}

All mice were euthanized by carbon dioxide asphyxiation and tissues including respiratory tissue (lungs; whole pluck), dermal tissue (glabrous perianal skin), and gastrointestinal tissue (ileum) were collected and flash-frozen in liquid nitrogen and stored in cryovials at $-80^{\circ} \mathrm{C}$.

\section{RNA, DNA extraction and cDNA synthesis}

Qiagen RNeasy kit (Cat \#74104) and Qiagen DNeasy blood and tissue kit (Cat \#69506, Qiagen, Germantown, MO) were used for RNA isolation and DNA isolation, respectively, according to the manufacturer's instructions. The Agencourt AMPure XP kit (Beckman Coulter, Brea, CA) was applied for the cDNA purification after cDNA synthesis. $100 \mu \mathrm{L}$ of cDNA was processed by adding $100 \mu \mathrm{L}$ of the AMPure XP beads. Forty $\mu \mathrm{L}$ of elution buffer was added to dilute the purified cDNA following the manufacturer's recommendations. The quality and quantity were measured by Qubit. Only one tissue type was used at a time to prevent cross-contamination of samples.

\section{Primer Information}

Primer A: 5'GTTTCCCAGTCACGATANNNNNNNNN3' a random primer used for cDNA synthesis in the first round and the specific primer B: 5'GTTTCCCAGTCACGATA3' used for the generated template application. Primers were purchased from Integrated DNA Technologies, (Coralville, IA). 


\section{Library preparation}

For the sequence library construction preparation, every 4 samples of the same type were pooled in equal volume for a single sequencing library. For instance, 4 DNA samples from the female mice sampled at the skin were pooled together and treated as one single pooling group.

Automated dual-indexed libraries were constructed with 100-250 ng cDNA or gDNA using the KAPA HTP Library Kit (KAPA Biosystems). 250 bp length inserts were targeted by using the SciClone NGS instrument (Perkin Elmer). Twenty-four cDNA libraries were pooled pre-capture generating an $18 \mu \mathrm{g}$ library pool. Twenty-four gDNA libraries were pooled pre-capture generating a $27 \mu \mathrm{g}$ library pool.

\section{Virome sequencing}

Both library pools were hybridized with a custom Nimblegen probe set (Roche, Madison, WI), termed "ViroCap", targeting a pan-virome space. The concentration of each captured library pool was accurately determined through qPCR (KAPA Biosystems) to produce cluster counts appropriate for the Illumina HiSeq4000 platform. One lane of $2 \times 125$ sequence data was generated per library pool yielding an average of $4 \mathrm{~Gb}$ of data per sample.

\section{Data analysis}

Two-way ANOVA followed by Holm-Sidak mehod. A $p$ value of less than 0.05 was used for all analyses (SigmaPlot 14.0).

\section{Acknowledgment}

These studies were partly funded by the University of Missouri Mutant Mouse Resource and Research Center (MMRRC; NIH U42 OD010918). We would also like to acknowledge 
the animal care staffs at Discovery Ridge, the MU DNA Core and Informatics Research Core facilities, and the Comparative Metagenomics Laboratory.

\section{Author Contributions}

$\mathrm{CF}$ and $\mathrm{AE}$ conceived and designed the study. All authors were responsible for the collection and analysis of data. CZ prepared the manuscript. All authors read and revised the manuscript.

\section{Additional Information}

Competing interests: The authors declare no competing interests. 


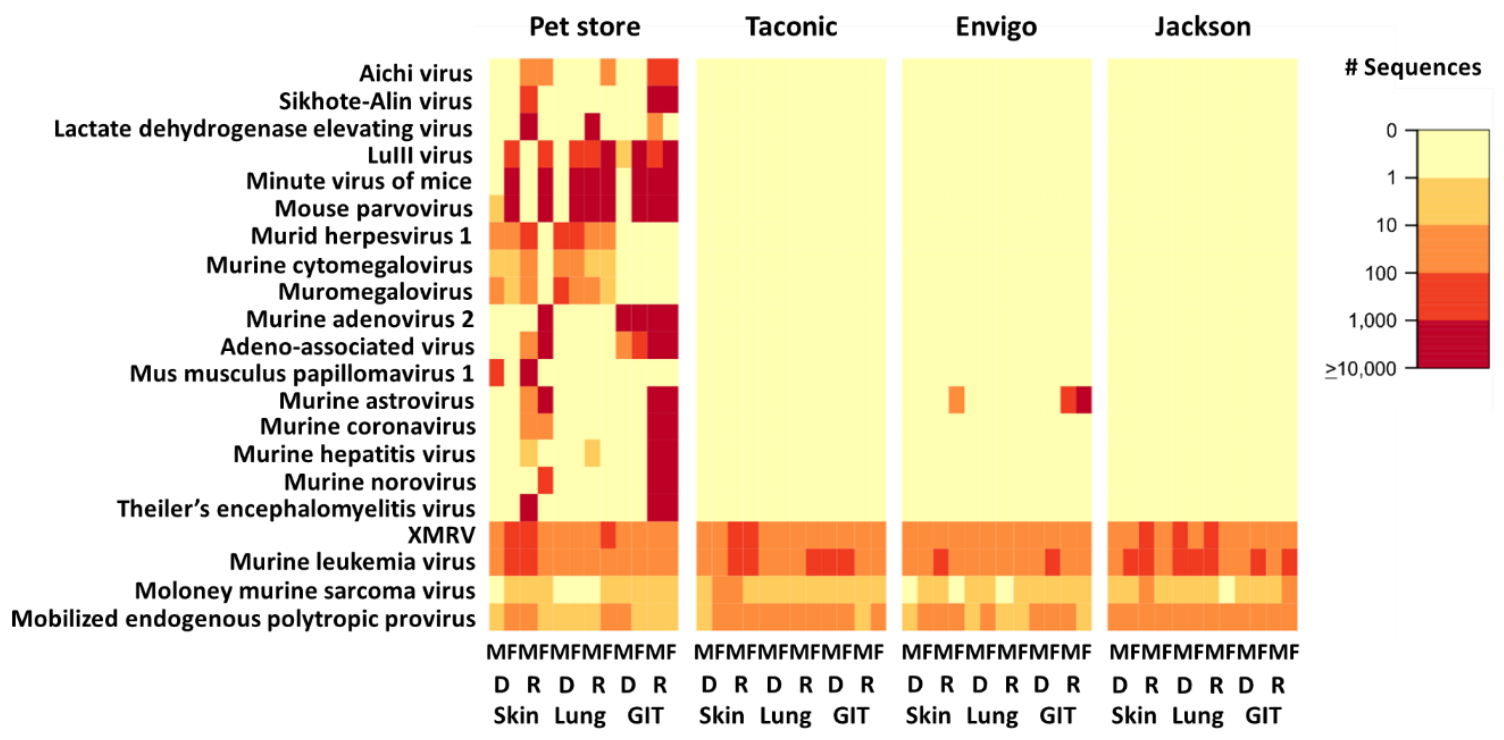

Figure 2-1. Heat map of vertebrate viruses from individual mice.

Mice are grouped according to the source from which they were obtained: Pet Store, Taconic Farms, Envigo and the Jackson Laboratory. RNA (R) and DNA (D) were isolated from samples of gastrointestinal tissue (GIT), lung, and Skin. Viruses detected are listed on the vertical axis. The value in the color key shows the range of detected sequence number. M: male; F: female. 


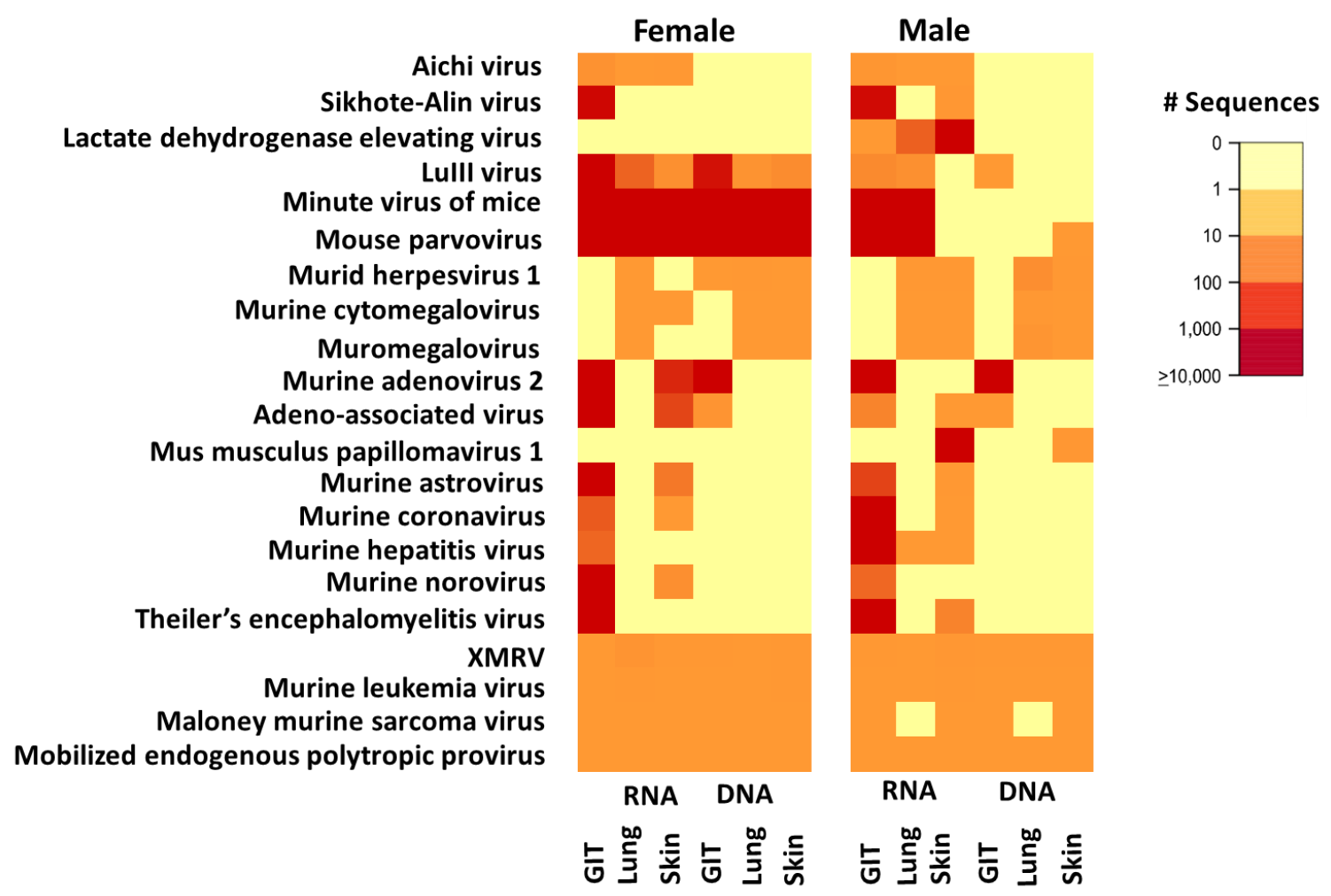

Figure 2-2. Heat map of vertebrate viruses from pet store mice.

Mice are grouped according to the sex including female (left) and male (right): RNA (R) and DNA (D) were isolated from samples of gastrointestinal tissue (GIT), lung, and Skin. Viruses detected are listed on the vertical axis. The value in the color key shows the range of detected sequence number. 

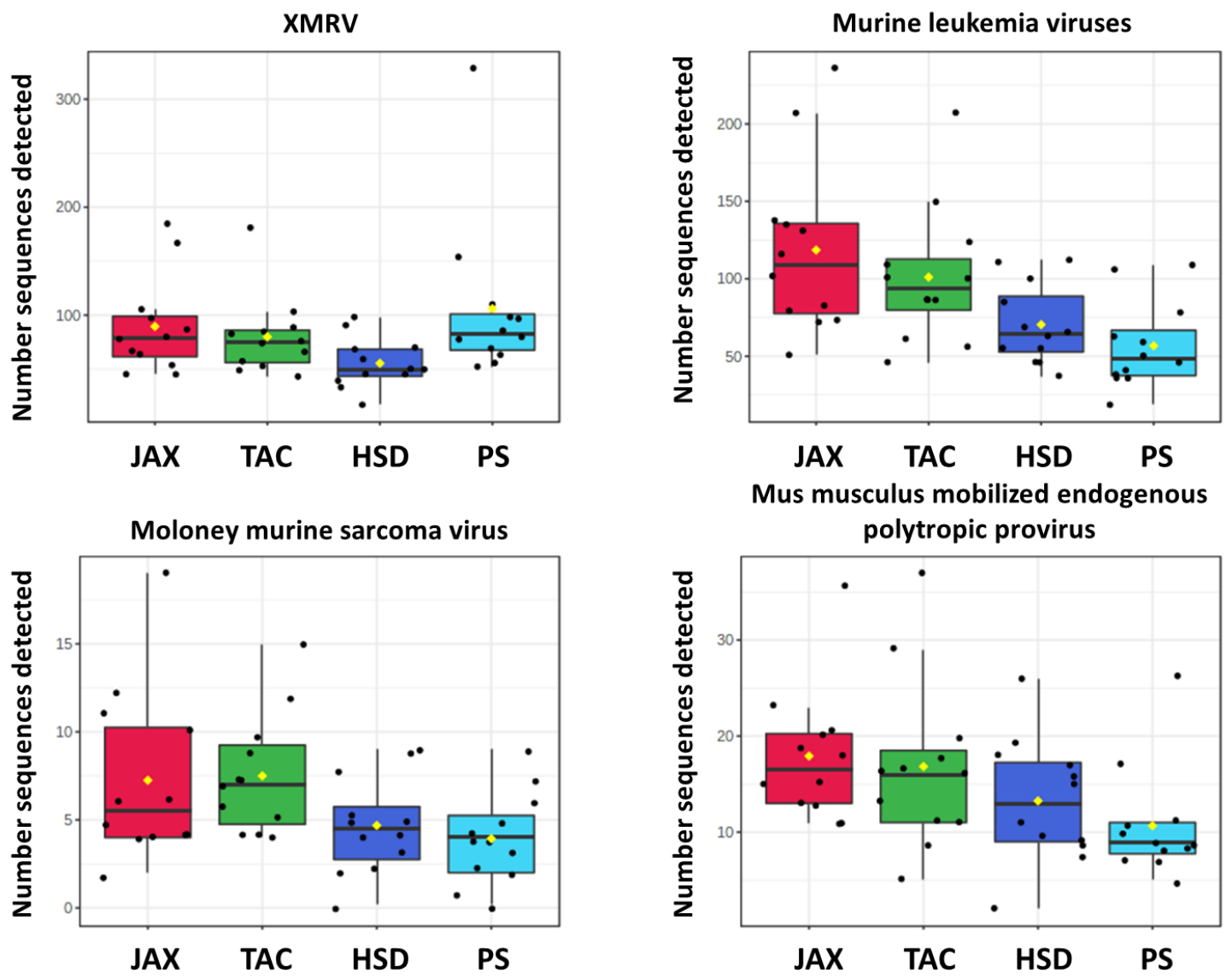

Figure 2-3. Retroviruses detected in mice obtained from different sources.

Resources: Jackson Laboratory (JAX), Taconic Farms (TAC), Envigo (HSD), and Pet store (PS). Twoway ANOVA followed by Holm-Sidak mehod) 


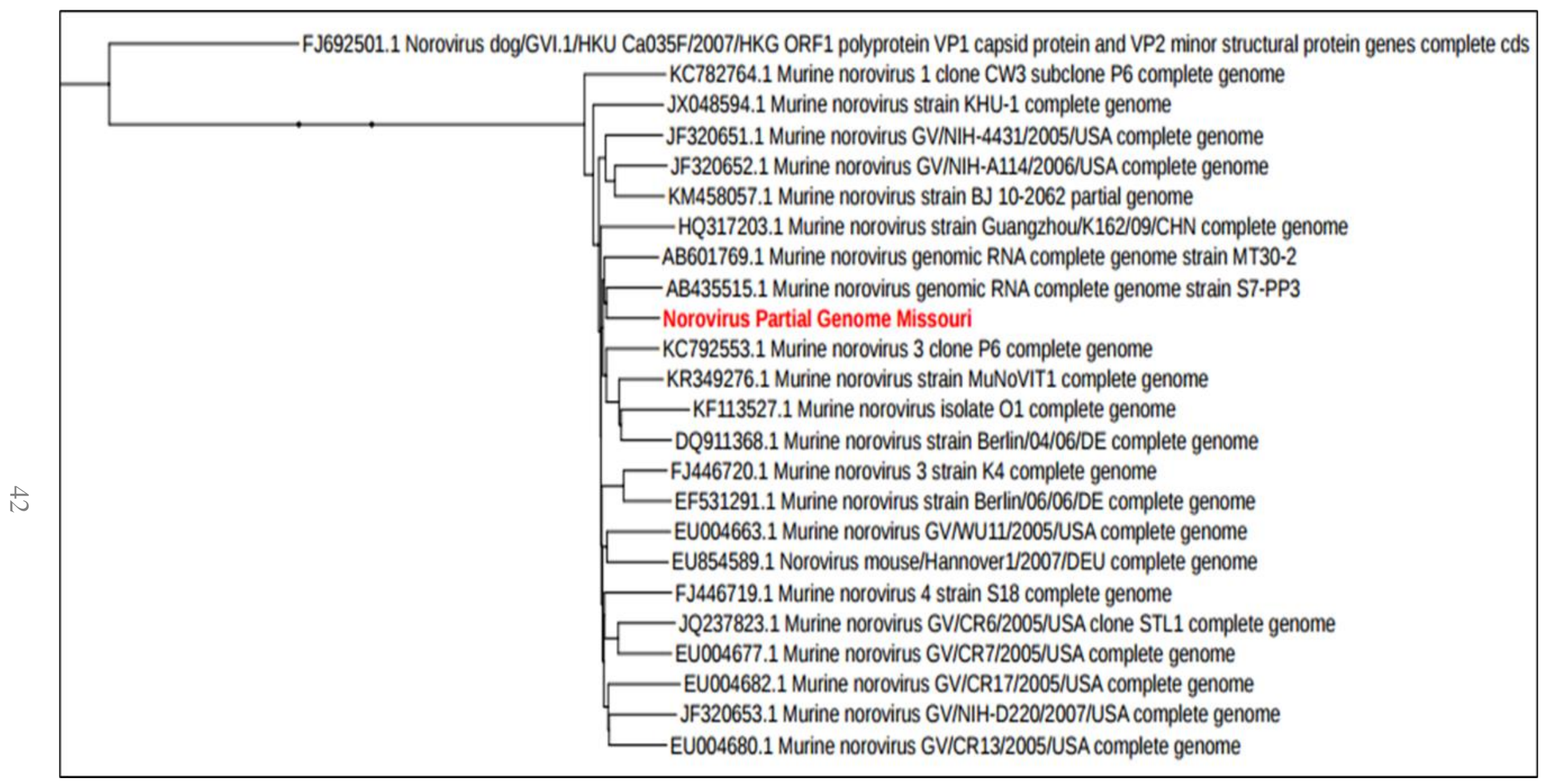

Figure 2-4. Phylogenetic tree of murine noroviruses.

A single representative dendrogram showing the phylogenetic relationship of one potentially unique virus (shown in red) identified in pet store mice (92\% identity to the next most-closely related stain). 
Table 2-1. Categorization of viruses identified (retroviruses excluded).

Table shows the summary of the identified viruses that belong to different viral families based on the common taxonomy for classification of viruses. Besides the retrovirus family that was shared by both pet store mice and lab mice, the 9 listed viral families in this table were only found in pet store mice. * Astrovirus was the only virus found also in lab mice.

\begin{tabular}{|l|l|l|}
\hline DNA/RNA Virus & \multicolumn{1}{|c|}{ Family } & \multicolumn{1}{c|}{ Virus Spe cies } \\
\hline RNA & Picornaviridae & Aichi Virus \\
\hline RNA & Picornaviridae & Skihote alin virus \\
\hline RNA & Picornaviridae & Theilers encephalomyelitis virus \\
\hline RNA & Arteriviridae & Lactate dehydrogenase elevating virus \\
\hline RNA & Astroviridae* & Murine astrovirus \\
\hline RNA & Coronaviridae & Murine coronavirus \\
\hline RNA & Coronaviridae & Murine hepatitis virus \\
\hline RNA & Caliciviridae & Murine norovirus \\
\hline DNA & Parvoviridae & LuIII virus \\
\hline DNA & Parvoviridae & Minute virus of mice \\
\hline DNA & Parvoviridae & Mouse parvovirus \\
\hline DNA & Parvoviridae & Adeno associated virus \\
\hline DNA & Herpesviridae & Murid herprsvirus 1 \\
\hline DNA & Herpesviridae & Murine cytomegalovirus \\
\hline DNA & Herpesviridae & Muromegalovirus \\
\hline DNA & Adenoviridae & Murine adenovirus 2 \\
\hline DNA & Papillomaviridae & Mus musculus papillomavirus. Type 1 \\
\hline
\end{tabular}


Table 2-2. Categorization and tissue tropism of viruses identified.

Table shows the detected tissue-specificity of vertebrate viral species and the percentage in the tested samples for GI, lung and skin tissue samples from pet store mice and laboratory mice.

\begin{tabular}{|c|c|c|c|c|}
\hline \multicolumn{5}{|c|}{$\begin{array}{r}\text { Tissue Specificity Vertebrate Viruses in Pet Store Mice } \\
\end{array}$} \\
\hline Viral Family & Viral Species & GI & Lung & Skin \\
\hline Retroviridae & XMRV & $4 / 4(100 \%)$ & $4 / 4(100 \%)$ & $4 / 4(100 \%)$ \\
\hline Retroviridae & Murine leukemia viruses & $4 / 4(100 \%)$ & $4 / 4(100 \%)$ & $4 / 4(100 \%)$ \\
\hline Retroviridae & Moloney murine sarcoma virus & $1 / 4(25 \%)$ & $1 / 4(25 \%)$ & $2 / 4(50 \%)$ \\
\hline Retroviridae & Mus musculus mobilized endogenous polytropic provirus & $4 / 4(100 \%)$ & $4 / 4(100 \%)$ & $4 / 4(100 \%)$ \\
\hline Astroviridae & Murine astrovirus & $2 / 4(50 \%)$ & 0/4 None & $2 / 4(50 \%)$ \\
\hline Picornaviridae & Aichi Virus & $2 / 4(50 \%)$ & $1 / 4(25 \%)$ & $2 / 4(50 \%)$ \\
\hline Picornaviridae & Skihote alin virus & $2 / 4(50 \%)$ & 0/4 None & $1 / 4(25 \%)$ \\
\hline Arteriviridae & Lactate dehydrogenase elevating virus & $1 / 4(25 \%)$ & $1 / 4(25 \%)$ & $1 / 4(25 \%)$ \\
\hline Parvoviridae & LuIII virus & $3 / 4(75 \%)$ & $3 / 4(75 \%)$ & $2 / 4(50 \%)$ \\
\hline Parvoviridae & Minute virus of mice & $3 / 4(75 \%)$ & $3 / 4(75 \%)$ & $2 / 4(50 \%)$ \\
\hline Parvoviridae & Mouse parvovirus & $3 / 4(75 \%)$ & $3 / 4(75 \%)$ & $2 / 4(50 \%)$ \\
\hline Herpesviridae & Murid herprsvirus 1 & 0/4 None & $4 / 4(100 \%)$ & $3 / 4(75 \%)$ \\
\hline Adenoviridae & Murine adenovirus 2 & $4 / 4(100 \%)$ & 0/4 None & $1 / 4(25 \%)$ \\
\hline Parvoviridae & Adeno associated virus & $4 / 4(100 \%)$ & 0/4 None & $2 / 4(50 \%)$ \\
\hline Papillomaviridae & Mus musculus papillomavirus. Type 1 & 0/4 None & 0/4 None & $2 / 4(50 \%)$ \\
\hline Coronaviridae & Murine coronavirus & $2 / 4(50 \%)$ & $0 / 4$ None & $2 / 4(50 \%)$ \\
\hline Coronaviridae & Murine hepatitis virus & $2 / 4(50 \%)$ & $0 / 4$ None & $1 / 4(25 \%)$ \\
\hline Caliciviridae & Murine norovirus & $2 / 4(50 \%)$ & 0/4 None & $1 / 4(25 \%)$ \\
\hline Picornaviridae & Theilers encephalomyelitis virus & $2 / 4(50 \%)$ & $0 / 4$ None & $1 / 4(25 \%)$ \\
\hline \multicolumn{5}{|c|}{ Tissue Specificity Vertebrate Viruses in Laboratory Mice } \\
\hline Retroviridae & XMRV & $12 / 12(100 \%)$ & $12 / 12(100 \%)$ & $12 / 12(100 \%)$ \\
\hline Retroviridae & Murine leukemia virus & $12 / 12(100 \%)$ & $12 / 12(100 \%)$ & $12 / 12(100 \%)$ \\
\hline Retroviridae & Moloney murine sarcoma virus & $6 / 12(50 \%)$ & $8 / 12(67 \%)$ & $8 / 12(67 \%)$ \\
\hline Retroviridae & Mus musculus mobilized endogenous polytropic provirus & $12 / 12(100 \%)$ & $11 / 12(92 \%)$ & $12 / 12(100 \%)$ \\
\hline Astroviridae & Murine astrovirus & $2 / 12(17 \%)$ & $0 / 12$ None & $1 / 12(8 \%)$ \\
\hline
\end{tabular}




\section{CHAPTER III}

Gut microbiome transfer method influences transfer efficiency and disease phenotype

(Chunye Zhang, Matthew Burch, Benjamin Olthoff, Aaron C. Ericsson*, Craig L. Franklin*) 


\subsection{Abstract}

Background: Complex gut microbiota $(\mathrm{GM})$ can influence the phenotype of mouse models of gastrointestinal (GI) disease. To identify contributing microbes or assess the influence of a complex GM on some physiological process, researchers frequently transfer GM between mice using different methods. Transfer of embryos (ET) into surrogate dams harboring the desired GM is the gold standard for transfer. However, this method requires expertise and is costly. Co-housing $(\mathrm{CH})$ weaning-age or adult mice is one of the most commonly used method of GM transfer, attractive due to its simplicity and low cost. Lastly, cross-fostering $(\mathrm{CF})$ of newborn pups to $\mathrm{GM}$ donor surrogate dams represents a third method of passive GM transfer. We hypothesized that ET and CF would be similar, and that both would transfer GM with a higher efficiency compared to $\mathrm{CH}$ method. To assess whether the mice generated using different transfer methods have different susceptibility to disease phenotype in the disease model, we systematically investigated the effect of three transfer methods (ET vs. $\mathrm{CF}$ vs. $\mathrm{CH}$ ) on the disease severity in the commonly used DSSinduced colitis model. We also investigated the recipient genetic background influence on the GM transfer efficiency and potential subsequent influence on disease susceptibility.

Results: Our results suggested that both the recipient genetic background and the richness of donor GM influenced the GM transfer efficiency and disease susceptibility. Additionally, our results demonstrated that the transfer method influenced the transfer efficiency, and the disease susceptibility differed between groups generated using different transfer methods. GM transferred by ET and CF showed high similarity to donor GM (i.e., higher transfer efficiency) and less disease severity compared with transfer by $\mathrm{CH}$, suggesting that $\mathrm{CF}$ is 
a viable alternative to ET. Our results suggest that data generated using the $\mathrm{CH}$ method should be interpreted with caution.

Conclusions: Our findings highlight the importance of recipient host genetics and GM transfer methods on both transfer efficiency and the phenotype of animal disease models. These results also raise caution when interpreting data using $\mathrm{CH}$ in an experimental design. Keywords: Gut microbiome transfer, embryo transfer, cross foster, co-house, DSSinduced colitis, mouse model

\subsection{Background}

The collection of microorganisms that live in human and non-human animals' gastrointestinal tract, known as the gut microbiome (GM), is associated with health and disease [191-193]. Our previous study showed that supplier-dependent differences in the GM contribute to differences in disease phenotype in several disease models, such as the $\mathrm{IL}^{-/-}$mouse model of inflammatory bowel disease (IBD) and the Polyposis in Rat Colon (Pirc) rat model of colorectal cancer $[72,194]$. Experimental transfer of the GM using animal models is an extremely popular approach to identify associations between differing GM and disease phenotypes, create a well-controlled GM environment for further investigation of underlying mechanisms, and improve the reproducibility of biomedical research using animal models $[98,101,102,104,107,195,196]$. Accumulating studies show that many factors can contribute to the variation of the GM $[70,71,197]$. In this project, we focus on different methods of GM transfer and the subsequent change of disease phenotype in mice generated via the different methods. Additionally, the influence of host genetic factors was investigated using embryo transfer rederivation of two substrains (C57BL/6J and C57BL/6NHsd) that originated from a similar genetic background. 
There are several commonly used methods of experimental GM transfer [198, 199]. Embryo transfer (ET) using surrogate dams harboring a desired GM is considered the gold standard [97]. Simply co-housing (CH) GM donor and recipient mice is also commonly used in the literature [200-203]. As ET requires considerable expertise and infrastructure, cross-fostering $(\mathrm{CF})$ of pups within the first 24 hours of life to a surrogate dam harboring the GM of interest represents a third option to be used as a GM transfer method [198, 199]. While yet to be investigated, the latter showed promise based on its common use to eliminate targeted bacterial pathogens [204, 205]. Our hypothesis is that the different GM transfer methods differ in transfer efficiency, and result in subsequent differences in the disease phenotype of a commonly used mouse model. Specifically, we hypothesized that ET would provide complete transfer of the GM from birth dam to offspring, $\mathrm{CH}$ would result in the lowest transfer efficiency, and CF would be intermediate between ET and $\mathrm{CH}$ in transfer efficiency.

As we have shown previously that transfer of the GM between mice via repeated gastric gavage of antibiotic-treated mice is dependent on the relative richness of the donor and recipient GM, two different substrains of the commonly used C57BL/6 mouse, C57BL/6J (B6J) and C57BL/6NHsd (B6NHsd), harboring low richness and high richness GM [108], respectively, were used as GM recipients. CD1 mice harboring the well-characterized low richness GM1 and high richness GM4 (originally derived from C57BL/6J and C57BL/6NHsd mice, respectively) were used as GM donors [97]. This allowed for reciprocal transfers (i.e., high richness GM4 donors and low richness B6J recipients, and low richness GM1 donors and high richness B6NHsd recipients) using each of the three different transfer methods. Additionally, the ET studies were performed using a fully 
crossed study design to determine the influence of recipient substrain genetics on the composition of the GM at adulthood. At 7 weeks of age, all recipient mice were subjected to the DSS-induced model of chronic colitis using the classical approach $[206,207]$. The primary metrics of disease severity were percent weight loss and colon length, with histological evaluation used to confirm the development of colitis.

\subsection{Materials and Methods}

Mice: Two colonies of mice were used as GM donor mice: MU:CD-1 (CD-1) mice harboring a standard complex low richness microbiome (GM1) originating from B6J mice (the Jackson Laboratory, Bar Harbor, ME), and CD-1 mice harboring relatively high richness GM4 originating from B6NHsd mice (Envigo, Indianapolis, IN) [97]. Separate colonies of CD-1 mice harboring those two GMs have been maintained at our facility for over 35 generations, using a rotational breeding scheme and annual introduction of external CD-1 genetics via ET to maintain allelic heterozygosity in each colony. B6J and B6NHsd mice (offspring of mice supplied by the respective supplier) were used as GM recipient mice. GM transfers were then carried out via 1) breeding of recipient mice, collection of embryos, and surgical embryo transfer to pseudopregnant GM donor dams; 2) breeding of recipient mice and fostering of neonatal pups $(<12 \mathrm{hr})$ on to surrogate GM donor dams nursing newborn litters; or 3) timed breeding of GM recipient and donor mice, followed by co-housing in a 1:1 ratio beginning at weaning (21d). These three methods resulted in recipient mice that were exposed to the donor GM at embryonic, immediate post-natal, or weaning stages of life (Figure 1).

All mice were housed in the AAALAC International-accredited Discovery Ridge vivarium (Columbia, MO) in micro-isolator cages on ventilated racks (Thoren Caging Systems Inc., 
Hazelton, PA). Ad libitum supply of irradiated 5058 (breeder) or 5053 (maintenance) chow (LabDiet, St. Louis, MO) and acidified autoclaved water were provided. All animal experiments were approved by the University of Missouri Institutional Animal Care and Use Committee (protocol 9587) and followed the recommendations set forth in the Guide for the Care and Use of Laboratory Animals.

Study group nomenclature: Throughout the manuscript, the different groups of mice are designated as recipient substrain (B6NHsd or B6J) followed by the GM to be transferred (GM1 or GM4) and the method of transfer (ET, CF or CH). For example, B6NHsd (GM4ET) represents a B6NHsd mouse to which GM4 has been transferred using embryo transfer. The study design and schematic graph are presented in Figure 1.

Embryo transfer method (ET): For this group, B6J and B6NHsd mice, obtained directly from the Jackson Laboratory and Envigo respectively, were bred, and embryos were collected at the zygote cell stage and surgically transferred to pseudopregnant CD-1 surrogate dams. Embryo collection and transfer were performed following the previously described procedure [97]. Briefly, B6J and B6NHsd embryo donor mice were serially injected with luteinizing hormone-releasing hormone and gonadotropins for estrus synchronization. On day 4, B6J and B6NHsd embryo donor mice were mated to intact males to generate embryos. GM donor CD-1 surrogate dams were mated to vasectomized stud males to induce pseudopregnancy. Four days later, embryos were collected and surgically transferred to plug-positive CD-1 surrogate dams. All procedures were performed at the MU Mutant Mouse Resource and Research Center.

A fully crossed study design was used for this arm of the study, with B6J and B6NHsd embryos each being transferred to CD-1 surrogate dams harboring low richness GM1 or 
high richness GM4, and resulting in four different sub-groups using the embryo transfer method: B6J (GM4ET, $n=24)$, B6NHsd (GM1ET, $n=24)$, B6J (GM1ET, $n=24)$, and B6NHsd (GM4ET, $n=24)$. Both female and male mice were included in the experiment design.

Cross-foster transfer method (CF): B6J and B6NHsd mice, obtained directly from the suppliers, were bred to generate pups for use as recipient mice. Pups were reciprocally cross-fostered to CD-1 GM donor mice harboring high richness GM4 or low richness GM1, respectively, within 24 hours after birth to generate two transfer sub-groups with opposite transfer direction. B6J (GM4CF, $n=13)$ and B6NHsd (GM1CF, $n=11)$. For these studies, CD-1 females were bred to CD-1 males two days prior to breeding of B6 mice to ensure that CD-1 surrogate dams had litters prior to B6 parturition. This ensured that B6 pups could be transferred within 24 hours after birth to a foster-ready mother. Approximately three CD-1 mice/litter were kept and included in fostered litters in order to prevent cannibalism and further facilitate GM transfer. Extra pups that were not used for the study from donor or recipient were humanely euthanized by $\mathrm{CO}_{2}$ asphyxiation according to protocol.

Co-housing transfer method $(\mathbf{C H})$ : B6J and B6NHsd mice, obtained directly from the suppliers, were bred to generate recipient mice. At 21 days of age, recipient mice were weaned and reciprocally co-housed with weanling CD-1 donors harboring high richness GM4 or low richness GM1, respectively, with two donor and two recipient mice per cage, to generate two sub-groups, B6J (GM4CH, $n=12)$ and B6NHsd (GM1CH, $n=12)$. Only females were used in the $\mathrm{CH}$ study to avoid the inter-male aggression among nonlittermates when co-housed at weaning. 
DSS administration: At seven weeks of age, all recipient mice received freshly prepared 2.5\% DSS (MP Biomedicals, Irvine, CA. mol. wt. 36-50 kDa) in their drinking water for 7 days, followed by 10 days of DSS-free drinking water, and this was repeated for four cycles to induce chronic, relapsing inflammation. During the DSS-treatment, the weight change was tracked every other day on an individual basis. At the end of the $4^{\text {th }}$ cycle, all mice were humanely euthanized for sample collection. During the study, any mouse that lost more than $20 \%$ of its initial body weight or exhibited clinic signs such as dehydration or lethargy was humanely euthanized.

Sample collection: At 3 and 7 weeks of age, mice were placed in a sterile autoclaved cage and allowed to defecate after which 2-3 fecal pellets were collected. After DSS treatment, mice were humanely euthanized and endpoint feces and cecal contents were collected for GM analysis. The colon length was carefully measured from the cecocolic junction to the rectum. The colon was rinsed with $10 \%$ neutral buffered formalin, divided into three pieces and arranged in histology cassette, followed by fixation in formalin in preparation for paraffin embedding. Fecal samples were also collected from ET recipient dams, CF surrogate dams, and all CD-1 mice used in $\mathrm{CH}$ experiments.

DNA extraction: The QIAamp PowerFecal DNA Kit (Qiagen, Germantown, MD) was used for isolation of DNA from fecal samples. Quantification of extracted DNA was performed using Qubit® 2.0 Fluorometer and Qubit dsDNA BR assay (Invitrogen, Waltham, MA) following the manufacturer's protocol.

16S rRNA gene library preparation and sequencing: The V4 region of the bacterial 16S rRNA gene was amplified using the U515F/806R primers [208], to generate dual-indexed amplicon libraries which were pooled for sequencing using the Illumina MiSeq instrument 
and V2 chemistry with $2 \times 250$ bp paired-end reads (coverage approaching 100,000 reads per sample) at the University of Missouri DNA Core facility (Columbia, MO).

Statistical analysis: $16 \mathrm{~S}$ rRNA gene sequence analytical processing such as trimming, screening and aligning contiguous sequences were performed by the University of Missouri Informatics Research Core Facility (Columbia, MO). The Beta-diversity obtained by principal coordinate analysis $(\mathrm{PCoA})$ using $1 / 4$ root-transformed sequence data and alphadiversity indices were performed using Past 3.20 software [209] at the University of Missouri Metagenomics Center (Columbia, MO). Permutational multivariate analysis of variance (One-way PERMANOVA) based on both weighted (Bray-Curtis) and unweighted (Jaccard) distances were used to compare the compositional differences between different transfer groups. Analysis of DSS-induced weight loss was performed using three-factor ANOVA followed by Holm-Sidak post-hoc testing when main effects were found (ET substrain assessment) or two-factor ANOVA followed by Student-Newman-Keuls Method (transfer method comparisons). Analysis of colon length was performed using one-way ANOVA, with pairwise comparison based on the Student-Newman-Keuls method. Significance was considered when $p$ value is less than 0.05 .

Histology examination: All slides of GI tissues were trimmed, embedded, and sectioned by the histology services of IDEXX BioAnalytics (Columbia, MO). Histopathological examination was performed by two experienced pathologists in a blinded fashion to confirm the development of chronic colitis after treatment. Review of sections confirmed DSS colitis in all treated mice, but inconsistent sectioning precluded scoring of severity. 


\subsection{Results}

\subsubsection{Substrain genetics influences the GM transfer efficiency following ET}

In order to first assess the influence of substrain genetics on GM transfer efficiency, the gold standard GM transfer method (ET) was used to generate four groups of recipient mice: B6J(GM1ET), B6J(GM4ET), B6NHsd(GM1ET), and B6NHsd(GM4ET).

Principal coordinate analysis (PCoA) of $16 \mathrm{~S}$ rRNA data revealed that the donor GM was the primary determinant of the offspring GM composition at 7 weeks, with substrains receiving GM1 or GM4 from their birth dam separating along PCo1 (34.19\% variation) (Fig. 2A). However, PCoA also revealed significant substrain-dependent differences captured by PCo2 (19.42\% variation), which were confirmed using One-way PERMANOVA $(p=0.0001 ; \mathrm{F}=51.93$, Bray-Curtis $)$. This result indicated that the donor (i.e., biological dam) GM is the primary source of variability affecting the transfer outcome, but that differences in recipient genetics, even at the level of substrain, also affect the final GM composition.

As expected, the Chao-1 richness index was significantly different between GM1 and GM4 (Fig. 2B). No difference was detected between different substrains that received GM4, while there was a significant difference between substrains that received GM1 $(p<0.001)$. In addition to the expected differences between GM1 and GM4, there were differences in the patterns of relative abundance in a substrain-based manner regardless of the GM received (Fig. 2C).

In conclusion, following ET transfer, the offspring GM is highly similar to the GM from the surrogate (birth) dam in richness and composition, however the recipient genetics also subtly influence the transferred GM composition. 


\subsubsection{Mice generated using ET differ in susceptibility to DSS-induced colitis in GM- and substrain-dependent manner}

To assess the influence of different GMs and substrains on disease susceptibility, mice were subjected to a commonly used regimen of cyclical DSS administration to induce chronic, intermittent colitis. Comparison of DSS-associated effects on weight showed that B6J(GM4ET) mice experienced less weight loss post-treatment compared with other ET groups (Fig. 3A). The B6NHsd (GM1ET) group experienced greater weight loss compared with other ET groups. Three-way ANOVA with substrain, GM, and time as factors revealed that substrain (B6J vs. B6NHsd: $p<0.001, \mathrm{~F}=310.88$ ), GM (GM1 vs. GM4: $p<$ $0.001, \mathrm{~F}=328.76)$ and time $(p<0.001, \mathrm{~F}=88.52)$ affected weight loss with multiple interactions.

Comparisons of DSS-associated colon length (Fig. 3B) showed a main effect of treatment $(p<0.001, \mathrm{~F}=612.72)$, confirming that DSS administration resulted in significant shortening of the colon. Notably, while untreated B6NHsd mice had significantly greater colon lengths compared to B6J mice $(p=0.018, \mathrm{t}=2.38)$, B6NHsd mice in DSS-treatment groups, regardless of GM, showed significantly greater colon shortening than $\mathrm{B} 6 \mathrm{~J}$ mice ( $p$ $<0.001, \mathrm{t}=5.032)$ validating the differences observed in weight loss, and suggesting that the decrease in colon length is associated with differential susceptibility to DSS treatment between substrains. Collectively, these results highlight the integrated influence of host genetics and GM on susceptibility to DSS-induced weight change and colitis. 


\subsubsection{Transfer methods (ET, CF, CH) differ in transfer efficiency when transferring high richness GM4 to recipient $\mathrm{B} 6 \mathrm{~J}$ mice}

Studies comparing different transfer methods were performed using CD-1 donor mice of either high richness GM4 or low richness GM1 (derived from Envigo and Jackson, respectively) and recipients from the reciprocal source.

Principal coordinate analysis of GM4 donors and B6J recipients from all three transfer methods showed a clear separation of all three recipient groups (Fig. 4A), with differences confirmed by One-way PERMANOVA ( $p=0.0001 ; \mathrm{F}=25.57$, Bray-Curtis). Samples from mice in the ET and CF groups clustered closer to the donor samples than samples from recipient mice generated using the $\mathrm{CH}$ method. As expected, marked separation of the $\mathrm{CH}$ group from donor controls was also observed at 3-weeks of age (Fig. S1A). At 3weeks of age, the richness of $\mathrm{B} 6 \mathrm{~J}(\mathrm{GM} 4 \mathrm{CF})$ and $\mathrm{B} 6 \mathrm{~J}(\mathrm{GM} 4 \mathrm{CH})$ recipient mice was significantly lower than the donor mice (Fig. 4B). By 7-weeks of age however, there was no difference in richness between any of the recipient groups and the donor GM. LEfSe analysis (Fig. 4C and Fig. 4D) detected a limited number of taxa preferentially enriched at 7 weeks in B6J mice receiving GM4 via $\mathrm{CH}$, relative to $\mathrm{ET}$ and $\mathrm{CF}$, all within the class Clostridia and including an annotation likely representing segmented filamentous bacteria (SFB). Thus, while all three methods resulted in some degree of GM transfer, the transfer efficiency of high richness GM4 into B6J mice differed between methods in transfer completeness, with ET and CF providing more complete transfer than $\mathrm{CH}$. 


\subsubsection{B6J(GM4) mice generated using different transfer methods display differential susceptibility to DSS-induced colitis}

Administration of DSS to B6J mice that received high richness GM4 via different transfer methods resulted in significant differences in weight loss depending on the transfer method (Fig. 5). Specifically, the DSS-induced weight loss in the $\mathrm{CH}$ group was significantly greater than that in ET and CF groups. Comparison of colon lengths post-DSS treatment among B6J recipient mice that received GM4 using different transfer methods showed no significant difference between groups (data not shown). The differences in weight loss suggest that GM4 was less protective against disease when incompletely transferred at a later age via co-housing.

\subsubsection{Transfer methods differ in transfer efficiency when transferring low richness GM1 to recipient B6NHsd mice}

To further assess the influence of transfer method and differences in richness between donor and recipient on transfer efficiency, we transferred low richness GM1 into B6NHsd mouse using all three methods. One-way PERMANOVA comparing donor and recipient groups showed the significant differences between donor and recipients generated using the different methods. Principal coordinate analysis of GM1 donors and B6NHsd recipients generated using ET, $\mathrm{CF}$ and $\mathrm{CH}$ methods showed a clear separation of the $\mathrm{CH}$ group from the ET and CF groups (Fig. 6A), with differences confirmed by One-way PERMANOVA ( $p=0.0001 ; \mathrm{F}=44.58$, Bray-Curtis). Samples from mice generated using ET and CF

methods also clustered much closer to donor samples than samples from recipients generated using $\mathrm{CH}$. Similarly, notable separation of the $\mathrm{CH}$ group from donor control was also observed at 3-weeks of age recipient mice (Fig. S1B). Comparisons of richness (Fig. 
6B) revealed that, at 3- and 7-weeks of age, the richness of samples from recipients generated using ET showed no difference from the richness of donor samples. Samples from recipients generated via $\mathrm{CF}$ were less rich than donor samples at 3-weeks of age and remained low at 7-weeks of age. In contrast, $\mathrm{CH}$ recipients harbored a significantly greater richness GM pre-transfer which remained significantly greater than that of donors following $\mathrm{CH}$. In contrast to the transfer of GM4 to B6J recipients, transfer of low richness GM1 to B6NHsd mice was less effective, particularly in the $\mathrm{CH}$ group (the richness of donor and recipient at 7-weeks of age: $\mathrm{p}<0.0001$ ). LEfSe analysis of recipients at 7 weeks of age revealed significantly enriched taxa in mice generated using $\mathrm{ET}, \mathrm{CF}$, and $\mathrm{CH}$ methods (Fig. 6C and Fig. 6D). In conclusion, for both transfer directions, our results showed that the ET and CF methods resulted in greater transfer completeness and efficiency compared with the $\mathrm{CH}$ method.

\subsubsection{B6NHsd(GM1) mice generated using different transfer methods display differential susceptibility to DSS-induced colitis}

Comparison of DSS-induced weight loss between transfer groups paralleled that seen in B6J(GM4) mice, as mice generated using ET had significantly less weight loss compared to the $\mathrm{CF}$ and $\mathrm{CH}$ groups (Fig. 7A). Remarkably, mice generated using $\mathrm{CH}$ experienced severe weight loss (i.e., more than 20\%) beginning around day 10 post-DSS treatment and were humanely euthanized according to our IACUC protocol. A survival curve was used to show the rate of removal from study of B6NHsd mice generated using $\mathrm{CH}$ method (Fig. 7B).

Overall, the weight loss differed in the transfer groups generated using ET, $\mathrm{CF}$, and $\mathrm{CH}$ method. Mice in the ET group displayed significantly less weight loss compared to mice 
generated using $\mathrm{CF}$ and $\mathrm{CH}$, regardless of transfer direction, while mice in the $\mathrm{CH}$ group experienced more severe weight loss, especially when attempting to transfer low richness GM1 to B6NHsd mice already colonized with a high richness GM.

\subsection{Discussion}

In recent years, modulation of the gut microbiome through GM transfer has become increasingly popular in biomedical research, using multiple approaches [210-213]. The transfer of disease phenotype via GM transfer is critical for demonstrating a causative influence of the GM on a disease phenotype. Microbiome transfer is also used as a possible therapeutic approach for certain diseases.

Thus, it is essential to have a better understanding of the microbiome transfer efficiency using different transfer methods and scenarios, and a sense of whether and how the different transfer methods may inherently affect the phenotype of disease models. Additionally, optimized practices for GM transfer in the research community are necessary from the perspective of reproducibility. For example, if models are found to lack reproducibility between labs, the GM can be explored as a culprit first by characterization of composition. Should differences in model phenotypes correlate with differences in GM, transfer studies can be used to begin to establish cause and effect relationships between GM and phenotype.

There are several approaches for GM transfer. ET is considered the gold standard since the pups obtain their GM through natural means including exposure to vaginal microbiota during delivery, and maternal fecal and environmental microbiota immediately after birth and during nursing and maternal care. Cross fostering of pups onto GM donor mice within the first 24 hours of life represents a cost-effective alternative to ET. Offspring GM is 
populated by the surrogate (donor) maternal fecal and environmental microbiota but is exposed to the vaginal microbiota of the birth mother, rather than the surrogate dam [198]. Nursing and maternal care likely play a critical role in shaping the recipient microbiota in both ET and CF-derived offspring [203] and the presence of littermates may help to amplify colonization of offspring. Inclusion of pups naturally born to the surrogate dam may also facilitate some sharing of maternal vaginal microbiota to their fostered littermates. In contrast, co-housing of weanling recipient mice with donor mice occurs after establishment of the offspring GM and ignores developmental influences of the transferred GM on the recipient. Despite this shortcoming, co-housing is a commonly used method to normalize the microbiome between mice due to its simplicity [203]. However, it does have limitations, as demonstrated by the current study and other research teams [201, 203].

While embryo transfer results in a natural vertical GM transfer between dam and offspring, this method is costly and requires substantial expertise and infrastructure, making it an impractical method for most labs. Alternatively, the current study shows that crossfostering results in similar transfer efficiency when compared to ET. This method is advantageous over ET because of ease of use and low cost [97, 107, 198, 199].

Co-housing as a transfer method produced mixed results. While $\mathrm{CH}$ resulted in less complete transfer of the rich GM4 to recipient B6J mice when compared to ET or CF, transfer was nonetheless partially effective whereas the $\mathrm{CH}$-mediated transfer of the sparse GM1 to B6NHsd recipients resulted in a hybrid recipient profile that was actually more dissimilar to donor mice than the pre-transfer profiles. These data are in agreement with previous findings showing that the successful transfer of GM to antibiotic-treated mice via 
repeated intra-gastric gavage is dependent on the starting relative richness of donor and recipient GMs [108].

Co-housing also resulted in exacerbation of DSS disease severity as evidenced by increased weight loss in the $\mathrm{B} 6 \mathrm{~J}(\mathrm{GM} 4 \mathrm{CH})$ group and marked weight loss leading to removal from study in the B6NHsd(GM1CH) group. The reasons for this are unknown, but may be related to compounding weaning stress with the stress of being placed in a new cage with strange donor mice. This may result in sufficient stress to modulate the immune system and exacerbate inflammation. However, this seems unlikely as DSS was not administered until mice were seven weeks of age and had been with the donor mice for a full month. The increased disease severity (as measured via weight loss) observed in B6J $(\mathrm{GM} 4 \mathrm{CH})$ mice relative to $\mathrm{B} 6 \mathrm{~J}(\mathrm{GM} 4 \mathrm{ET})$ and $\mathrm{B} 6 \mathrm{JGM} 4 \mathrm{CF}$ is intuitive in the context of decreased efficiency of $\mathrm{CH}$-mediated transfer of the rich GM4 shown to be protective in the fully crossed ET studies. However, the reciprocal series of transfers yielded unexpected results as the $\mathrm{CH}$-mediated transfer of GM1 (shown to confer increased disease severity) to B6NHsd, resulted in extremely poor transfer efficiency by seven weeks of age, and yet disease was severely exacerbated. We speculate that there may be differences between $\mathrm{B} 6 \mathrm{~J}(\mathrm{GM} 4 \mathrm{CH})$ and $\mathrm{B} 6 \mathrm{NH}$ sd $(\mathrm{GM} 1 \mathrm{CH})$ mice in the antigen burden placed on the immune system due to DSS administration. B6J mice housed with GM4 donors at weaning are readily colonized with the donor GM due to the inherent difference in richness (donor > recipient) and coprophagy, and development of tolerance to those bacteria over the following four weeks may occur before administration of DSS. In contrast, B6NHsd recipient mice may be, at least partially, resistant to colonization with the donor GM due to the inverse relationship in richness (donor < recipient), despite coprophagy. Lacking full 
tolerance to the GM, perhaps the immune system of $\mathrm{B} 6 \mathrm{NHsd}(\mathrm{GM} 1 \mathrm{CH})$ mice is exposed to a greater number of previously unrecognized bacteria following DSS exposure and ulceration of the mucosa. While additional experiments are needed to answer those questions, the current findings provide compelling evidence that the method of transfer and relationship between donor and recipient in starting GM richness can significantly influence both transfer efficiency and model phenotypes.

These findings highlight the need for appropriate controls in studies wherein the GM is experimentally transferred, particularly using $\mathrm{CH}$. Such controls could include transfer of irrelevant GM profiles not associated with phenotypic changes, transfer of the target GM using multiple methods, or simply second-generation mice born to recipient mice. The absence of such controls makes interpretation of experimental outcomes difficult. Surprisingly, we were unable to identify any controlled studies wherein different transfer methods were directly compared.

Lastly, our data demonstrate a significant effect of recipient genetics, even at the level of substrain, on the final GM profile when the GM is transferred via ET. Org et al. previously demonstrated host genetic control of the GM and identified loci associated with the relative abundance of certain taxa [214]. Our data provide GM differing between substrains, such as certain taxa are enriched in B6J recipients regardless of the GM compared with B6NHsd substrain. These findings underscore the multi-layered influence of host genetics and GM composition on model outcomes, and again emphasize the necessity of appropriate controls.

\subsection{Conclusions}

In conclusion, our results demonstrate that both the transfer method and transfer direction influence experimental GM transfer efficiency. ET showed the highest transfer efficiency, 
while the CF method, with the advantage of lower cost and complexity compared to ET, provided a possible viable alternative option for GM transfer studies where high efficiency is desired. The $\mathrm{CH}$ method was particularly problematic when attempting to transfer a relatively sparse GM to a recipient with a richer starting GM and collectively, our results suggest that $\mathrm{CH}$ should be carefully considered when used as a GM transfer approach, and only in conjunction with the appropriate controls.

\section{List of abbreviations}

ANOVA: analysis of variance; $\mathrm{B} 6 \mathrm{~J}$ : $\mathrm{C} 57 \mathrm{BL} / 6$ mice; $\mathrm{B} 6 \mathrm{~J}(\mathrm{GM} 1 \mathrm{CF})$ : $\mathrm{B} 6 \mathrm{~J}$ mice cross fostered to a CD-1 colony harboring GM1; B6J(GM1ET): B6J mice derived by CMTR (embryo transfer) using surrogates from CD-1 colony harboring GM1; B6J(GM4CF): B6J mice cross fostered to a CD-1 colony harboring GM4; B6J(GM4CH): B6J mice co-housed at weaning with a CD-1 colony harboring GM4; B6J(GM4ET): B6J mice derived by CMTR (embryo transfer) using surrogates from CD-1 colony harboring GM4; B6NHsd(GM1CF): B6NHsd mice cross fostered to a CD-1 colony harboring GM1; B6NHsd(GM1CH): B6Hsd mice co-housed at weaning with a CD-1 colony harboring GM1; B6NHsd(GM1ET): B6Hsd mice derived by CMTR (embryo transfer) using surrogates from CD-1 colony harboring GM1; B6NNsd: C57BL/6NHsd mice ordered from Hsd/Envigo; CF: Cross foster; CH: Co-house; DSS: Dextran sulfate sodium; ET: Embryo transfer; GI: gastrointestinal. GM: Gut microbiome; GM1: GM maintained in our CD-1 colony through embryo transfer that originated from Jackson Laboratory; GM4: GM maintained in our CD-1 colony through embryo transfer that originated from Hsd/Envigo Laboratory; IBD: inflammatory bowel disease; Jax: Jackson Laboratory; LEfSe: linear discriminant analysis Effect Size; PCoA: Principal coordinates analysis; One-way 
PERMANOVA: Permutational multivariate analysis of variance; SEM: standard error of the mean.

\section{Ethics approval and consent to participate}

No applicable.

\section{Availability of data and material}

All sequence data presented in the current manuscript are available in the NCBI Sequence Read Archive under BioProject ID PRJNA694463. The data supporting the results are available in the figures of this paper.

\section{Competing interests}

The authors declare that there is no conflict of interest.

\section{Funding}

This project was funded by NIH U42 OD010918 (University of Missouri Mutant Mouse Resource and Research Center).

\section{Authors' contributions}

All the authors have read and approved this manuscript. CF and AE conceived and supervised the project. CZ performed the study and analyzed all data. $\mathrm{MB}$ and $\mathrm{BO}$ performed part of the mouse work. $\mathrm{CF}, \mathrm{AE}$ and $\mathrm{CZ}$ were collectively responsible for the interpretation of data. $\mathrm{CZ}$ drafted the original manuscript. $\mathrm{CF}$ and $\mathrm{AE}$ critically revised and edited the manuscript. CF conceived the development of distinct standardized complex microbiota communities (GM1 and GM4), used as GM donors in the present transfer study.

\section{Acknowledgments}

We would like to acknowledge Dr. Marcia Hart for the generation of the standardized complex GM colonies, the cryobiology lab at the MMRRC for their work performing 
embryo transfer procedures, the MMRRC colony management lab and animal care staff for our vivarium, the MU DNA Core and Informatics Research Core facilities, Giedre Turner, Rebecca A. Dorfmeyer and the Comparative Metagenomics Laboratory at Discovery Ridge.

\section{Author's information}

${ }^{1}$ Department of Veterinary Pathobiology, University of Missouri, Columbia, MO 65201, USA.

${ }^{2}$ Comparative Medicine Program, University of Missouri, Columbia, MO 65201, USA.

${ }^{3}$ University of Missouri College of Veterinary Medicine, Columbia, MO 65201, USA.

${ }^{4}$ University of Missouri Metagenomics Center, Columbia, Missouri, MO 65201, USA.

${ }^{5}$ Mutant Mouse Resource and Research Center, University of Missouri, 4011 Discovery Drive, Columbia, MO 65201, USA. 
A

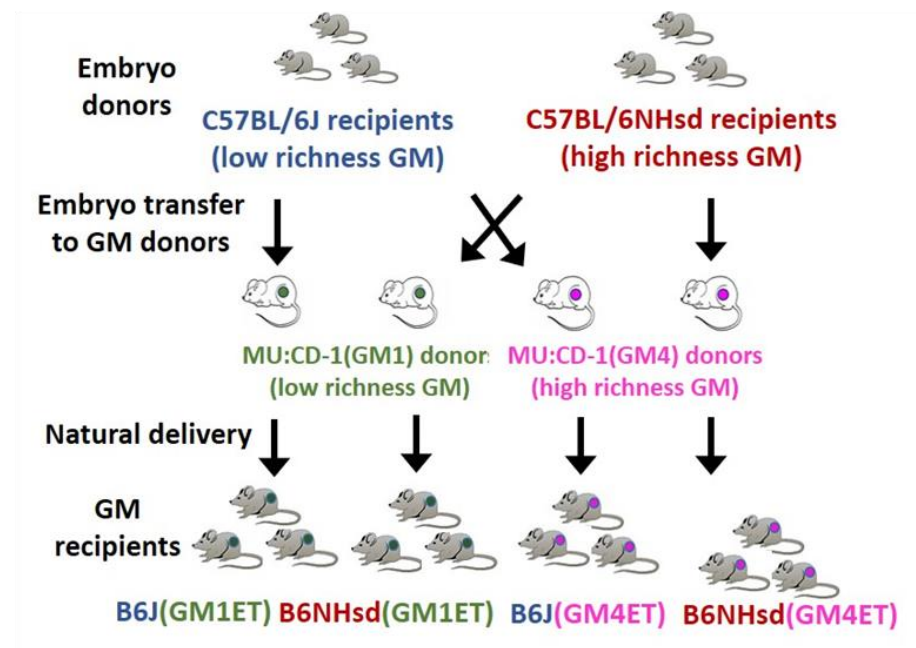

B

C

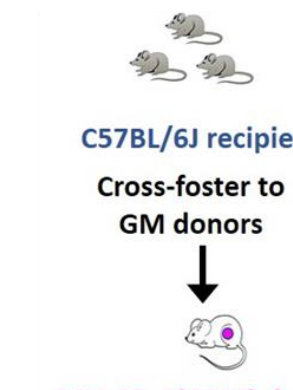

MU:CD-1(GM4) donors (high richness GM)

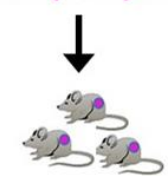

B6J(GM4CF)

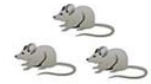

Co-house with

GM donors
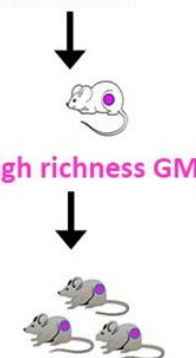

B6J(GM4CH)

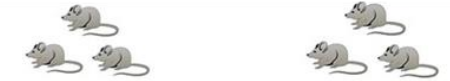

C57BL/6NHsd recipients (high richness GM) Cross-foster to GM donors

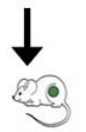

Co-house with

GM donors

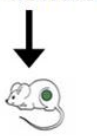

MU:CD-1(GM1) donors (low richness GM)
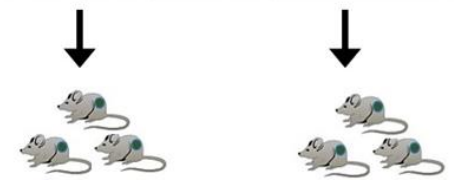

B6NHsd(GM1CF) B6NHsd(GM1CH)

D

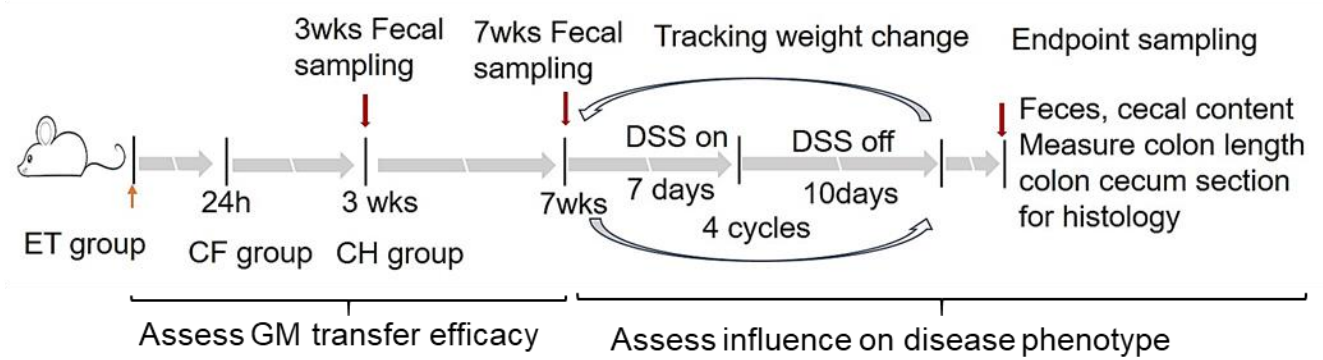

Figure 3-1. Experimental design of GM transfer studies and chronic DSS colitis.

(A) Substrain controlled transfer of GM1 and GM4. (B) Transfer of GM4 via cross fostering and co-housing methods. (C) Transfer of GM1 using cross fostering and co-housing methods. (D) Timeline of DSS treatment to induced chronic colitis. 

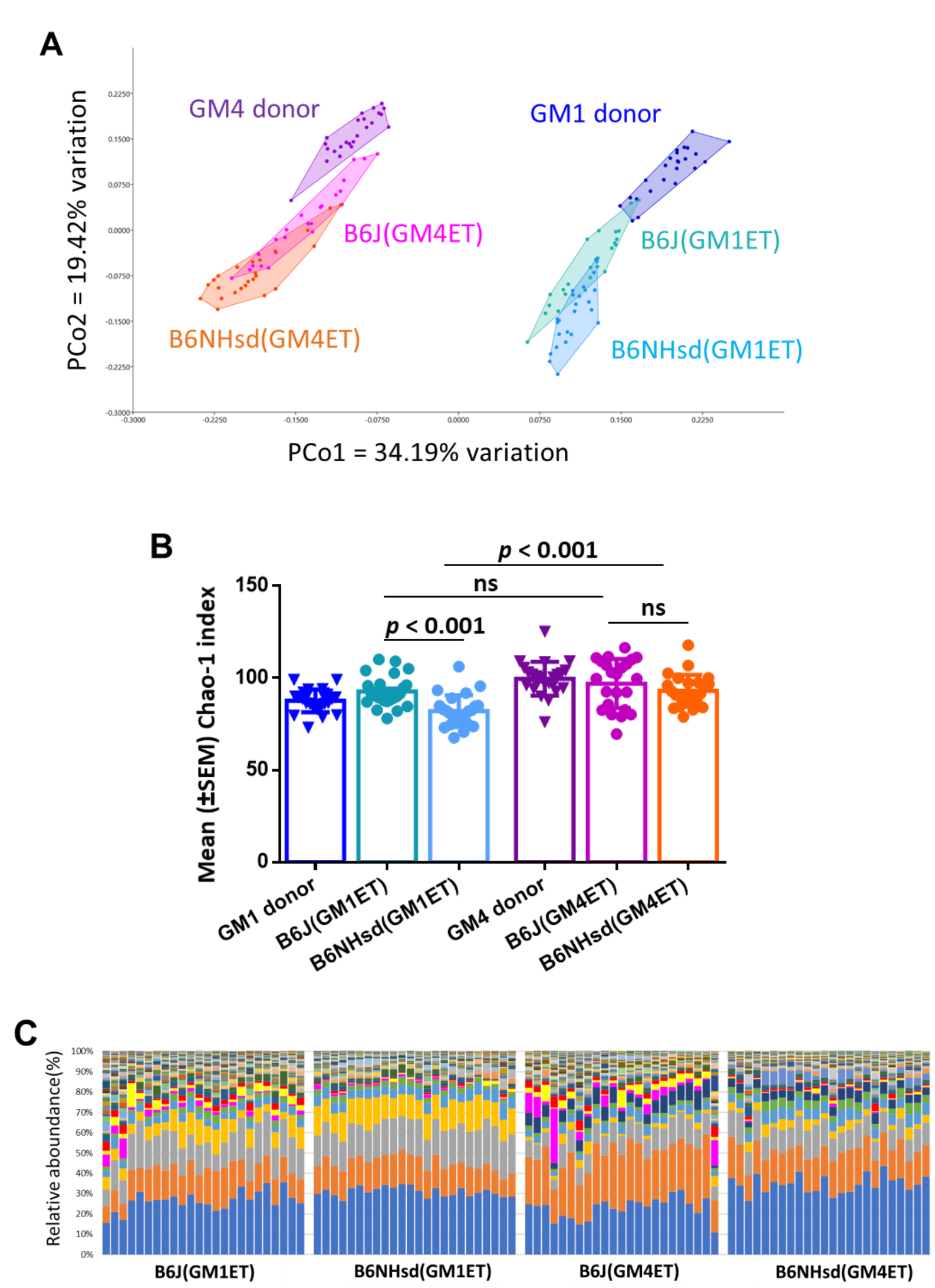
Figure 3-2. Donor GM (primary) and recipient genetics (secondary) sources of GM variability in embryo transfer derived recipient mice.

(A) Principal Coordinate Analysis plot of samples from seven-week-old B6J and B6NHsd mice colonized with GM1 or GM4. ( $p=0.0001 ; \mathrm{F}=51.93$, Bray-Curtis.). (B) Chao-1 index the same mice. (B6J vs. B6NHsd: $p<0.001$; GM1 vs. GM4: $p<0.001$; within B6NHsd, GM1 vs. GM4: $p<0.001$; within GM1, B6J vs. B6NHsd: $p<0.001$; two-way ANOVA followed by student-Neman-Keuls method for pairwise multiple comparison). (C) Bar chart showing differing reletive aboundance between substrain B6J and B6NHsd that received GM4 and GM1 respectively. 


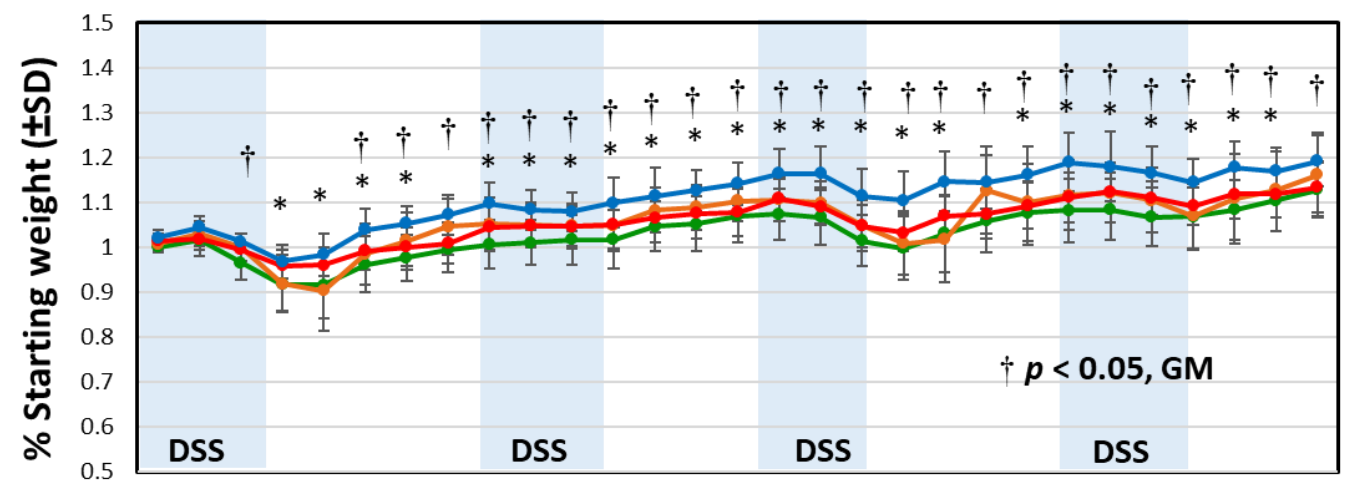

$136 \quad 810131517202224272931343638414345485052555759626466$

Time (Days)

$\rightarrow$ B6NHsd(GM1ET) $\rightarrow$ B6NHsd(GM4ET) $\rightarrow$ B6J(GM1ET) $\rightarrow$ B6J(GM4ET)

B
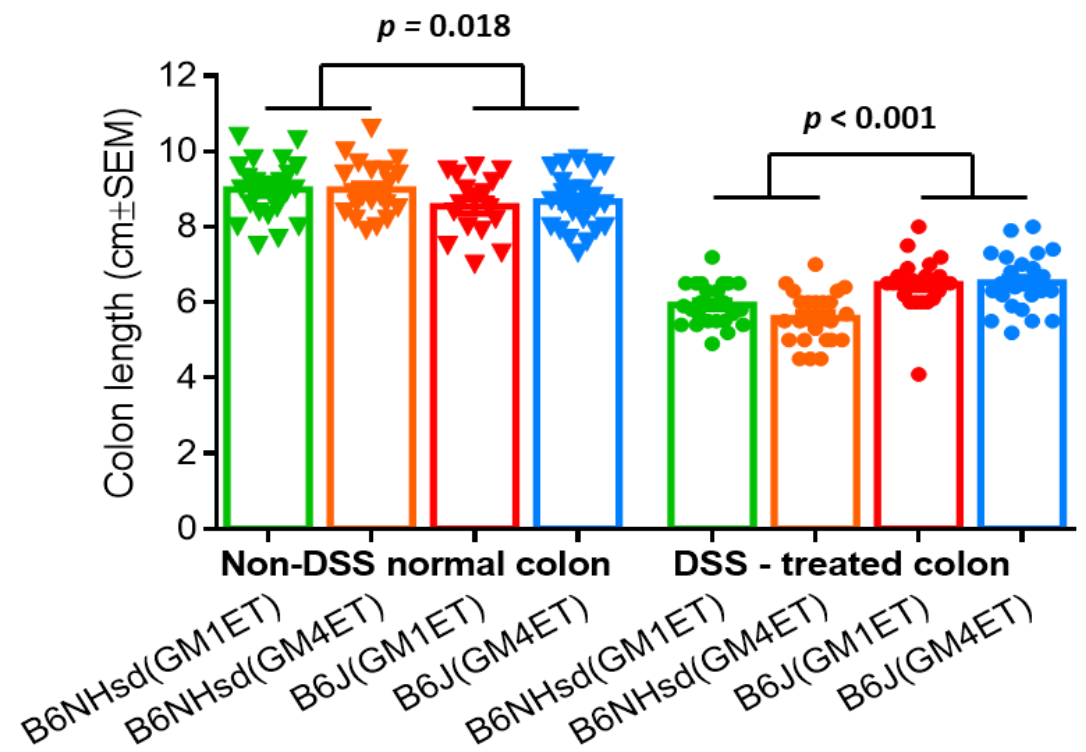

Figure 3-3. Both donor GM and recipient substrain influence susceptibility to DSS-induced colitis in mice derived by embryo transfer.

(A) Comparison of DSS-induced weight change between substrains that received GM1 and GM4 via embryo transfer. Three-way ANOVA of weight changes revealed main effects of substrain $(p<0.001, \mathrm{~F}=310.88)$, GM $(p<0.001, \mathrm{~F}=328.76)$ and time $(p<0.001, \mathrm{~F}=88.52)$ with multiple interactions (substrain X GM, $p<$ 0.001, $\mathrm{F}=27.67$; substrain $\mathrm{X}$ time, $p<0.001, \mathrm{~F}=2.09$; $\mathrm{GM} \mathrm{X}$ time, $p=0.041, \mathrm{~F}=1.51$ ) complicating 
interpretation. The line graph shows significant differences between GM1 and GM4 within substrain (*) and significant differences between B6J and B6NHsd within GM (†). (B) Comparison of colon lengths of untreated and DSS-treated mice from both substrains on both GMs revealed a main effect of treatment $(p<$ $0.001, F=612.72$ ). While no main effects of substrain and GM were seen, interpretation was complicated by a treatment $\mathrm{X}$ substrain interaction $(p<0.001, \mathrm{~F}=28.87)$ and visual inspection of the data showed that untreated B6NHsd mice had longer colon lengths than untreated B6N mice but shorter colon lengths after DSS treatment. Post-hoc analysis verified this observation with significant differences seen in substrain within both the untreated $(p=0.018, \mathrm{t}=2.38)$ and treated $(p<0.001, \mathrm{t}=5.032)$ groups. Three-way ANOVA followed by Holm-Sidak method for pairwise multiple comparison. 
A

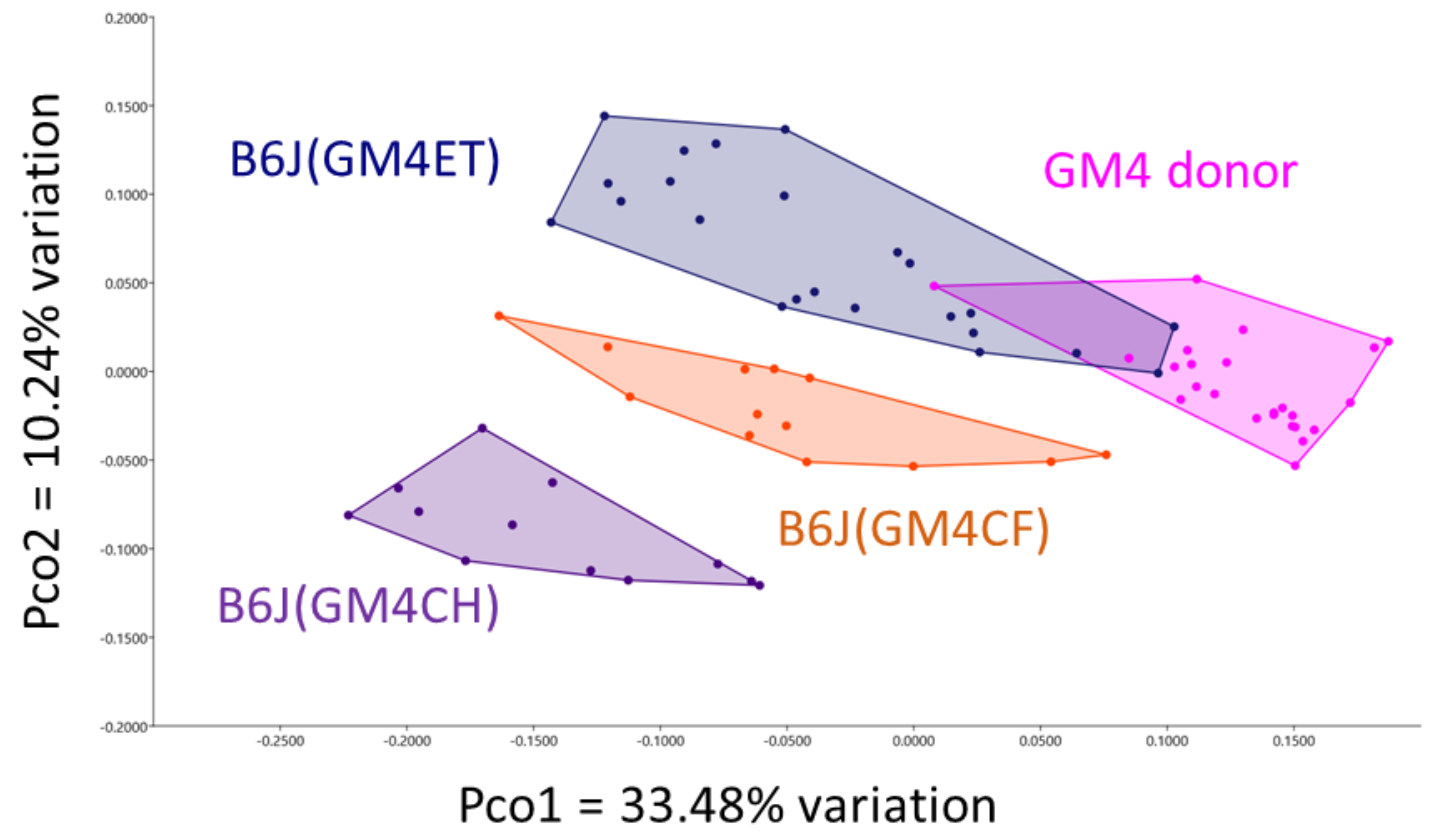

B

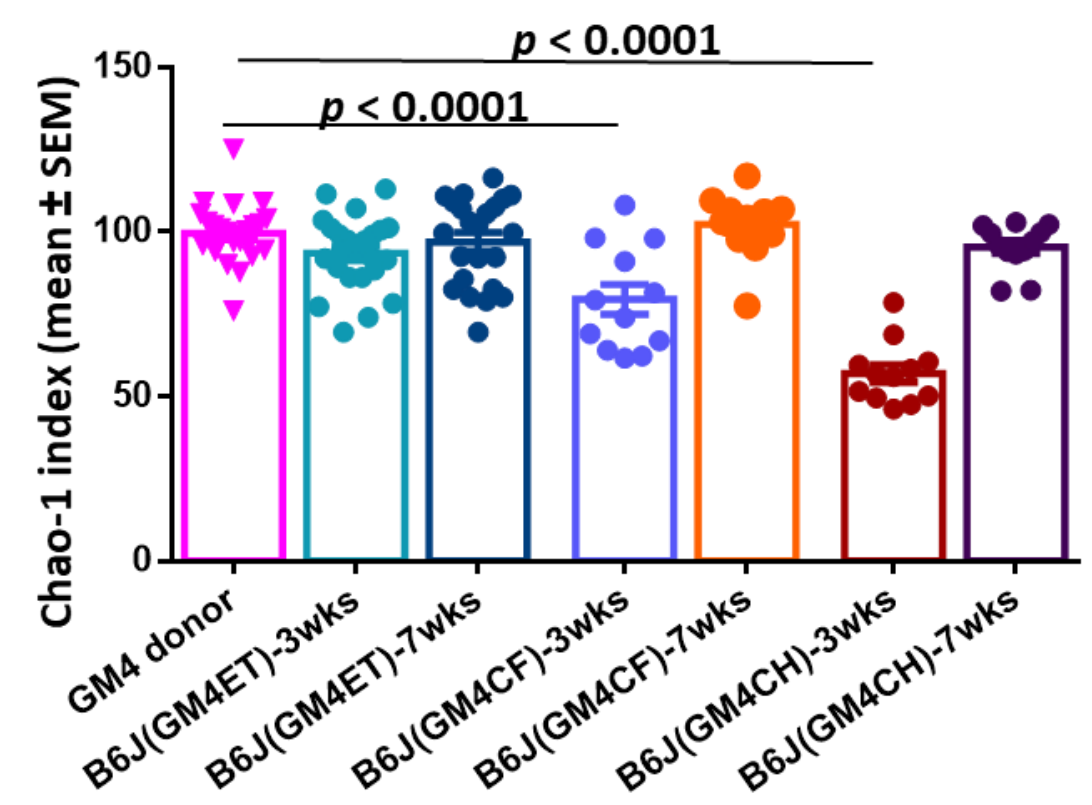



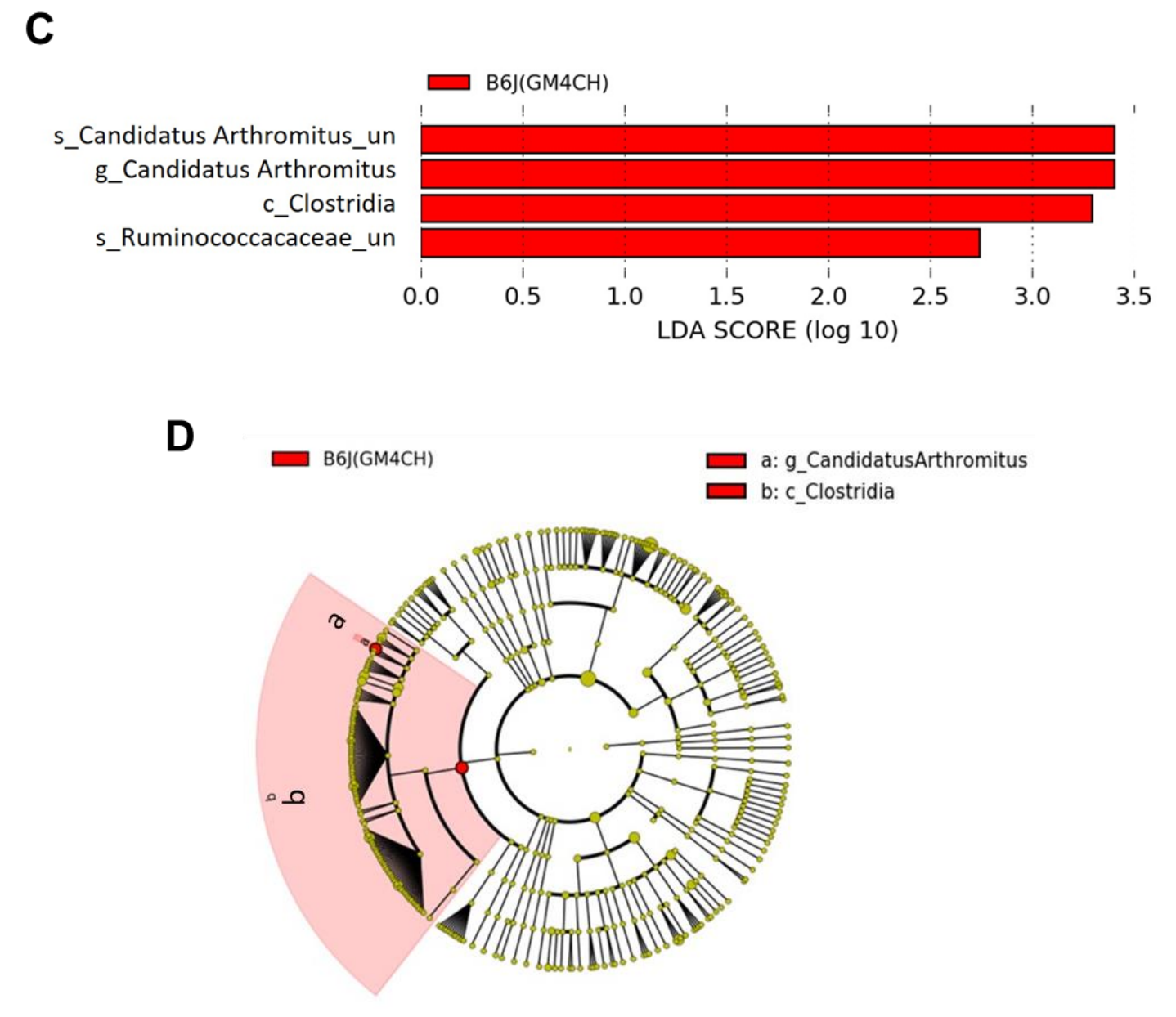

Figure 3-4. Differing transfer efficiency among transfer methods when transferring high richness GM4 to B6J mice.

(A) Principal Coordinate Analysis plot of B6J mice receiving GM4 via embryo transfer (ET), cross fostering $(\mathrm{CF})$, and co-housing $(\mathrm{CH})$ at 7 -weeks of age compared to $\mathrm{CD}-1$ (GM4) donor. ( $p=0.0001 ; \mathrm{F}=25.57$, BrayCurtis). (B) Chao-1 index of the same B6J mice. Statistical analysis (One-way ANOVA) to compare the recipient groups and the donor control group. (C and D) Linear discriminant analysis effect size (LEfSe) analysis and Cladogram show compositional differences and taxa that were significantly overrepresented in each group. Cladogram circles represent the different taxonomic levels from phylum (innermost circle) to species (outermost circle). Annotation represents $p_{-}$phylum, $c_{-}$class, o_ order, $f_{-}$family, g_ genus, or s_ species from inside to outside. 


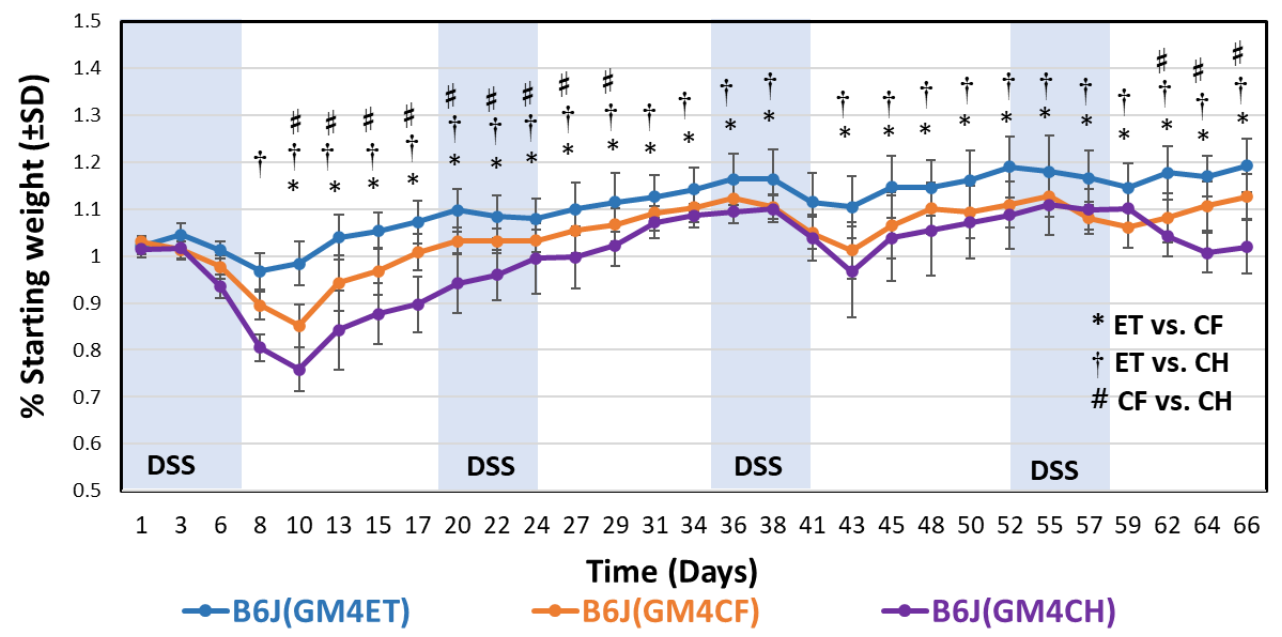

Figure 3-5. Recipients with the same B6 substrain genetics received the same GM4 through different transfer methods that display different susceptibility to DSS-induced colitis.

Comparison of DSS-induced weight change between recipient B6J mice that transferred with GM4 through different ET, $\mathrm{CF}$, and $\mathrm{CH}$ transfer method. Two-way ANOVA (time and transfer method) revealed the main effects of time $(p<0.001, \mathrm{~F}=78.12)$ and transfer method $(p<0.001, \mathrm{~F}=522.66)$ with interactions (transfer method X time, $p<0.001, \mathrm{~F}=7.51$ ). Student-Neman-Keuls method for pairwise multiple comparison showed significant difference between methods (ET vs. CH: $p<0.001$; ET vs. CF: $p<0.001$; CF vs. CH: $p<0.001)$. 
A

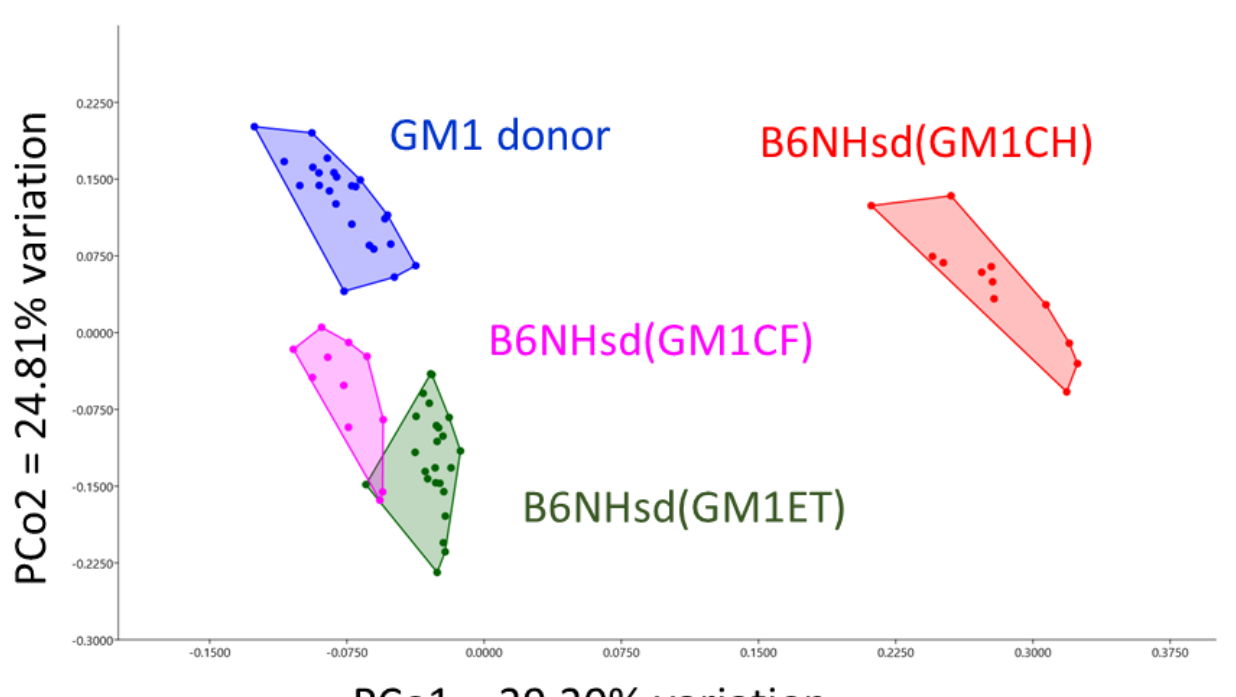

PCo1 $=29.20 \%$ variation

B

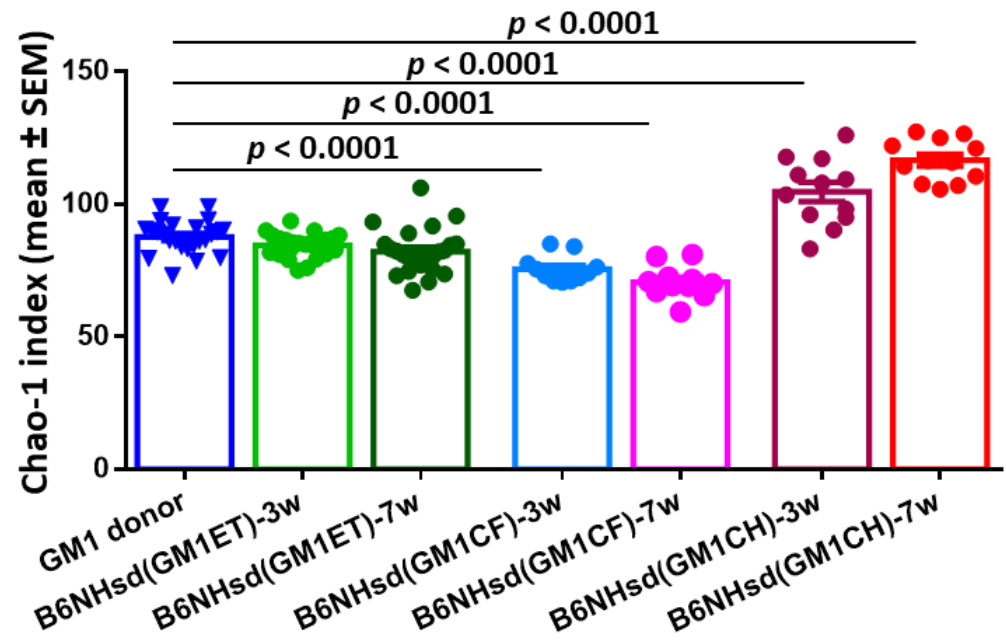

C

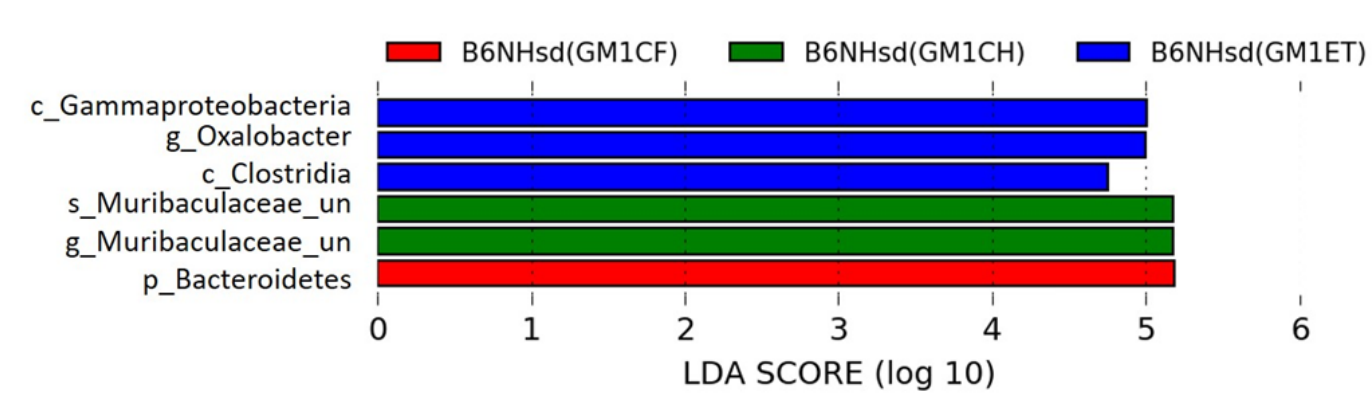




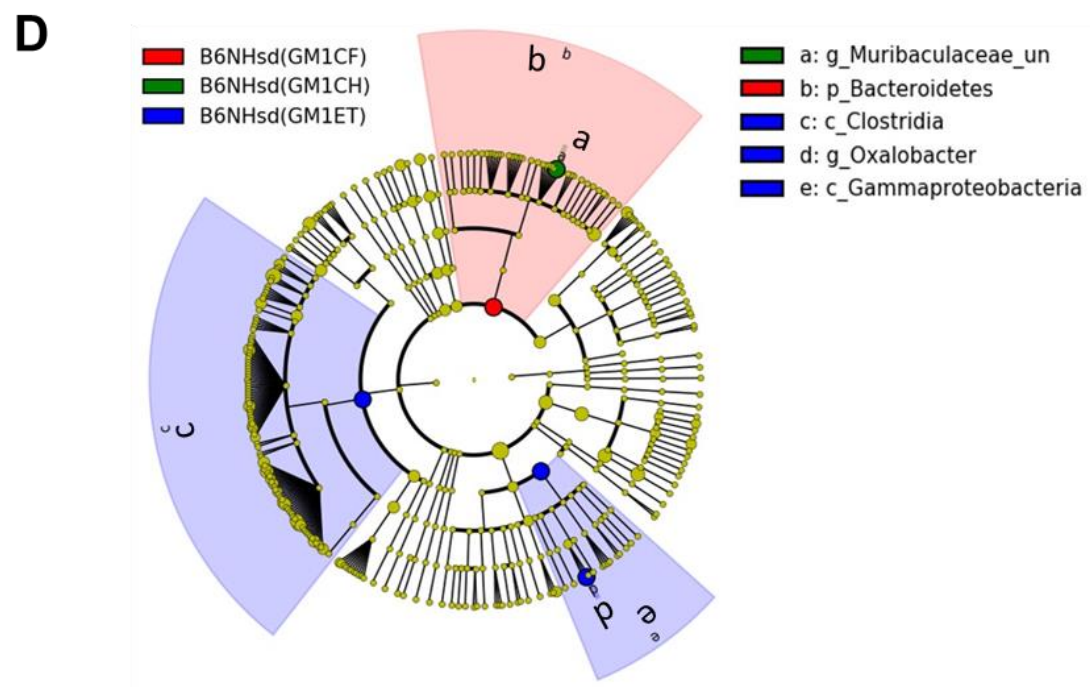

Figure 3-6. Different transfer method differs in GM transfer efficiency when transfer low richness GM1 to B6NHsd mice through ET, CF, and CH methods.

(A) Principal Coordinate Analysis plot of B6NHsd recipient groups transferred with GM1 that was generated using ET, $\mathrm{CF}$, and $\mathrm{CH}$ methods at 7-weeks of age compared to CD-1(GM1) donor. ( $p=0.0001 ; \mathrm{F}=44.58$, Bray-Curtis). (B) Chao-1 index of the B6NHsd recipient groups generated using different transfer methods ET, CF, and CH. Statistical analysis (One-way ANOVA) to compare the recipient groups and donor control group). (C and D) Linear discriminant analysis (LDA) effect size (LEfSe) analysis and Cladogram showed compositional difference and taxa that were significantly overrepresented in each group when performing the comparison between mice groups that generated using ET, CF and CH method, B6NHsd (GM1ET), B6NHsd (GM1CF) and B6NHsd (GM1CH) at 7weeks of age. Cladogram annotation: p_phylum, c_class, $o_{-}$order, $f_{-}$family, $g_{-}$genus, or s_ species from inside to outside. Red, green and blue color-coded nodes stand for the species that are overrepresented in each group). 


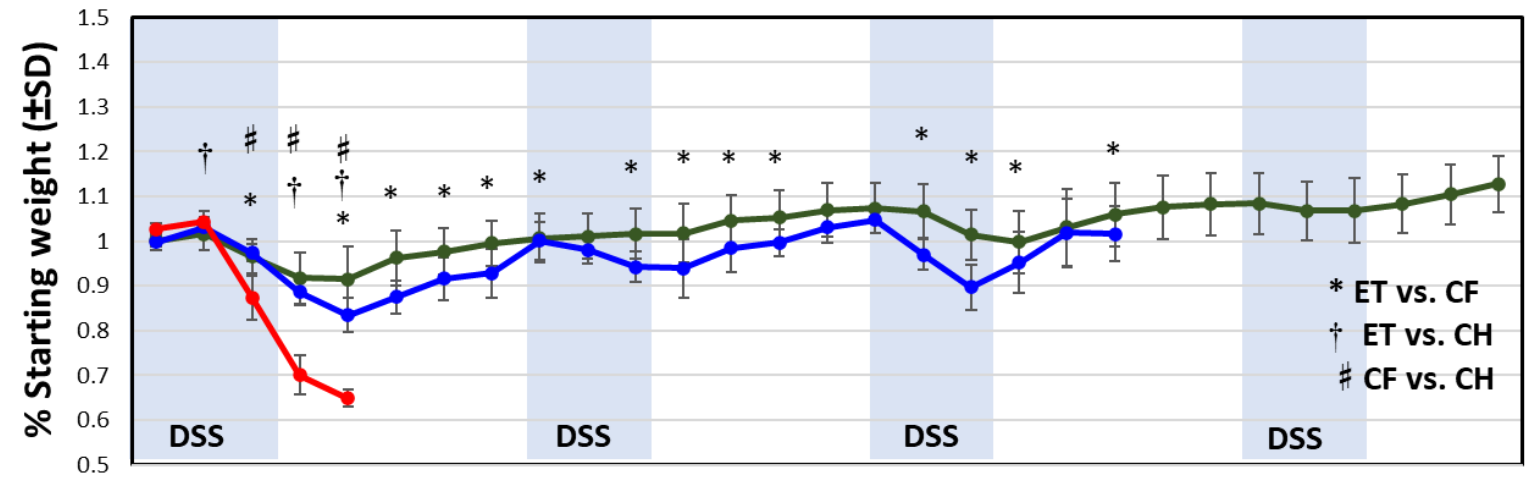

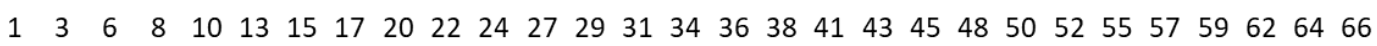
Time (Days)

$\rightarrow$ B6NHsd(GM1ET) $\rightarrow$ B6NHsd(GM1CF) $\rightarrow$ B6NHsd(GM1CH)

B

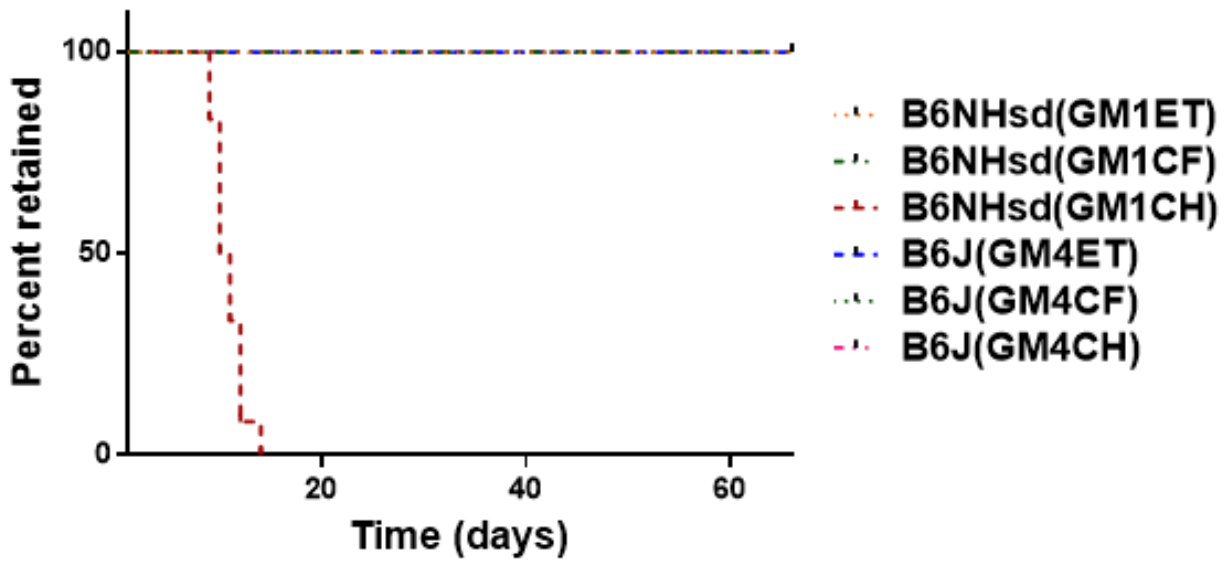

Figure 3-7. Recipient mice with the same B6NHsd genetics received the same GM1 through different transfer methods that display different susceptibility to DSS-induced colitis.

(A) Comparison of DSS-induced weight change between recipient B6NHsd mice that transferred with GM1 through different ET, $\mathrm{CF}$, and $\mathrm{CH}$ transfer method. Two-way ANOVA (time and transfer method) comparison within 10 days revealed the main effects of time $(p<0.001, \mathrm{~F}=194.87)$ and transfer method $(p$ $<0.001, \mathrm{~F}=58.28$ ) with interactions (transfer method $\mathrm{X}$ time, $p<0.001, \mathrm{~F}=31.33$ ). Student-Neman-Keuls method for pairwise multiple comparison showed significant difference between methods (ET vs. CH: $p<$ 0.001; CF vs. CH: $p<0.001)$ and no significant difference between ET vs. CF method within 10 days. Twoway ANOVA (time and transfer method) comparison between ET and CF within 1-48 days revealed the main effects of time $(p<0.001, \mathrm{~F}=21.73)$ and transfer method $(p<0.001, \mathrm{~F}=102.98)$ with interactions (transfer 
method $\mathrm{X}$ time, $p<0.001, \mathrm{~F}=4.52$ ). Student-Neman-Keuls method for pairwise multiple comparison showed significant difference between methods (ET vs. CF: $p<0.001$. (B) The survival curve showed the survival proportions of all the B6J and B6NHsd mice groups generated using different transfer methods ET, CF, and CH. (Kaplan Meier survival analysis in GraphPad Prism) From days 49-66, weights were inadvertently not recorded for the B6NHsd (GM1CF) group. 


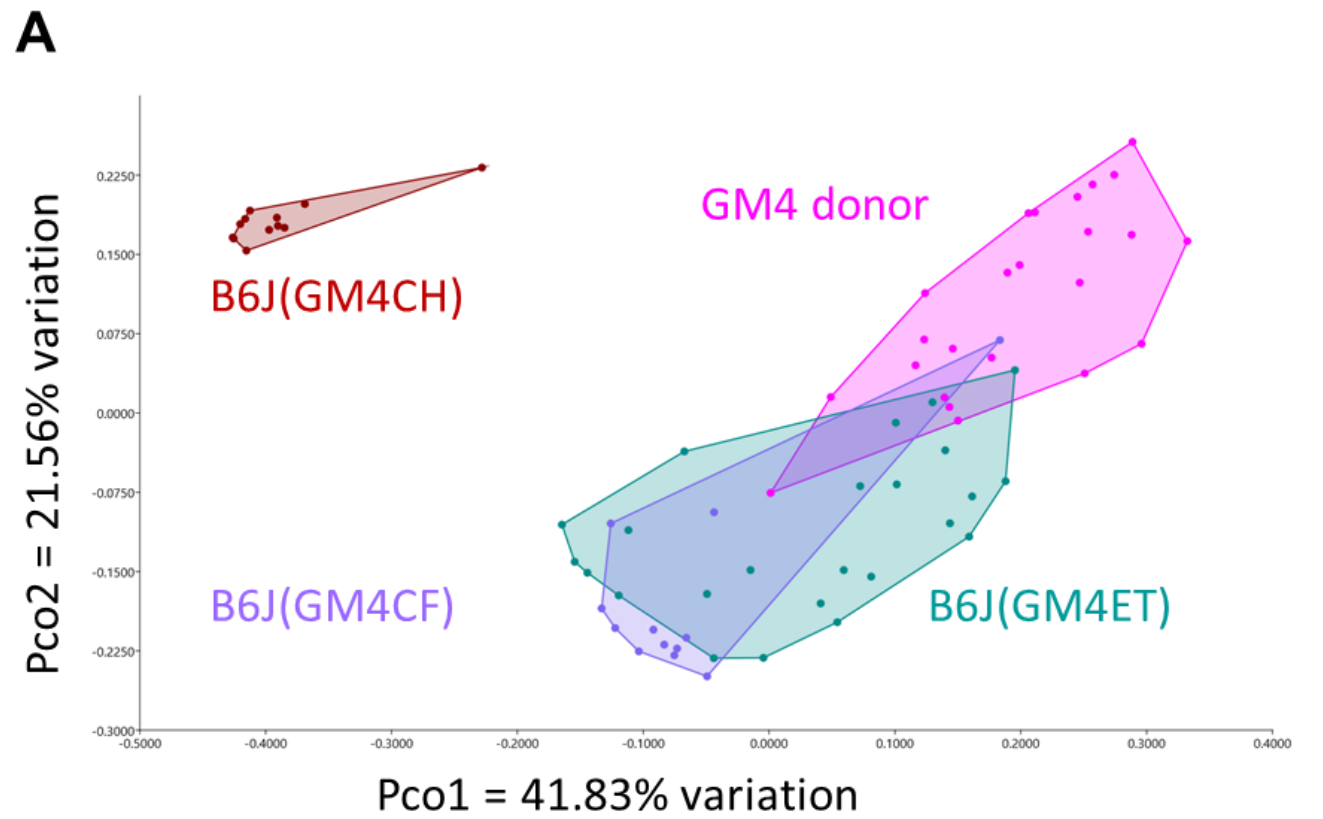

B

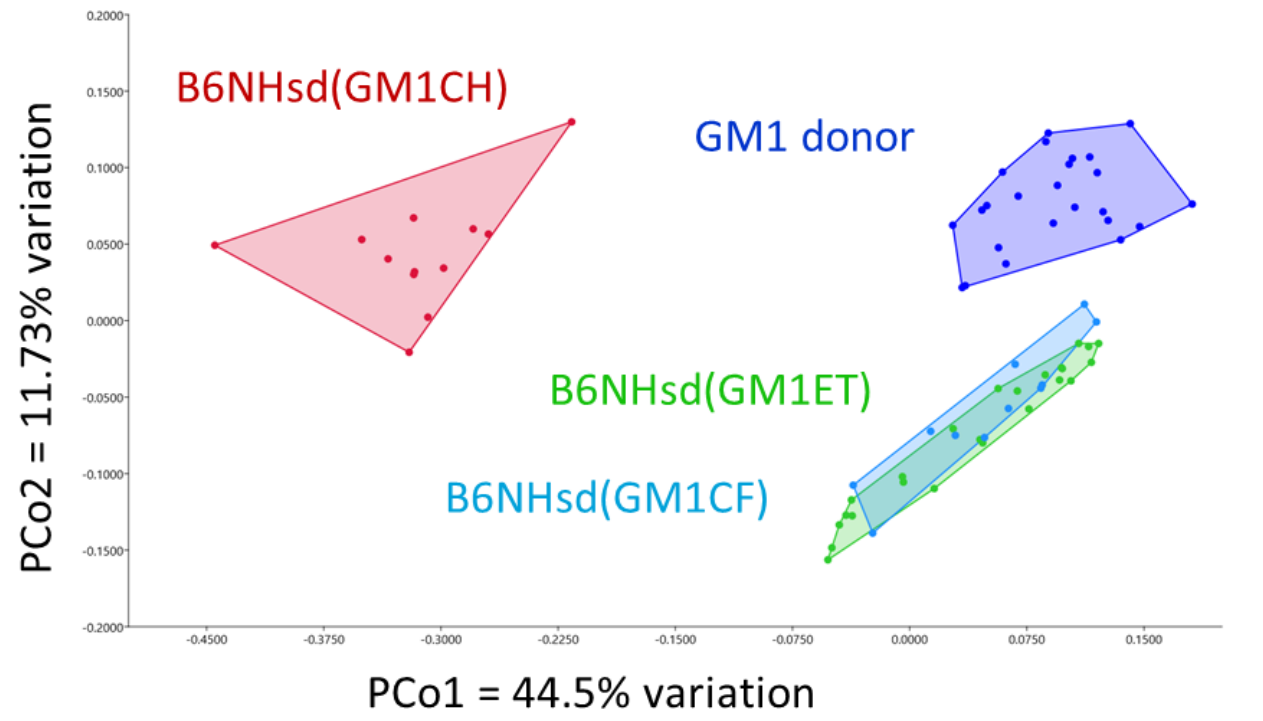

Figure 3-S1. Principal Analysis plot of recipients at three-week-old and CD-1 GM donor control. Linear discriminant analysis (LDA) effect size (LEfSe) analysis and Cladogram.

(A) Recipient B6J mice that transferred with GM4 using ET, CF and CH methods $(p=0.0001 ; \mathrm{F}=38.51$, Bray-Curtis.) and (B) Recipient B6NHsd mice that transferred with GM1 using ET, CF and CH methods ( $p$ $=0.0001 ; \mathrm{F}=16.43$, Bray-Curtis. . 


\section{CHAPTER IV}

Summary and future perspective 


\subsection{Summary}

Accumulating data showed the significant role of gut microbiome in a variety of disease. Mouse model is most frequently and wildly used for studying variety of human disease. However, there is urgent need to strengthen repeatability and improve the reproducibility between studies performed in different institutions using the same mouse disease model. there is also an urgent need to improve the informativeness of mouse models for human disease and enhance the translatability of biomedical research to human diseases using animal models. Our previous study and other studies revealed the variation of gut microbiome between vendor, institutions, and many other factors including both husbandry and environment factors such as diet, cage, bedding, can influence the gut microbiome. The variation of gut microbiome between animal disease model may yield a discrepancy in the research result which could cause poor reproducibility using animal disease models. The gut microbiome between traditional lab mice differs from the wild or pet store mice that experience much more antigen exposure compared to the lab mice. The gut microbiome of lab mice raised under standard condition with less antigen experience display less colonization resistance and less resilience to disease. Thus, the consideration of the informativeness and the study translatability of using lab animal to study human disease should be given.

In the first part of our study, we investigated the virome components of the lab mice and pet store mice. By analyzing the virome difference between lab mice and pet store mice, we found that the pet store mice harbor significant more virome components both in richness and diversity compared to lab mice. This indicated that the pet store mice are more antigen experienced than lab mice. The virome component is important regarding to 
translatability of using animal model to study human disease. Recent study showed transferring the microbiome from wild mice to lab mice result in a higher similarity to adult human immune response, in which case the study showed the lab mice originally showed the immune system like human neonates. Transferring human microbiome to lab mice, in terms of humanized mice is popular in recent days to mimic the human microbiome in study. Although the characterization of virome component is needed to fully understand the contribution of the microbiome on disease mechanism and to enhance the translatability of using mouse model studying human disease.

At the same time, we also investigated the virome component between different vendors of lab mice. Interestingly, we found that, even for the same lab mice, the virome component differs between different vendors. This is consistence with our previous study that the gut microbiome bacterial differs between the different vendors. This could be a potential cause of the poor reproducibility of biomedical research study.

Gut microbiomes manipulation is an option to normalize the microbiome between and minimize the variation between mice. What is more, by transferring the certain microbiome to an interested genetic generated mouse model, researchers could have the opportunity to investigate any disease in a well-controlled microbiome environment which is benefit for identifying the contributing microbiome, explore the drug metabolism pathway and disease mechanism pathway, as well as diagnostic and therapeutic development. By transferring the gut microbiome from human to animal model, the researchers obtain the opportunity to study certain disease under a microbiome environment that close to human, in which way, enhance the informative or translatability of using animal model for human disease. 
In this current study, we also focused on filling the research gap of evaluating the transfer efficiency using different transfer methods, and to provide a better tool for the biomedical research community, we investigated the gold standard gut microbiome transfer method ET, the commonly used co-house method and we also explore using cross foster as a transfer strategy with significant higher transfer efficiency compared to co-house method. Our result showed cross-foster can be used as optional method to transfer the GM with higher transfer efficacy compared to $\mathrm{CH}$ method and $\mathrm{CF}$ showed the advantage of ease of use and cost less compared to ET method.

We also assess the disease susceptibility of the mouse model that generated using different transfer methods. Our result showed the mice generated using $\mathrm{CH}$ method display sever susceptibility to DSS-induced colitis. The ET method display less susceptible to disease phenotype.

We designed experiment to evaluate both the GM and recipient genetic influence on GM transfer efficacy and the subsequent influence on disease susceptibility using DSS-induced mouse model. We found that both the GM and genetic had influence on transfer efficacy and have subsequent influence on disease phenotype. Thus, when consider using GM transfer as a manner to modulate the microbiome between mice or create certain desired microbiome environment, the study design needs to take both the recipient mouse genetic background and the donor mice GM into consideration. We also noticed that, in the case of transfer the GM between mice, it is more efficiency when transfer GM of a donor mice that normally colonized with high richness GM into a recipient mouse that normally colonized with low richness GM such as transfer GM4 into B6J mice that normally colonized with low richness GM. On the other hand, if transfer the GM in the opposite 
direction, for example, transfer the GM from a donor that normally colonized low richness GM into a recipient mouse that normally colonized with high richness GM is less efficacy such as transfer GM1 into B6NHsd recipient that normally colonized with already higher richness GM. This result is consistence with our previous discovery that transferring GM using fecal microbiome transfer method, in which study the result also showed the transfer efficiency depends on the GM richness of recipient and the donor. The disease susceptibility of generated mice between different substrain showed both the received GM and the recipient host genetic substrain contribut to disease susceptibility regarding to weight loss and colon length.

Based on what we found from the substrain control experimental group that GM and recipient genetic both had influence on GM transfer efficacy and the subsequent disease susceptibility, then we transferred the same GM to the same genetic background mice using different transfer methods to investigate the transfer methods influence on the transfer efficacy and subsequent influence on disease phenotype.

We first transfer the low richness GM1 to the same genetic background B6NHsd mice that normally harboring high richness GM using ET, CF, and $\mathrm{CH}$ method. We found that using $\mathrm{CF}$ method result in a better transfer efficacy compared to $\mathrm{CH}$ method and the mice that generated using $\mathrm{CH}$ method display significant weight loss compare with the mice generated using ET and CF methods. The result indicated better transfer efficacy and less disease susceptibility using $\mathrm{CF}$ method compared to commonly used $\mathrm{CH}$ method. Then we also transfer the high richness GM4 into the same genetic background B6J mice via different transfer method to evaluate the different transfer method influence on transfer efficacy and disease susceptibility. This transfer direction is the opposite transfer direction 
regarding to the richness of donor and recipient. Surprisingly, we discovered that in this transfer direction, the result showed significant poor transfer efficacy using $\mathrm{CH}$ method compared to both $\mathrm{CF}$ and ET method. What is worse, the mice generated using $\mathrm{CH}$ method display sever disease susceptibility due to the administration of DSS in drinking water. Most of mice were humanly euthanized due to the severe weight loss that more than 20$30 \%$ based on our protocol. This result further highlights the transfer method and transfer direction influence on transfer efficacy and subsequent influence on disease severity of animal disease model.

Collectively, the GM richness of donor and recipient should be considered when do the GM transfer between mice. The same GM transfer to different recipient genetic background could result in different GM profile and different disease susceptibility. The transfer method has influence on transfer efficacy and have subsequent influence on the disease severity of generated mice. Co-house method should be used with caution to avoid potential problem especially for the study of disease that closely associated with the gut microbiome. This current study provides a possible option to further explore the better way to enhance the animal model reproducibility and translatability of using animal model for human disease.

\subsection{Future perspective}

For future research directions that derived from this current study, based on the valuable experimental-based data that provided, there are several investigation directions worthy for further exploration. First, we noticed both the GM and genetics have influence on transfer efficacy and have subsequent influence on disease phenotype. A well-designed study is needed for further investigation of the integrated function of genetic and microbiome, such 
as the interlink/crosstalk between the transferable microbiome component and the genetic factor. The above-mentioned exploration will shed light to the relative research toward to the precision medicine by considering the microbiome and genetic background together. Second, the study on metabolism and immune response is another exploration direction, such as how the transferred GM have resulted in difference of metabolism and immune response, what is the contributing microbiome and which part of the metabolism and immune response were most influenced by transfer method. Although, this is challenging to design the study because of the variation of immune response and different metabolism based on different disease model. Third, the consideration of the potential influence of using cohouse method to normalize the gut microbiome. Transfer the GM to certain model, the best time point to expose the recipient to the foreign microbiome from donor is critical. This also inspires us to think about the best intervention time point to use probiotic or other gut microbiome modulation mediated treatment. Last but not the lease, the exploration of certain benefit microbiome or the combination of beneficial microbiome group as therapeutic stratify to create positive microbiome environment to enhance the drug metabolism or reduce the susceptibility to certain infection or decrease the possibility to get disease.

To fully understand and enhance the reproducibility and translatability, the characterization of the virome component using different transfer method should be further investigated and the potential influence of the immune system development in a long run also need to be investigated. Furthermore, the exploration of the best way to improve or mimic the antigen experience-like wild mice model or humanized mice disease model is valuable in biomedical research. 


\section{REFERENCES}

1. Richard ML, Sokol H. The gut mycobiota: insights into analysis, environmental interactions and role in gastrointestinal diseases. Nat Rev Gastroenterol Hepatol. 2019;16(6):331-45; doi: 10.1038/s41575-019-0121-2.

2. Suhr MJ, Hallen-Adams HE. The human gut mycobiome: pitfalls and potentials--a mycologist's perspective. Mycologia. 2015;107(6):1057-73; doi: 10.3852/15-147.

3. Rowland I, Gibson G, Heinken A, Scott K, Swann J, Thiele I, et al. Gut microbiota functions: metabolism of nutrients and other food components. Eur J Nutr. 2018;57(1):1-24; doi: 10.1007/s00394-017-1445-8.

4. Skrypnik K, Suliburska J. Association between the gut microbiota and mineral metabolism. J Sci Food Agric. 2018;98(7):2449-60; doi: 10.1002/jsfa.8724.

5. Chelakkot C, Ghim J, Ryu SH. Mechanisms regulating intestinal barrier integrity and its pathological implications. Exp Mol Med. 2018;50(8):103; doi: 10.1038/s12276-018-0126-x.

6. Cani PD, Possemiers S, Van de Wiele T, Guiot Y, Everard A, Rottier O, et al. Changes in gut microbiota control inflammation in obese mice through a mechanism involving GLP-2-driven improvement of gut permeability. Gut. 2009;58(8):1091-103; doi: 10.1136/gut.2008.165886.

7. Ducarmon QR, Zwittink RD, Hornung BVH, van Schaik W, Young VB, Kuijper EJ. Gut Microbiota and Colonization Resistance against Bacterial Enteric Infection. Microbiol Mol Biol Rev. 2019;83(3); doi: 10.1128/mmbr.00007-19. 
8. Zhang N, He QS. Commensal Microbiome Promotes Resistance to Local and Systemic Infections. Chin Med J (Engl). 2015;128(16):2250-5; doi: 10.4103/03666999.162502.

9. Zimmermann M, Zimmermann-Kogadeeva M, Wegmann R, Goodman AL. Mapping human microbiome drug metabolism by gut bacteria and their genes. Nature. 2019;570(7762):462-7; doi: 10.1038/s41586-019-1291-3.

10. Neuman H, Debelius JW, Knight R, Koren O. Microbial endocrinology: the interplay between the microbiota and the endocrine system. FEMS Microbiol Rev. 2015;39(4):509-21; doi: 10.1093/femsre/fuu010.

11. Franzosa EA, Sirota-Madi A, Avila-Pacheco J, Fornelos N, Haiser HJ, Reinker S, et al. Gut microbiome structure and metabolic activity in inflammatory bowel disease. Nat Microbiol. 2019;4(2):293-305; doi: 10.1038/s41564-018-0306-4.

12. Halfvarson J, Brislawn CJ, Lamendella R, Vázquez-Baeza Y, Walters WA, Bramer LM, et al. Dynamics of the human gut microbiome in inflammatory bowel disease. Nat Microbiol. 2017;2:17004; doi: 10.1038/nmicrobiol.2017.4.

13. Wilson ID, Nicholson JK. Gut microbiome interactions with drug metabolism, efficacy, and toxicity. Transl Res. 2017;179:204-22; doi: 10.1016/j.trsl.2016.08.002.

14. Carroll IM, Ringel-Kulka T, Siddle JP, Ringel Y. Alterations in composition and diversity of the intestinal microbiota in patients with diarrhea-predominant irritable bowel syndrome. Neurogastroenterol Motil. 2012;24(6):521-30, e248; doi: 10.1111/j.1365-2982.2012.01891.x. 
15. Tap J, Derrien M, Törnblom H, Brazeilles R, Cools-Portier S, Doré J, et al. Identification of an Intestinal Microbiota Signature Associated With Severity of Irritable Bowel Syndrome. Gastroenterology. 2017;152(1):111-23.e8; doi: 10.1053/j.gastro.2016.09.049.

16. Chong PP, Chin VK, Looi CY, Wong WF, Madhavan P, Yong VC. The Microbiome and Irritable Bowel Syndrome - A Review on the Pathophysiology, Current Research and Future Therapy. Front Microbiol. 2019;10:1136; doi: 10.3389/fmicb.2019.01136.

17. Feng Q, Liang S, Jia H, Stadlmayr A, Tang L, Lan Z, et al. Gut microbiome development along the colorectal adenoma-carcinoma sequence. Nat Commun. 2015;6:6528; doi: 10.1038/ncomms7528.

18. Dai Z, Coker OO, Nakatsu G, Wu WKK, Zhao L, Chen Z, et al. Multi-cohort analysis of colorectal cancer metagenome identified altered bacteria across populations and universal bacterial markers. Microbiome. 2018;6(1):70; doi: 10.1186/s40168-018-0451-2.

19. Antharam VC, Li EC, Ishmael A, Sharma A, Mai V, Rand KH, et al. Intestinal dysbiosis and depletion of butyrogenic bacteria in Clostridium difficile infection and nosocomial diarrhea. J Clin Microbiol. 2013;51(9):2884-92; doi: 10.1128/jcm.00845-13.

20. Pérez-Cobas AE, Artacho A, Ott SJ, Moya A, Gosalbes MJ, Latorre A. Structural and functional changes in the gut microbiota associated to Clostridium difficile infection. Front Microbiol. 2014;5:335; doi: 10.3389/fmicb.2014.00335. 
21. Vogt NM, Kerby RL, Dill-McFarland KA, Harding SJ, Merluzzi AP, Johnson SC, et al. Gut microbiome alterations in Alzheimer's disease. Sci Rep. 2017;7(1):13537; doi: 10.1038/s41598-017-13601-y.

22. Cryan JF, O'Riordan KJ, Sandhu K, Peterson V, Dinan TG. The gut microbiome in neurological disorders. Lancet Neurol. 2020;19(2):179-94; doi: 10.1016/s14744422(19)30356-4.

23. Bradley CP, Teng F, Felix KM, Sano T, Naskar D, Block KE, et al. Segmented Filamentous Bacteria Provoke Lung Autoimmunity by Inducing Gut-Lung Axis Th17 Cells Expressing Dual TCRs. Cell Host Microbe. 2017;22(5):697-704.e4; doi: 10.1016/j.chom.2017.10.007.

24. Dang AT, Marsland BJ. Microbes, metabolites, and the gut-lung axis. Mucosal Immunol. 2019;12(4):843-50; doi: 10.1038/s41385-019-0160-6.

25. Behary J, Amorim N, Jiang XT, Raposo A, Gong L, McGovern E, et al. Gut microbiota impact on the peripheral immune response in non-alcoholic fatty liver disease related hepatocellular carcinoma. Nat Commun. 2021;12(1):187; doi: $10.1038 / \mathrm{s} 41467-020-20422-7$.

26. Tripathi A, Debelius J, Brenner DA, Karin M, Loomba R, Schnabl B, et al. The gut-liver axis and the intersection with the microbiome. Nat Rev Gastroenterol Hepatol. 2018;15(7):397-411; doi: 10.1038/s41575-018-0011-z.

27. Zhang C, Yang M, Ericsson AC. The Potential Gut Microbiota-Mediated Treatment Options for Liver Cancer. Frontiers in Oncology. 2020;10(2214); doi: 10.3389/fonc.2020.524205. 
28. Jie Z, Xia H, Zhong SL, Feng Q, Li S, Liang S, et al. The gut microbiome in atherosclerotic cardiovascular disease. Nat Commun. 2017;8(1):845; doi: 10.1038/s41467-017-00900-1.

29. Zhernakova DV, Le TH, Kurilshikov A, Atanasovska B, Bonder MJ, Sanna S, et al. Individual variations in cardiovascular-disease-related protein levels are driven by genetics and gut microbiome. Nat Genet. 2018;50(11):1524-32; doi: 10.1038/s41588-018-0224-7.

30. Zhang X, Chen BD, Zhao LD, Li H. The Gut Microbiota: Emerging Evidence in Autoimmune Diseases. Trends Mol Med. 2020;26(9):862-73; doi: 10.1016/j.molmed.2020.04.001.

31. Zeraati M, Enayati M, Kafami L, Shahidi SH, Salari AA. Gut microbiota depletion from early adolescence alters adult immunological and neurobehavioral responses in a mouse model of multiple sclerosis. Neuropharmacology. 2019;157:107685; doi: 10.1016/j.neuropharm.2019.107685.

32. Ribet D, Cossart P. How bacterial pathogens colonize their hosts and invade deeper tissues. Microbes Infect. 2015;17(3):173-83; doi: 10.1016/j.micinf.2015.01.004.

33. Kuss SK, Best GT, Etheredge CA, Pruijssers AJ, Frierson JM, Hooper LV, et al. Intestinal microbiota promote enteric virus replication and systemic pathogenesis. Science. 2011;334(6053):249-52; doi: 10.1126/science.1211057.

34. Kaper JB, Nataro JP, Mobley HL. Pathogenic Escherichia coli. Nat Rev Microbiol. 2004;2(2):123-40; doi: 10.1038/nrmicro818. 
35. Kurkjian HM, Akbari MJ, Momeni B. The impact of interactions on invasion and colonization resistance in microbial communities. PLoS Comput Biol. 2021;17(1):e1008643; doi: 10.1371/journal.pcbi.1008643.

36. Nardi RM, Silva ME, Vieira EC, Bambirra EA, Nicoli JR. Intragastric infection of germfree and conventional mice with Salmonella typhimurium. Braz J Med Biol Res. 1989;22(11):1389-92.

37. Brugiroux S, Beutler M, Pfann C, Garzetti D, Ruscheweyh HJ, Ring D, et al. Genome-guided design of a defined mouse microbiota that confers colonization resistance against Salmonella enterica serovar Typhimurium. Nat Microbiol. 2016;2:16215; doi: 10.1038/nmicrobiol.2016.215.

38. Belkaid Y, Harrison OJ. Homeostatic Immunity and the Microbiota. Immunity. 2017;46(4):562-76; doi: 10.1016/j.immuni.2017.04.008.

39. Zheng D, Liwinski T, Elinav E. Interaction between microbiota and immunity in health and disease. Cell Res. 2020;30(6):492-506; doi: 10.1038/s41422-020-03327.

40. Ericsson AC, Hagan CE, Davis DJ, Franklin CL. Segmented filamentous bacteria: commensal microbes with potential effects on research. Comp Med. 2014;64(2):90-8.

41. Klaasen HL, Koopman JP, Van den Brink ME, Van Wezel HP, Beynen AC. Monoassociation of mice with non-cultivable, intestinal, segmented, filamentous bacteria. Arch Microbiol. 1991;156(2):148-51; doi: 10.1007/bf00290989. 
42. Talham GL, Jiang HQ, Bos NA, Cebra JJ. Segmented filamentous bacteria are potent stimuli of a physiologically normal state of the murine gut mucosal immune system. Infect Immun. 1999;67(4):1992-2000.

43. Kaiser P, Diard M, Stecher B, Hardt WD. The streptomycin mouse model for Salmonella diarrhea: functional analysis of the microbiota, the pathogen's virulence factors, and the host's mucosal immune response. Immunol Rev. 2012;245(1):5683; doi: 10.1111/j.1600-065X.2011.01070.x.

44. Cerutti A, Rescigno M. The biology of intestinal immunoglobulin A responses. Immunity. 2008;28(6):740-50; doi: 10.1016/j.immuni.2008.05.001.

45. Pabst O. New concepts in the generation and functions of IgA. Nat Rev Immunol. 2012;12(12):821-32; doi: 10.1038/nri3322.

46. Ivanov, II, Atarashi K, Manel N, Brodie EL, Shima T, Karaoz U, et al. Induction of intestinal Th17 cells by segmented filamentous bacteria. Cell. 2009;139(3):48598; doi: 10.1016/j.cell.2009.09.033.

47. Garland CD, Lee A, Dickson MR. Segmented filamentous bacteria in the rodent small intestine: Their colonization of growing animals and possible role in host resistance toSalmonella. Microb Ecol. 1982;8(2):181-90; doi: 10.1007/bf02010451.

48. Heczko U, Abe A, Finlay BB. Segmented filamentous bacteria prevent colonization of enteropathogenic Escherichia coli $\mathrm{O} 103$ in rabbits. J Infect Dis. 2000;181(3):1027-33; doi: 10.1086/315348.

49. Endt K, Stecher B, Chaffron S, Slack E, Tchitchek N, Benecke A, et al. The microbiota mediates pathogen clearance from the gut lumen after non-typhoidal 
Salmonella diarrhea. PLoS Pathog. 2010;6(9):e1001097; doi: 10.1371/journal.ppat.1001097.

50. Boullier S, Tanguy M, Kadaoui KA, Caubet C, Sansonetti P, Corthésy B, et al. Secretory IgA-mediated neutralization of Shigella flexneri prevents intestinal tissue destruction by down-regulating inflammatory circuits. J Immunol. 2009;183(9):5879-85; doi: 10.4049/jimmunol.0901838.

51. Hedblom GA, Reiland HA, Sylte MJ, Johnson TJ, Baumler DJ. Segmented Filamentous Bacteria - Metabolism Meets Immunity. Front Microbiol. 2018;9:1991; doi: 10.3389/fmicb.2018.01991.

52. Schnupf P, Gaboriau-Routhiau V, Gros M, Friedman R, Moya-Nilges M, Nigro G, et al. Growth and host interaction of mouse segmented filamentous bacteria in vitro. Nature. 2015;520(7545):99-103; doi: 10.1038/nature14027.

53. Liang SC, Tan XY, Luxenberg DP, Karim R, Dunussi-Joannopoulos K, Collins M, et al. Interleukin (IL)-22 and IL-17 are coexpressed by Th17 cells and cooperatively enhance expression of antimicrobial peptides. J Exp Med. 2006;203(10):2271-9; doi: 10.1084/jem.20061308.

54. Goto Y. [Commensal bacteria prevent pathogenic bacterial infection by inducing of activation of host immune system]. Nihon Saikingaku Zasshi. 2020;75(2):18594; doi: 10.3412/jsb.75.185.

55. Wang Y, Yin Y, Chen X, Zhao Y, Wu Y, Li Y, et al. Induction of Intestinal Th17 Cells by Flagellins From Segmented Filamentous Bacteria. Front Immunol. 2019;10:2750; doi: 10.3389/fimmu.2019.02750. 
56. Zheng Y, Valdez PA, Danilenko DM, Hu Y, Sa SM, Gong Q, et al. Interleukin-22 mediates early host defense against attaching and effacing bacterial pathogens. Nat Med. 2008;14(3):282-9; doi: 10.1038/nm1720.

57. Whary MT, Fox JG. Natural and experimental Helicobacter infections. Comp Med. 2004;54(2):128-58.

58. Ericsson AC, Myles M, Davis W, Ma L, Lewis M, Maggio-Price L, et al. Noninvasive detection of inflammation-associated colon cancer in a mouse model. Neoplasia. 2010;12(12):1054-65; doi: 10.1593/neo.10940.

59. Lavelle A, Sokol H. Gut microbiota-derived metabolites as key actors in inflammatory bowel disease. Nat Rev Gastroenterol Hepatol. 2020;17(4):223-37; doi: 10.1038/s41575-019-0258-z.

60. Tremblay S, Romain G, Roux M, Chen XL, Brown K, Gibson DL, et al. Bile Acid Administration Elicits an Intestinal Antimicrobial Program and Reduces the Bacterial Burden in Two Mouse Models of Enteric Infection. Infect Immun. 2017;85(6); doi: 10.1128/iai.00942-16.

61. Winston JA, Theriot CM. Impact of microbial derived secondary bile acids on colonization resistance against Clostridium difficile in the gastrointestinal tract. Anaerobe. 2016;41:44-50; doi: 10.1016/j.anaerobe.2016.05.003.

62. Jacobson A, Lam L, Rajendram M, Tamburini F, Honeycutt J, Pham T, et al. A Gut Commensal-Produced Metabolite Mediates Colonization Resistance to Salmonella Infection. Cell Host Microbe. 2018;24(2):296-307.e7; doi: 10.1016/j.chom.2018.07.002. 
63. Descamps HC, Herrmann B, Wiredu D, Thaiss CA. The path toward using microbial metabolites as therapies. EBioMedicine. 2019;44:747-54; doi: 10.1016/j.ebiom.2019.05.063.

64. Peng L, Li ZR, Green RS, Holzman IR, Lin J. Butyrate enhances the intestinal barrier by facilitating tight junction assembly via activation of AMP-activated protein kinase in Caco-2 cell monolayers. J Nutr. 2009;139(9):1619-25; doi: 10.3945/jn.109.104638.

65. Qiao Y, Qian J, Lu Q, Tian Y, Chen Q, Zhang Y. Protective effects of butyrate on intestinal ischemia-reperfusion injury in rats. J Surg Res. 2015;197(2):324-30; doi: 10.1016/j.jss.2015.04.031.

66. Feng Y, Wang Y, Wang P, Huang Y, Wang F. Short-Chain Fatty Acids Manifest Stimulative and Protective Effects on Intestinal Barrier Function Through the Inhibition of NLRP3 Inflammasome and Autophagy. Cell Physiol Biochem. 2018;49(1):190-205; doi: 10.1159/000492853.

67. Sun M, Wu W, Chen L, Yang W, Huang X, Ma C, et al. Microbiota-derived shortchain fatty acids promote Th1 cell IL-10 production to maintain intestinal homeostasis. Nat Commun. 2018;9(1):3555; doi: 10.1038/s41467-018-05901-2.

68. Kang S, Denman SE, Morrison M, Yu Z, Dore J, Leclerc M, et al. Dysbiosis of fecal microbiota in Crohn's disease patients as revealed by a custom phylogenetic microarray. Inflamm Bowel Dis. 2010;16(12):2034-42; doi: 10.1002/ibd.21319.

69. Turner PV. The role of the gut microbiota on animal model reproducibility. Animal Model Exp Med. 2018;1(2):109-15; doi: 10.1002/ame2.12022. 
70. Ericsson AC, Davis JW, Spollen W, Bivens N, Givan S, Hagan CE, et al. Effects of vendor and genetic background on the composition of the fecal microbiota of inbred mice. PLoS One. 2015;10(2):e0116704; doi: 10.1371/journal.pone.0116704.

71. Ericsson AC, Gagliardi J, Bouhan D, Spollen WG, Givan SA, Franklin CL. The influence of caging, bedding, and diet on the composition of the microbiota in different regions of the mouse gut. Sci Rep. 2018;8(1):4065; doi: 10.1038/s41598018-21986-7.

72. Hart ML, Ericsson AC, Franklin CL. Differing Complex Microbiota Alter Disease Severity of the IL-10(-/-) Mouse Model of Inflammatory Bowel Disease. Front Microbiol. 2017;8:792; doi: 10.3389/fmicb.2017.00792.

73. Martin-Gallausiaux C, Larraufie P, Jarry A, Béguet-Crespel F, Marinelli L, Ledue F, et al. Butyrate Produced by Commensal Bacteria Down-Regulates Indolamine 2,3-Dioxygenase 1 (IDO-1) Expression via a Dual Mechanism in Human Intestinal Epithelial Cells. Front Immunol. 2018;9:2838; doi: 10.3389/fimmu.2018.02838.

74. Palm NW, de Zoete MR, Cullen TW, Barry NA, Stefanowski J, Hao L, et al. Immunoglobulin A coating identifies colitogenic bacteria in inflammatory bowel disease. Cell. 2014;158(5):1000-10; doi: 10.1016/j.cell.2014.08.006.

75. Justice MJ, Dhillon P. Using the mouse to model human disease: increasing validity and reproducibility. Dis Model Mech. 2016;9(2):101-3; doi: 10.1242/dmm.024547.

76. Nair RR, Corrochano S, Gasco S, Tibbit C, Thompson D, Maduro C, et al. Uses for humanised mouse models in precision medicine for neurodegenerative disease. Mammalian Genome. 2019;30(7):173-91; doi: 10.1007/s00335-019-09807-2. 
77. Tao L, Reese TA. Making Mouse Models That Reflect Human Immune Responses. Trends Immunol. 2017;38(3):181-93; doi: 10.1016/j.it.2016.12.007.

78. Krych L, Hansen CH, Hansen AK, van den Berg FW, Nielsen DS. Quantitatively different, yet qualitatively alike: a meta-analysis of the mouse core gut microbiome with a view towards the human gut microbiome. PLoS One. 2013;8(5):e62578; doi: 10.1371/journal.pone.0062578.

79. Beura LK, Hamilton SE, Bi K, Schenkel JM, Odumade OA, Casey KA, et al. Normalizing the environment recapitulates adult human immune traits in laboratory mice. Nature. 2016;532(7600):512-6; doi: 10.1038/nature17655.

80. Rosshart SP, Vassallo BG, Angeletti D, Hutchinson DS, Morgan AP, Takeda K, et al. Wild Mouse Gut Microbiota Promotes Host Fitness and Improves Disease Resistance. Cell. 2017;171(5):1015-28.e13; doi: 10.1016/j.cell.2017.09.016.

81. Rioux JD, Daly MJ, Silverberg MS, Lindblad K, Steinhart H, Cohen Z, et al. Genetic variation in the $5 \mathrm{q} 31$ cytokine gene cluster confers susceptibility to Crohn disease. Nat Genet. 2001;29(2):223-8; doi: 10.1038/ng1001-223.

82. Raj T, Li YI, Wong G, Humphrey J, Wang M, Ramdhani S, et al. Integrative transcriptome analyses of the aging brain implicate altered splicing in Alzheimer's disease susceptibility. Nat Genet. 2018;50(11):1584-92; doi: 10.1038/s41588-0180238-1.

83. Zhao W, Rasheed A, Tikkanen E, Lee JJ, Butterworth AS, Howson JMM, et al. Identification of new susceptibility loci for type 2 diabetes and shared etiological pathways with coronary heart disease. Nat Genet. 2017;49(10):1450-7; doi: 10.1038/ng.3943. 
84. Goodrich JK, Waters JL, Poole AC, Sutter JL, Koren O, Blekhman R, et al. Human genetics shape the gut microbiome. Cell. 2014;159(4):789-99; doi: 10.1016/j.cell.2014.09.053.

85. Frazer KA, Murray SS, Schork NJ, Topol EJ. Human genetic variation and its contribution to complex traits. Nat Rev Genet. 2009;10(4):241-51; doi: $10.1038 / \mathrm{nrg} 2554$.

86. Samson M, Libert F, Doranz BJ, Rucker J, Liesnard C, Farber CM, et al. Resistance to HIV-1 infection in caucasian individuals bearing mutant alleles of the CCR-5 chemokine receptor gene. Nature. 1996;382(6593):722-5; doi: 10.1038/382722a0.

87. Kamatani Y, Wattanapokayakit S, Ochi H, Kawaguchi T, Takahashi A, Hosono N, et al. A genome-wide association study identifies variants in the HLA-DP locus associated with chronic hepatitis B in Asians. Nat Genet. 2009;41(5):591-5; doi: 10.1038/ng.348.

88. Al-Qahtani AA, Al-Anazi MR, Abdo AA, Sanai FM, Al-Hamoudi W, Alswat KA, et al. Association between HLA variations and chronic hepatitis B virus infection in Saudi Arabian patients. PLoS One. 2014;9(1):e80445; doi: 10.1371/journal.pone.0080445.

89. Nishida N, Ohashi J, Khor SS, Sugiyama M, Tsuchiura T, Sawai H, et al. Understanding of HLA-conferred susceptibility to chronic hepatitis B infection requires HLA genotyping-based association analysis. Sci Rep. 2016;6:24767; doi: $10.1038 /$ srep24767.

90. Manry J, Nédélec Y, Fava VM, Cobat A, Orlova M, Thuc NV, et al. Deciphering the genetic control of gene expression following Mycobacterium leprae antigen 
stimulation. PLoS Genet. 2017;13(8):e1006952; doi: 10.1371/journal.pgen.1006952.

91. Fransen F, Zagato E, Mazzini E, Fosso B, Manzari C, El Aidy S, et al. BALB/c and C57BL/6 Mice Differ in Polyreactive IgA Abundance, which Impacts the Generation of Antigen-Specific IgA and Microbiota Diversity. Immunity. 2015;43(3):527-40; doi: 10.1016/j.immuni.2015.08.011.

92. Ashworth A, Bardgett ME, Fowler J, Garber H, Griffith M, Curran CP. Comparison of Neurological Function in Males and Females from Two Substrains of C57BL/6 Mice. Toxics. 2015;3(1):1-17; doi: 10.3390/toxics3010001.

93. Nicholson A, Reifsnyder PC, Malcolm RD, Lucas CA, MacGregor GR, Zhang W, et al. Diet-induced obesity in two C57BL/6 substrains with intact or mutant nicotinamide nucleotide transhydrogenase (Nnt) gene. Obesity (Silver Spring). 2010;18(10):1902-5; doi: 10.1038/oby.2009.477.

94. Kang SK, Hawkins NA, Kearney JA. C57BL/6J and C57BL/6N substrains differentially influence phenotype severity in the Scn1a (+/-) mouse model of Dravet syndrome. Epilepsia Open. 2019;4(1):164-9; doi: 10.1002/epi4.12287.

95. Simon MM, Greenaway S, White JK, Fuchs H, Gailus-Durner V, Wells S, et al. A comparative phenotypic and genomic analysis of C57BL/6J and C57BL/6N mouse strains. Genome Biol. 2013;14(7):R82; doi: 10.1186/gb-2013-14-7-r82.

96. Bourdi M, Davies JS, Pohl LR. Mispairing C57BL/6 substrains of genetically engineered mice and wild-type controls can lead to confounding results as it did in studies of JNK2 in acetaminophen and concanavalin A liver injury. Chem Res Toxicol. 2011;24(6):794-6; doi: 10.1021/tx200143x. 
97. Hart ML, Ericsson AC, Lloyd KCK, Grimsrud KN, Rogala AR, Godfrey VL, et al. Development of outbred CD1 mouse colonies with distinct standardized gut microbiota profiles for use in complex microbiota targeted studies. Sci Rep. 2018;8(1):10107; doi: 10.1038/s41598-018-28448-0.

98. Moskowitz JE, Doran AG, Lei Z, Busi SB, Hart ML, Franklin CL, et al. Integration of genomics, metagenomics, and metabolomics to identify interplay between susceptibility alleles and microbiota in adenoma initiation. BMC Cancer. 2020;20(1):600; doi: 10.1186/s12885-020-07007-9.

99. Moskowitz JE, Andreatta F, Amos-Landgraf J. The gut microbiota modulates differential adenoma suppression by $\mathrm{B} 6 / \mathrm{J}$ and $\mathrm{B} 6 / \mathrm{N}$ genetic backgrounds in Apc(Min) mice. Mamm Genome. 2019;30(9-10):237-44; doi: 10.1007/s00335019-09814-3.

100. Wang Y, Wang B, Wu J, Jiang X, Tang H, Nielsen OH. Modulation of Gut Microbiota in Pathological States. Engineering. 2017;3(1):83-9; doi: https://doi.org/10.1016/J.ENG.2017.01.013.

101. Schmidt TSB, Raes J, Bork P. The Human Gut Microbiome: From Association to Modulation. Cell. 2018;172(6):1198-215; doi: 10.1016/j.cell.2018.02.044.

102. Kang DW, Adams JB, Coleman DM, Pollard EL, Maldonado J, McDonoughMeans S, et al. Long-term benefit of Microbiota Transfer Therapy on autism symptoms and gut microbiota. Sci Rep. 2019;9(1):5821; doi: 10.1038/s41598-01942183-0. 
103. Allegretti JR, Mullish BH, Kelly C, Fischer M. The evolution of the use of faecal microbiota transplantation and emerging therapeutic indications. Lancet. 2019;394(10196):420-31; doi: 10.1016/s0140-6736(19)31266-8.

104. Nichols RG, Peters JM, Patterson AD. Interplay Between the Host, the Human Microbiome, and Drug Metabolism. Hum Genomics. 2019;13(1):27; doi: 10.1186/s40246-019-0211-9.

105. De Filippis F, Vitaglione P, Cuomo R, Berni Canani R, Ercolini D. Dietary Interventions to Modulate the Gut Microbiome-How Far Away Are We From Precision Medicine. Inflamm Bowel Dis. 2018;24(10):2142-54; doi: 10.1093/ibd/izy080.

106. Weersma RK, Zhernakova $\mathrm{A}, \mathrm{Fu}$ J. Interaction between drugs and the gut microbiome. Gut. 2020;69(8):1510-9; doi: 10.1136/gutjnl-2019-320204.

107. Franklin CL, Ericsson AC. Microbiota and reproducibility of rodent models. Lab Anim (NY). 2017;46(4):114-22; doi: 10.1038/laban.1222.

108. Ericsson AC, Personett AR, Turner G, Dorfmeyer RA, Franklin CL. Variable Colonization after Reciprocal Fecal Microbiota Transfer between Mice with Low and High Richness Microbiota. Front Microbiol. 2017;8:196; doi: 10.3389/fmicb.2017.00196.

109. Magne F, Gotteland M, Gauthier L, Zazueta A, Pesoa S, Navarrete P, et al. The Firmicutes/Bacteroidetes Ratio: A Relevant Marker of Gut Dysbiosis in Obese Patients? Nutrients. 2020;12(5); doi: 10.3390/nu12051474. 
110. Li Z, Ni M, Yu H, Wang L, Zhou X, Chen T, et al. Gut Microbiota and Liver Fibrosis: One Potential Biomarker for Predicting Liver Fibrosis. Biomed Res Int. 2020;2020:3905130; doi: 10.1155/2020/3905130.

111. Rubinstein MR, Wang X, Liu W, Hao Y, Cai G, Han YW. Fusobacterium nucleatum promotes colorectal carcinogenesis by modulating E-cadherin/ $\beta$-catenin signaling via its FadA adhesin. Cell Host Microbe. 2013;14(2):195-206; doi: 10.1016/j.chom.2013.07.012.

112. Zheng Y, Fang Z, Xue Y, Zhang J, Zhu J, Gao R, et al. Specific gut microbiome signature predicts the early-stage lung cancer. Gut Microbes. 2020;11(4):1030-42; doi: 10.1080/19490976.2020.1737487.

113. Kociolek LK, Gerding DN. Breakthroughs in the treatment and prevention of Clostridium difficile infection. Nat Rev Gastroenterol Hepatol. 2016;13(3):150-60; doi: 10.1038/nrgastro.2015.220.

114. Drekonja D, Reich J, Gezahegn S, Greer N, Shaukat A, MacDonald R, et al. Fecal Microbiota Transplantation for Clostridium difficile Infection: A Systematic Review. Ann Intern Med. 2015;162(9):630-8; doi: 10.7326/m14-2693.

115. Khanna S, Pardi DS, Kelly CR, Kraft CS, Dhere T, Henn MR, et al. A Novel Microbiome Therapeutic Increases Gut Microbial Diversity and Prevents Recurrent Clostridium difficile Infection. J Infect Dis. 2016;214(2):173-81; doi: 10.1093/infdis/jiv766.

116. Brandt LJ. Fecal transplantation for the treatment of Clostridium difficile infection. Gastroenterol Hepatol (N Y). 2012;8(3):191-4. 
117. Mardini HE, Grigorian AY. Probiotic mix VSL\#3 is effective adjunctive therapy for mild to moderately active ulcerative colitis: a meta-analysis. Inflamm Bowel Dis. 2014;20(9):1562-7; doi: 10.1097/mib.0000000000000084.

118. Mizuno S, Masaoka T, Naganuma M, Kishimoto T, Kitazawa M, Kurokawa S, et al. Bifidobacterium-Rich Fecal Donor May Be a Positive Predictor for Successful Fecal Microbiota Transplantation in Patients with Irritable Bowel Syndrome. Digestion. 2017;96(1):29-38; doi: 10.1159/000471919.

119. Plichta DR, Graham DB, Subramanian S, Xavier RJ. Therapeutic Opportunities in Inflammatory Bowel Disease: Mechanistic Dissection of Host-Microbiome Relationships. Cell. 2019;178(5):1041-56; doi: 10.1016/j.cell.2019.07.045.

120. Abdel-Gadir A, Stephen-Victor E, Gerber GK, Noval Rivas M, Wang S, Harb H, et al. Microbiota therapy acts via a regulatory $\mathrm{T}$ cell MyD88/ROR $\gamma \mathrm{t}$ pathway to suppress food allergy. Nat Med. 2019;25(7):1164-74; doi: 10.1038/s41591-0190461-z.

121. Chen YY, Chen DQ, Chen L, Liu JR, Vaziri ND, Guo Y, et al. Microbiomemetabolome reveals the contribution of gut-kidney axis on kidney disease. J Transl Med. 2019;17(1):5; doi: 10.1186/s12967-018-1756-4.

122. Nallu A, Sharma S, Ramezani A, Muralidharan J, Raj D. Gut microbiome in chronic kidney disease: challenges and opportunities. Transl Res. 2017;179:24-37; doi: $10.1016 / j \cdot \operatorname{trsl} \cdot 2016.04 .007$.

123. Sharon G, Cruz NJ, Kang DW, Gandal MJ, Wang B, Kim YM, et al. Human Gut Microbiota from Autism Spectrum Disorder Promote Behavioral Symptoms in Mice. Cell. 2019;177(6):1600-18.e17; doi: 10.1016/j.cell.2019.05.004. 
124. Zhang Y, Gu Y, Ren H, Wang S, Zhong H, Zhao X, et al. Gut microbiome-related effects of berberine and probiotics on type 2 diabetes (the PREMOTE study). Nat Commun. 2020;11(1):5015; doi: 10.1038/s41467-020-18414-8.

125. Koh A, Mannerås-Holm L, Yunn NO, Nilsson PM, Ryu SH, Molinaro A, et al. Microbial Imidazole Propionate Affects Responses to Metformin through p38 $\gamma$ Dependent Inhibitory AMPK Phosphorylation. Cell Metab. 2020;32(4):643-53.e4; doi: 10.1016/j.cmet.2020.07.012.

126. Depommier C, Everard A, Druart C, Plovier H, Van Hul M, Vieira-Silva S, et al. Supplementation with Akkermansia muciniphila in overweight and obese human volunteers: a proof-of-concept exploratory study. Nat Med. 2019;25(7):1096-103; doi: 10.1038/s41591-019-0495-2.

127. Choi BS, Daoust L, Pilon G, Marette A, Tremblay A. Potential therapeutic applications of the gut microbiome in obesity: from brain function to body detoxification. Int J Obes (Lond). 2020;44(9):1818-31; doi: 10.1038/s41366-0200618-3.

128. Helmink BA, Khan MAW, Hermann A, Gopalakrishnan V, Wargo JA. The microbiome, cancer, and cancer therapy. Nature Medicine. 2019;25(3):377-88; doi: 10.1038/s41591-019-0377-7.

129. Sivan A, Corrales L, Hubert N, Williams JB, Aquino-Michaels K, Earley ZM, et al. Commensal Bifidobacterium promotes antitumor immunity and facilitates anti-PDL1 efficacy. Science. 2015;350(6264):1084-9; doi: 10.1126/science.aac4255. 
130. Qiu Q, Lin Y, Ma Y, Li X, Liang J, Chen Z, et al. Exploring the Emerging Role of the Gut Microbiota and Tumor Microenvironment in Cancer Immunotherapy. Front Immunol. 2020;11:612202; doi: 10.3389/fimmu.2020.612202.

131. Suraya R, Nagano T, Kobayashi K, Nishimura Y. Microbiome as a Target for Cancer Therapy. Integr Cancer Ther. 2020;19:1534735420920721; doi: $10.1177 / 1534735420920721$.

132. Vétizou M, Pitt JM, Daillère R, Lepage P, Waldschmitt N, Flament C, et al. Anticancer immunotherapy by CTLA-4 blockade relies on the gut microbiota. Science. 2015;350(6264):1079-84; doi: 10.1126/science.aad1329.

133. Zheng Y, Wang T, Tu X, Huang Y, Zhang H, Tan D, et al. Gut microbiome affects the response to anti-PD-1 immunotherapy in patients with hepatocellular carcinoma. J Immunother Cancer. 2019;7(1):193; doi: 10.1186/s40425-019-0650-9.

134. Peng Z, Cheng S, Kou Y, Wang Z, Jin R, Hu H, et al. The Gut Microbiome Is Associated with Clinical Response to Anti-PD-1/PD-L1 Immunotherapy in Gastrointestinal Cancer. Cancer Immunol Res. 2020;8(10):1251-61; doi: 10.1158/2326-6066.Cir-19-1014.

135. Routy B, Le Chatelier E, Derosa L, Duong CPM, Alou MT, Daillère R, et al. Gut microbiome influences efficacy of PD-1-based immunotherapy against epithelial tumors. Science. 2018;359(6371):91-7; doi: 10.1126/science.aan3706.

136. York A. Microbiome: Gut microbiota sways response to cancer immunotherapy. Nat Rev Microbiol. 2018;16(3):121; doi: 10.1038/nrmicro.2018.12. 
137. Matson V, Fessler J, Bao R, Chongsuwat T, Zha Y, Alegre ML, et al. The commensal microbiome is associated with anti-PD-1 efficacy in metastatic melanoma patients. Science. 2018;359(6371):104-8; doi: 10.1126/science.aao3290.

138. Wang F, Yin Q, Chen L, Davis MM. Bifidobacterium can mitigate intestinal immunopathology in the context of CTLA-4 blockade. Proc Natl Acad Sci U S A. 2018;115(1):157-61; doi: 10.1073/pnas.1712901115.

139. Routy B, Le Chatelier E, Derosa L, Duong CPM, Alou MT, Daillere R, et al. Gut microbiome influences efficacy of PD-1-based immunotherapy against epithelial tumors. Science. 2018;359(6371):91-7; doi: 10.1126/science.aan3706.

140. Gopalakrishnan V, Spencer CN, Nezi L, Reuben A, Andrews MC, Karpinets TV, et al. Gut microbiome modulates response to anti-PD-1 immunotherapy in melanoma patients. Science. 2018;359(6371):97-103; doi: 10.1126/science.aan4236.

141. Swanson HI. Drug Metabolism by the Host and Gut Microbiota: A Partnership or Rivalry? Drug Metab Dispos. 2015;43(10):1499-504; doi: 10.1124/dmd.115.065714.

142. Colotti G, Rinaldi T. The central role of gut microbiota in drug metabolism and personalized medicine. Future Med Chem. 2020;12(13):1197-200; doi: 10.4155/fmc-2020-0023.

143. Koppel N, Maini Rekdal V, Balskus EP. Chemical transformation of xenobiotics by the human gut microbiota. Science. 2017;356(6344); doi: 10.1126/science.aag2770. 
144. Wallace BD, Wang H, Lane KT, Scott JE, Orans J, Koo JS, et al. Alleviating cancer drug toxicity by inhibiting a bacterial enzyme. Science. 2010;330(6005):831-5; doi: 10.1126/science. 1191175 .

145. Vandamme TF. Use of rodents as models of human diseases. J Pharm Bioallied Sci. 2014;6(1):2-9; doi: 10.4103/0975-7406.124301.

146. Perrin S. Preclinical research: Make mouse studies work. Nature. 2014;507(7493):423-5; doi: 10.1038/507423a.

147. Collins FS, Tabak LA. Policy: NIH plans to enhance reproducibility. Nature. 2014;505(7485):612-3; doi: 10.1038/505612a.

148. Wegorzewska I, Bell S, Cairns NJ, Miller TM, Baloh RH. TDP-43 mutant transgenic mice develop features of ALS and frontotemporal lobar degeneration. Proc Natl Acad Sci U S A. 2009;106(44):18809-14; doi: 10.1073/pnas.0908767106.

149. Gill A, Kidd J, Vieira F, Thompson K, Perrin S. No benefit from chronic lithium dosing in a sibling-matched, gender balanced, investigator-blinded trial using a standard mouse model of familial ALS. PLoS One. 2009;4(8):e6489; doi: 10.1371/journal.pone.0006489.

150. Pizzasegola C, Caron I, Daleno C, Ronchi A, Minoia C, Carri MT, et al. Treatment with lithium carbonate does not improve disease progression in two different strains of SOD1 mutant mice. Amyotroph Lateral Scler. 2009;10(4):221-8; doi: 10.1080/17482960902803440.

151. Seok J, Warren HS, Cuenca AG, Mindrinos MN, Baker HV, Xu W, et al. Genomic responses in mouse models poorly mimic human inflammatory diseases. Proc Natl Acad Sci U S A. 2013;110(9):3507-12; doi: 10.1073/pnas.1222878110. 
152. Visconti A, Le Roy CI, Rosa F, Rossi N, Martin TC, Mohney RP, et al. Interplay between the human gut microbiome and host metabolism. Nat Commun. 2019;10(1):4505; doi: 10.1038/s41467-019-12476-z.

153. Paone P, Cani PD. Mucus barrier, mucins and gut microbiota: the expected slimy partners? Gut. 2020;69(12):2232-43; doi: 10.1136/gutjnl-2020-322260.

154. Tlaskalova-Hogenova H, Stepankova R, Kozakova H, Hudcovic T, Vannucci L, Tuckova L, et al. The role of gut microbiota (commensal bacteria) and the mucosal barrier in the pathogenesis of inflammatory and autoimmune diseases and cancer: contribution of germ-free and gnotobiotic animal models of human diseases. Cell Mol Immunol. 2011;8(2):110-20; doi: 10.1038/cmi.2010.67.

155. Shreiner AB, Kao JY, Young VB. The gut microbiome in health and in disease. Curr Opin Gastroenterol. 2015;31(1):69-75; doi: 10.1097/mog.0000000000000139.

156. Kamada N, Nunez G. Regulation of the immune system by the resident intestinal bacteria. Gastroenterology. 2014;146(6):1477-88; doi: 10.1053/j.gastro.2014.01.060.

157. Quigley EM. Gut bacteria in health and disease. Gastroenterol Hepatol (N Y). 2013;9(9):560-9.

158. Kostic AD, Chun E, Robertson L, Glickman JN, Gallini CA, Michaud M, et al. Fusobacterium nucleatum potentiates intestinal tumorigenesis and modulates the tumor-immune microenvironment. Cell Host Microbe. 2013;14(2):207-15; doi: 10.1016/j.chom.2013.07.007. 
159. Le Chatelier E, Nielsen T, Qin J, Prifti E, Hildebrand F, Falony G, et al. Richness of human gut microbiome correlates with metabolic markers. Nature. 2013;500(7464):541-6; doi: 10.1038/nature12506.

160. de Vos WM, de Vos EA. Role of the intestinal microbiome in health and disease: from correlation to causation. Nutr Rev. 2012;70 Suppl 1:S45-56; doi: 10.1111/j.1753-4887.2012.00505.x.

161. Virgin HW. The virome in mammalian physiology and disease. Cell. 2014;157(1):142-50; doi: 10.1016/j.cell.2014.02.032.

162. Karlsson OE, Larsson J, Hayer J, Berg M, Jacobson M. The Intestinal Eukaryotic Virome in Healthy and Diarrhoeic Neonatal Piglets. PLoS One. 2016;11(3):e0151481; doi: 10.1371/journal.pone.0151481.

163. Ericsson AC, Montonye DR, Smith CR, Franklin CL. Modeling a Superorganism Considerations Regarding the Use of "Dirty" Mice in Biomedical Researchispipi J Biol Med. 2017;90(3):361-71.

164. Wylie TN, Wylie KM, Herter BN, Storch GA. Enhanced virome sequencing using targeted sequence capture. Genome Res. 2015;25(12):1910-20; doi: 10.1101/gr.191049.115.

165. Joh J, Jenson AB, King W, Proctor M, Ingle A, Sundberg JP, et al. Genomic analysis of the first laboratory-mouse papillomavirus. J Gen Virol. 2011;92(Pt 3):692-8; doi: 10.1099/vir.0.026138-0.

166. Schulz E, Gottschling M, Ulrich RG, Richter D, Stockfleth E, Nindl I. Isolation of three novel rat and mouse papillomaviruses and their genomic characterization. PLoS One. 2012;7(10):e47164; doi: 10.1371/journal.pone.0047164. 
167. Wang JW, Jiang R, Peng S, Chang YN, Hung CF, Roden RB. Immunologic Control of Mus musculus Papillomavirus Type 1. PLoS Pathog. 2015;11(10):e1005243; doi: 10.1371/journal.ppat.1005243.

168. Cladel NM, Budgeon LR, Cooper TK, Balogh KK, Hu J, Christensen ND. Secondary infections, expanded tissue tropism, and evidence for malignant potential in immunocompromised mice infected with Mus musculus papillomavirus 1 DNA and virus. J Virol. 2013;87(16):9391-5; doi: 10.1128/jvi.00777-13.

169. Handisurya A, Day PM, Thompson CD, Bonelli M, Lowy DR, Schiller JT. Strainspecific properties and $\mathrm{T}$ cells regulate the susceptibility to papilloma induction by Mus musculus papillomavirus 1. PLoS Pathog. 2014;10(8):e1004314; doi: 10.1371/journal.ppat.1004314.

170. Briese T, Kapoor A, Mishra N, Jain K, Kumar A, Jabado OJ, et al. Virome Capture Sequencing Enables Sensitive Viral Diagnosis and Comprehensive Virome Analysis. MBio. 2015;6(5):e01491-15; doi: 10.1128/mBio.01491-15.

171. Prussin AJ, 2nd, Marr LC, Bibby KJ. Challenges of studying viral aerosol metagenomics and communities in comparison with bacterial and fungal aerosols. FEMS Microbiol Lett. 2014;357(1):1-9; doi: 10.1111/1574-6968.12487.

172. Dammann P, Hilken G, Hueber B, Kohl W, Bappert MT, Mahler M. Infectious microorganisms in mice (Mus musculus) purchased from commercial pet shops in Germany. Lab Anim. 2011;45(4):271-5; doi: 10.1258/la.2011.010183. 
173. Farkas T, Fey B, Keller G, Martella V, Egyed L. Molecular detection of novel astroviruses in wild and laboratory mice. Virus Genes. 2012;45(3):518-25; doi: $10.1007 / \mathrm{s} 11262-012-0803-0$.

174. Maynard CL. 14 - The Microbiota in Immunity and Inflammation. In: Rich RR, Fleisher TA, Shearer WT, Schroeder HW, Frew AJ, Weyand CM, editors. Clinical Immunology (Fifth Edition). London: Content Repository Only!; 2019. p. 20719.e1.

175. Ungaro F, Massimino L, Furfaro F, Rimoldi V, Peyrin-Biroulet L, D'Alessio S, et al. Metagenomic analysis of intestinal mucosa revealed a specific eukaryotic gut virome signature in early-diagnosed inflammatory bowel disease. Gut Microbes. 2018:1-10; doi: 10.1080/19490976.2018.1511664.

176. Raghavendra P, Pullaiah T. Chapter 7 - Pathogen Identification Using Novel Sequencing Methods. In: Raghavendra P, Pullaiah T, editors. Advances in Cell and Molecular Diagnostics. Academic Press; 2018. p. 161-202.

177. Scher JU, Sczesnak A, Longman RS, Segata N, Ubeda C, Bielski C, et al. Expansion of intestinal Prevotella copri correlates with enhanced susceptibility to arthritis. Elife. 2013;2:e01202; doi: 10.7554/eLife.01202.

178. Shi Z, Gewirtz AT. Together Forever: Bacterial-Viral Interactions in Infection and Immunity. Viruses. 2018;10(3); doi: 10.3390/v10030122.

179. Norman JM, Handley SA, Virgin HW. Kingdom-agnostic metagenomics and the importance of complete characterization of enteric microbial communities. Gastroenterology. 2014;146(6):1459-69; doi: 10.1053/j.gastro.2014.02.001. 
180. Wylie KM, Weinstock GM, Storch GA. Emerging view of the human virome. Transl Res. 2012;160(4):283-90; doi: 10.1016/j.trsl.2012.03.006.

181. Lee K-H, Lim D, Greenhalgh D, Cho K. Highly Variable Genomic Landscape of Endogenous Retroviruses in the C57BL/6J Inbred Strain, Depending on Individual Mouse, Gender, Organ Type, and Organ Location \% International Journal of Genomics. 2017;2017:10; doi: 10.1155/2017/3152410.

182. Phan TG, Kapusinszky B, Wang C, Rose RK, Lipton HL, Delwart EL. The fecal viral flora of wild rodents. PLoS Pathog. 2011;7(9):e1002218; doi: 10.1371/journal.ppat.1002218.

183. Compton SR, Booth CJ, Macy JD. Murine Astrovirus Infection and Transmission in Neonatal CD1 Mice. J Am Assoc Lab Anim Sci. 2017;56(4):402-11.

184. Yokoyama CC, Loh J, Zhao G, Stappenbeck TS, Wang D, Huang HV, et al. Adaptive immunity restricts replication of novel murine astroviruses. J Virol. 2012;86(22):12262-70; doi: 10.1128/jvi.02018-12.

185. Ng TF, Kondov NO, Hayashimoto N, Uchida R, Cha Y, Beyer AI, et al. Identification of an astrovirus commonly infecting laboratory mice in the US and Japan. PLoS One. 2013;8(6):e66937; doi: 10.1371/journal.pone.0066937.

186. Robilotti E, Deresinski S, Pinsky BA. Norovirus. Clin Microbiol Rev. 2015;28(1):134-64; doi: 10.1128/cmr.00075-14.

187. Wobus CE, Thackray LB, Virgin HWt. Murine norovirus: a model system to study norovirus biology and pathogenesis. J Virol. 2006;80(11):5104-12; doi: 10.1128/jvi.02346-05. 
188. Karst SM, Wobus CE, Lay M, Davidson J, Virgin HWt. STAT1-dependent innate immunity to a Norwalk-like virus. Science. 2003;299(5612):1575-8; doi: 10.1126/science.1077905.

189. Cadwell K. Expanding the role of the virome: commensalism in the gut. J Virol. 2015;89(4):1951-3; doi: 10.1128/jvi.02966-14.

190. Kernbauer E, Ding Y, Cadwell K. An enteric virus can replace the beneficial function of commensal bacteria. Nature. 2014;516(7529):94-8; doi: 10.1038/nature13960.

191. Kåhrström CT, Pariente N, Weiss U. Intestinal microbiota in health and disease. Nature. 2016;535(7610):47-; doi: 10.1038/535047a.

192. Cho I, Blaser MJ. The human microbiome: at the interface of health and disease. Nat Rev Genet. 2012;13(4):260-70; doi: 10.1038/nrg3182.

193. Clemente JC, Ursell LK, Parfrey LW, Knight R. The impact of the gut microbiota on human health: an integrative view. Cell. 2012;148(6):1258-70; doi: 10.1016/j.cell.2012.01.035.

194. Ericsson AC, Akter S, Hanson MM, Busi SB, Parker TW, Schehr RJ, et al. Differential susceptibility to colorectal cancer due to naturally occurring gut microbiota. Oncotarget. 2015;6(32):33689-704; doi: 10.18632/oncotarget.5604.

195. Quigley EMM, Gajula P. Recent advances in modulating the microbiome. F1000Res. 2020;9; doi: 10.12688/f1000research.20204.1.

196. Jain N. The Need for Personalized Approaches to Microbiome Modulation. Front Public Health. 2020;8:144; doi: 10.3389/fpubh.2020.00144. 
197. Hasan N, Yang H. Factors affecting the composition of the gut microbiota, and its modulation. PeerJ. 2019;7:e7502-e; doi: 10.7717/peerj.7502.

198. Franklin CL, Ericsson AC. Complex Microbiota in Laboratory Rodents: Management Considerations. Ilar j. 2020; doi: 10.1093/ilar/ilaa011.

199. Ericsson AC, Franklin CL. Manipulating the Gut Microbiota: Methods and Challenges. Ilar j. 2015;56(2):205-17; doi: 10.1093/ilar/ilv021.

200. Neff EP. Littermate wanted: standardizing mouse gut microbiota requires more than cohousing. Lab Animal. 2019;48(7):197-; doi: 10.1038/s41684-019-0336-4.

201. Robertson SJ, Lemire P, Maughan H, Goethel A, Turpin W, Bedrani L, et al. Comparison of Co-housing and Littermate Methods for Microbiota Standardization in Mouse Models. Cell Rep. 2019;27(6):1910-9.e2; doi: 10.1016/j.celrep.2019.04.023.

202. Laukens D, Brinkman BM, Raes J, De Vos M, Vandenabeele P. Heterogeneity of the gut microbiome in mice: guidelines for optimizing experimental design. FEMS Microbiol Rev. 2016;40(1):117-32; doi: 10.1093/femsre/fuv036.

203. Caruso R, Ono M, Bunker ME, Núñez G, Inohara N. Dynamic and Asymmetric Changes of the Microbial Communities after Cohousing in Laboratory Mice. Cell Rep. 2019;27(11):3401-12.e3; doi: 10.1016/j.celrep.2019.05.042.

204. Artwohl JE, Purcell JE, Fortman JD. The use of cross-foster rederivation to eliminate murine norovirus, Helicobacter spp., and murine hepatitis virus from a mouse colony. J Am Assoc Lab Anim Sci. 2008;47(6):19-24. 
205. Clark SE, Purcell JE, Bi X, Fortman JD. Cross-Foster Rederivation Compared with Antibiotic Administration in the Drinking Water to Eradicate Bordetella pseudohinzii. J Am Assoc Lab Anim Sci. 2017;56(1):47-51.

206. Chassaing B, Aitken JD, Malleshappa M, Vijay-Kumar M. Dextran sulfate sodium (DSS)-induced colitis in mice. Curr Protoc Immunol. 2014;104:15.25.1-15.25.14; doi: 10.1002/0471142735.im1525s104.

207. Perše M, Cerar A. Dextran sodium sulphate colitis mouse model: traps and tricks. J Biomed Biotechnol. 2012;2012:718617; doi: 10.1155/2012/718617.

208. Caporaso JG, Lauber CL, Walters WA, Berg-Lyons D, Lozupone CA, Turnbaugh PJ, et al. Global patterns of $16 \mathrm{~S}$ rRNA diversity at a depth of millions of sequences per sample. Proc Natl Acad Sci U S A. 2011;108 Suppl 1(Suppl 1):4516-22; doi: 10.1073/pnas. 1000080107 .

209. Hammer O, Harper D, Ryan P. PAST: Paleontological Statistics Software Package for Education and Data Analysis. Palaeontologia Electronica. 2001;4:1-9.

210. Collins SM, Kassam Z, Bercik P. The adoptive transfer of behavioral phenotype via the intestinal microbiota: experimental evidence and clinical implications. Curr Opin Microbiol. 2013;16(3):240-5; doi: 10.1016/j.mib.2013.06.004.

211. Vrieze A, Van Nood E, Holleman F, Salojärvi J, Kootte RS, Bartelsman JF, et al. Transfer of intestinal microbiota from lean donors increases insulin sensitivity in individuals with metabolic syndrome. Gastroenterology. 2012;143(4):913-6.e7; doi: 10.1053/j.gastro.2012.06.031.

212. Kellermayer R. Fecal microbiota transplantation: great potential with many challenges. Transl Gastroenterol Hepatol. 2019;4:40; doi: 10.21037/tgh.2019.05.10. 
213. Ellekilde M, Selfjord E, Larsen CS, Jakesevic M, Rune I, Tranberg B, et al. Transfer of gut microbiota from lean and obese mice to antibiotic-treated mice. Sci Rep. 2014;4:5922; doi: 10.1038/srep05922.

214. Org E, Parks BW, Joo JW, Emert B, Schwartzman W, Kang EY, et al. Genetic and environmental control of host-gut microbiota interactions. Genome Res. 2015;25(10):1558-69; doi: 10.1101/gr.194118.115. 


\section{VITA}

I am a self-driven young scientist, who is determined to be a tenured faculty in academia. I earned my Bachelor's degree in Veterinary Medicine (BVM) and a Doctor of Veterinary Medicine (DVM) from Inner Mongolia Agriculture University in China. Then, I immediately started my master's study at Beijing University of Agriculture majored in Veterinary Medicine, and got my Master's degree (MS) in Microbiology \& Immunology. Following my passion, I started the Ph.D. study in Veterinary Pathobiology at University of Missouri-Columbia.

Out of the love of science, I actively explored many training opportunities for my career development, such as training at Beijing Academy of Agriculture and Forestry Sciences, Beijing Wanger Biotechnology Institution, and training at Texas A\&M University in Veterinary Pathobiology. I also joined the Biological Science \& Chemistry class as an audient student at Jackson State University.

My academic experience mostly focused on the animal disease model and gut microbiome, virome in lab mice and pet store mice, swine coronavirus TGEV and PRCV monoclonal antibody ELISA test method development, novel antimicrobial peptides design, characterization, and evaluation in vitro/in vivo, antimicrobial resistance whole-genome sequencing, and development and optimization of molecular diagnostic methods for bacteria, viruses, and parasites. As I move forward, encouraged by what I accomplished, I am confident that I will have a bright future in my academic career and continue to make a big contribution to the scientific community. 